\title{
Vibratory Mediated Spacing in Groups of Insect Larvae (Drepana arcuata, Lepidoptera; Scolytus multistriatus, Coleoptera)
}

By

Sarah M. Matheson

\begin{abstract}
A dissertation
submitted to the Faculty of Graduate Studies and Research in partial fulfillment of the requirements for the degree of Master of Science in Biology

Carleton University

Ottawa, Ontario
\end{abstract}

(C) 2010 Sarah Matheson 


$\begin{array}{ll}\text { Library and Archives } & \begin{array}{l}\text { Bibliotheque et } \\ \text { Canada }\end{array} \\ \begin{array}{l}\text { Published Heritage } \\ \text { Branch }\end{array} & \begin{array}{l}\text { Direction du } \\ \text { Patrimoine de l'édition }\end{array} \\ \begin{array}{l}395 \text { Wellington Street } \\ \text { Ottawa ON K1A ON4 } \\ \text { Canada }\end{array} & \begin{array}{l}\text { 395, rue Wellington } \\ \text { Ottawa ON K1A ON4 } \\ \text { Canada }\end{array}\end{array}$

Your file Votre référence

ISBN: 978-0-494-79611-5

Our file Notre reférence

ISBN: 978-0-494-79611-5

NOTICE:

The author has granted a nonexclusive license allowing Library and Archives Canada to reproduce, publish, archive, preserve, conserve, communicate to the public by telecommunication or on the Internet, loan, distribute and sell theses worldwide, for commercial or noncommercial purposes, in microform, paper, electronic and/or any other formats.

The author retains copyright ownership and moral rights in this thesis. Neither the thesis nor substantial extracts from it may be printed or otherwise reproduced without the author's permission.
AVIS:

L'auteur a accordé une licence non exclusive permettant à la Bibliothèque et Archives Canada de reproduire, publier, archiver, sauvegarder, conserver, transmettre au public par télécommunication ou par l'Internet, prêter, distribuer et vendre des thèses partout dans le monde, à des fins commerciales ou autres, sur support microforme, papier, électronique etlou autres formats.

L'auteur conserve la propriété du droit d'auteur et des droits moraux qui protège cette thèse. $\mathrm{Ni}$ la thèse ni des extraits substantiels de celle-ci ne doivent être imprimés ou autrement reproduits sans son autorisation.
In compliance with the Canadian Privacy Act some supporting forms may have been removed from this thesis.

While these forms may be included in the document page count, their removal does not represent any loss of content from the thesis.
Conformément à la loi canadienne sur la protection de la vie privée, quelques formulaires secondaires ont été enlevés de cette thèse.

Bien que ces formulaires aient inclus dans la pagination, il n'y aura aucun contenu manquant. 


\section{ABSTRACT}

Insect larvae often live in groups but little is known about mechanisms for withingroup spacing. This thesis tests the hypothesis that vibratory signals are used to mediate spacing in two larval model systems: bark beetle larvae (Scolytus multistriatus) living under bark, and early instar caterpillars (Drepana arcuata) living together in silk shelters. In S. multistriatus, a novel technique was developed for simultaneously recording vibrations while observing in-gallery behaviours, and preliminary results are reported. Early instars of $D$. arcuata produce four unique vibratory signals, and the data supports the hypothesis that they defend a "personal space" using these signals. Caterpillars show strong associations between signalling and moving around the nest. Signalling by a resıdent ıncreases as an intruder approaches its space. Also, gregarious early instar caterpillars signal significantly more than do solitary late instars or early instars of a congener (Drepana bilineata) that is solitary. These results support the hypothesis that caterpillars are constructing 'vibratory fences' to maintain personal space within a group. 


\section{ACKNOWLEDGEMENTS}

First and foremost, I would like to thank everyone who has been a part of this never-ending story about tiny young caterpillars making a hell of a lot of noise. Although I have never met them in person, I am extremely grateful to Tiffany Timbers and Becky Lynes for all the information they have collected to lay the groundwork for my project. Also, I want to thank all the unsung heroes along the way that have helped with data collection and analysis to try to understand vibrating caterpillars. I would like to give special thanks to my lab mates, who have become not just good friends, but my extended family. Veronica Bura, you have been an unwavering fountain of knowledge over the last three years, giving intellectual advice, countless mac or photoshop tips, the best store sales or even the latest blog scoop. Be prepared for endless phone calls from me at whatever new job you take on. Jackie Scott, your ambition and drive have always been a huge motivation although your impulsıvity hasn't quite rubbed off on me yet. You influenced many big changes in my life since we met (buying a house and getting married in the same year) and have been there helping along the way. Whenever I hear a pileated woodpecker I'll remember the afternoons when we had all had a little too much sugar. Thank you AJ Fleming for always having a movie playing on your laptop beside me to give me a much needed distraction on "those days", and to the lab boys (JP and Sen) who gave me someone to practice my maternal skills on outside of the house.

I would like to thank the members of my committee, Dr. Patrice Bouchard and Dr. Tom Sherratt for being supportive when the project took a right turn and for their helpful comments and input. I also want to thank my supervisor, Dr. Jayne Yack, for taking a shy undergrad under her wing. I can't remember exactly when I realized that I 
was an animal behaviourist, but I think it was around the time you told the infamous story of Bun Bun the rabbit's last words and asked the simple question- why would an animal act like this? Mama Jayne, you have been an incredıble mentor and have taught me so much over the years (including the proper use of 'however'), and I will try to always be a true biologist and bring up poop, death and sex whenever I can fit it into the conversation.

My family deserves the final thanks for their unwavering support over the years, even when I told them I was entering the world of creepy crawlies. Your unconditional love has always given me the freedom to do what I love and change my mind as many times as I need. I promise to always try to identify the bugs you bring me and not to get mad when you decide a spider needs to be 'relocated'. Last, but very much not least, I would like to thank Murray. You have been with me through my whole academic career, as a boyfriend, fiancé (briefly), and now my supportive husband. Thanks for always talking me off the ledge, continually reminding me not to take myself too seriously and, being by my side when I needed to "troop it out".

Funding for this study was provided to Dr. J. E. Yack by the Natural Sciences and Engineering Research Council (NSERC) and the Canadian Foundation for Innovation (CFI). Funding to S. Matheson was provided by Carleton University. 
ABSTRACT
ACKNOWLEDGEMENTS
TABLE OF CONTENTS $\ldots \ldots \ldots \ldots \ldots \ldots$
LIST OF TABLES
LIST OF FIGURES

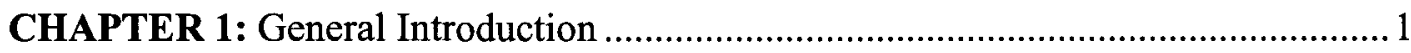

Vibratory communication ....................................................................... 4

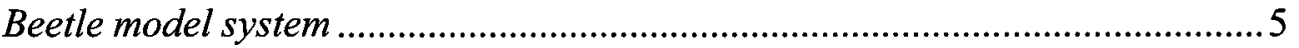

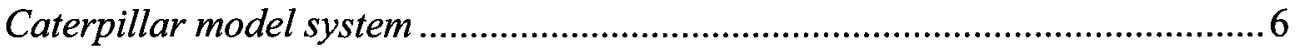

Thesis objectives ...................................................................................... 7

CHAPTER 2: Potential vibratory spacing mechanisms in smaller European elm bark beetle larvae (Scolytus multistriatus) ..................................................................... 8

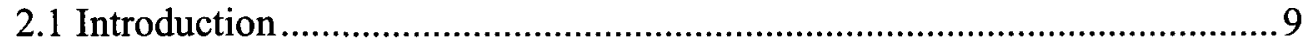

General bark beetle life history..................................................... 9

Sensory mechanisms available to bark beetle larvae.......................... 10

Life history of the smaller European elm bark beetle,

Scolytus multistriatus ...................................................................... 13

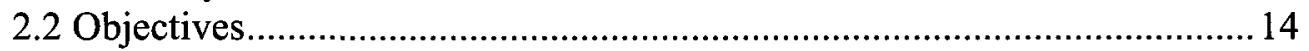

2.3 Methods, results and discussion ......................................................... 16

Preliminary vibration recordings with other beetle larvae ................. 16

Collecting and rearing S. multistriatus larvae ................................ 19

Assembly of the phloem sandwich .....................................................20

Vibration recordings and analysis of $\mathrm{S}$. multistriatus larvae in a phloem

sandwich .......................................................................................22

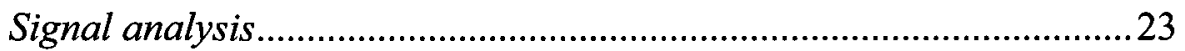

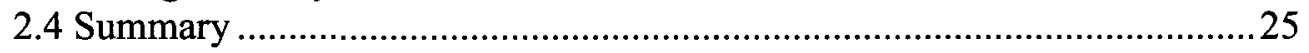

CHAPTER 3: The function of vibratory signals in gregarious instars of the masked birch

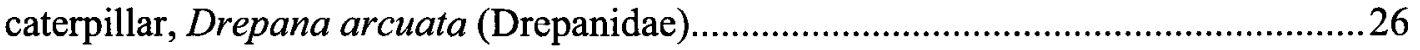

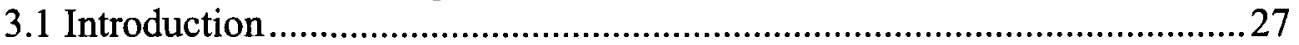

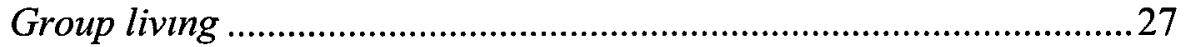

Vibratory signalling in caterpillars.................................................28

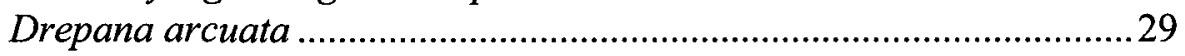

3.2 Hypotheses for the function of vibratory signals in early instar $D$. arcuata

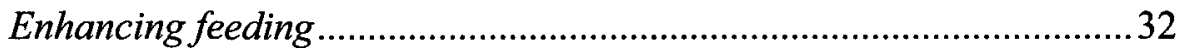

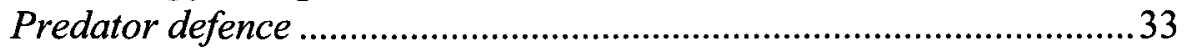

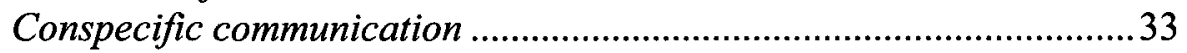

Signals function to space .............................................. 34

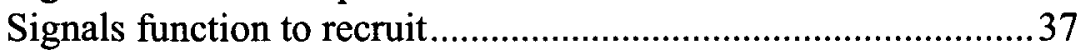




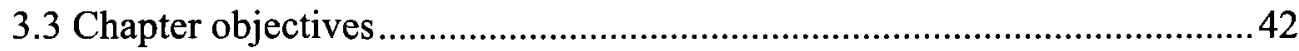

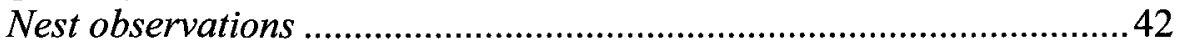

Nest manipulations ......................................................................... 43

Comparison with Drepana bilineata ............................................... 44

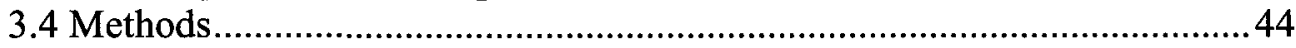

Animals and experimental setup .......................................................44

Vibration recordings and stgnal analysis .........................................45

Set-up for video recordings and video analysis .............................46

Stgnal/behaviour relationships ......................................................4 47

Signal rates across group sizes ...................................................... 48

Signal rates between undisturbed early instars and late instars ..........49

Behaviour patterns ...........................................................................49

Nest manıpulation and analysis .................................................5 50

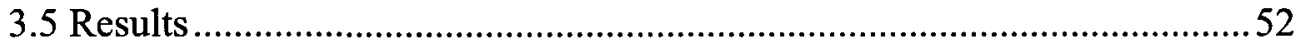

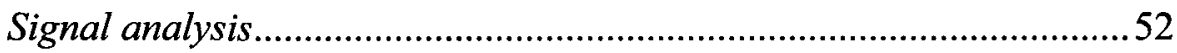

Signal/behaviour relationships ......................................................58

Signals across group sizes...............................................................62

Signal rates between undisturbed early instars and late instars .........65

Behaviour patterns ............................................................................65

Behaviour lengths ...........................................................66

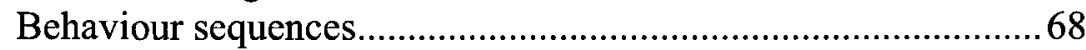

Nest manipulation analysis ............................................................ 70

Signal rates as intruder approaches resident ............................. 70

Resident's detection......................................................... 72

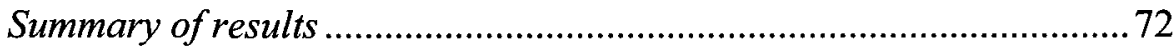

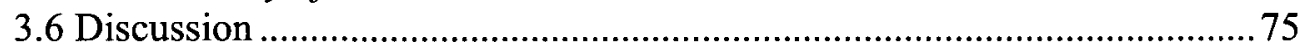

Vibratory repertoire of early instar D. arcuata caterpillars ............... 75

Function of vibratory signals .....................................................77

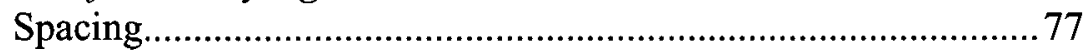

Recruitment............................................................................... 81

Why do early instar D. arcuata caterpillars need signals to mediate

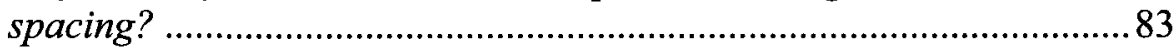

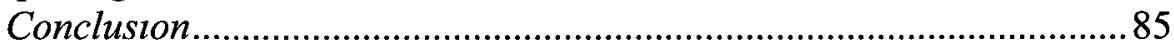

CHAPTER 4: Vibratory-mediated spacing between leaf territories in a non-gregarious

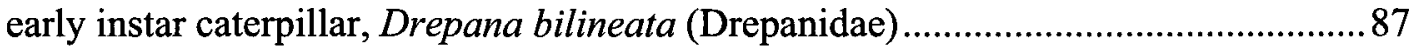

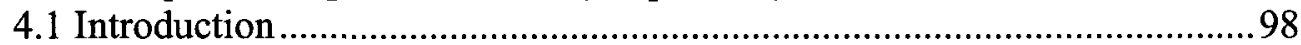

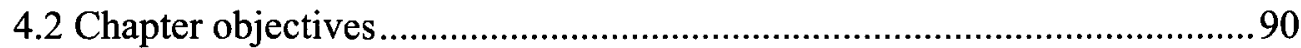

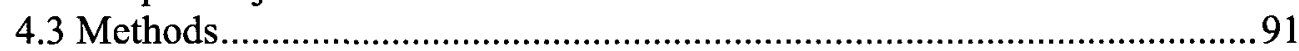

Animals and experimental setup ...................................................91

Vibration recordings and signal characterization ..............................91

Set-up for video recordings and behavıour analysis.......................... 92

Comparison of signal rates between D. bilineata and D. arcuata .........93

Signal/behaviour relationships of $\mathrm{D}$. bilineata caterpillars .................94

Caterpillar manipulation and analysis ............................................94

Intruder approach frequency ............................................. 95 


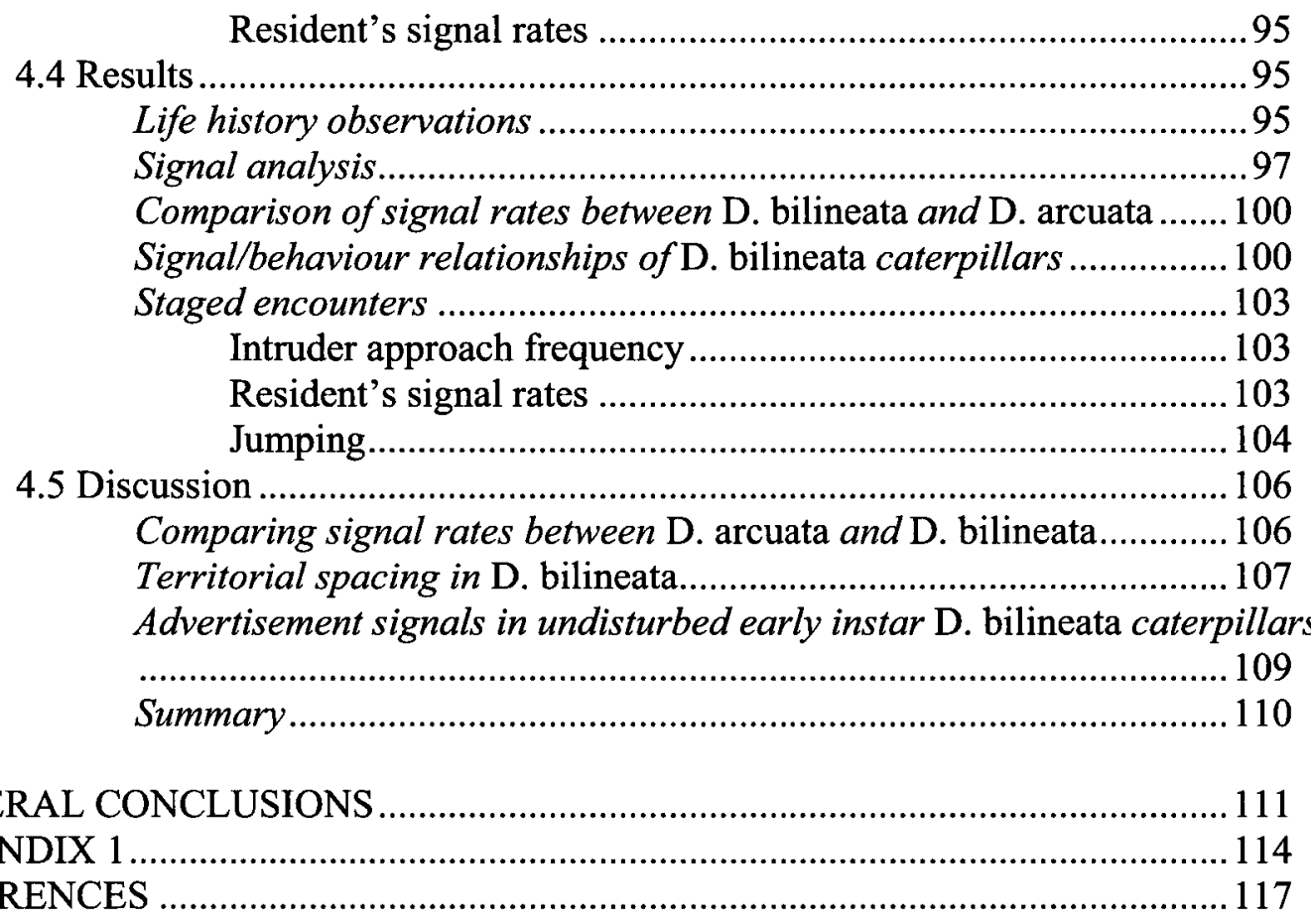




\section{LIST OF TABLES}

3.1 Two hypotheses, and corresponding predictions, explaining the function of vibratory signalling in early instar D. arcuata caterpillars. 40

3.2 Temporal/spectral characteristics and amplitude of four vibratory signals produced by early instar $D$. arcuata caterpillars

3.3 Rates of signals produced per behavioural state by individual early instar D. arcuata caterpillars. 60

3.4 Individual signal rates of solitary early instar $D$. arcuata caterpillars and individuals in groups. 63

3.5 Average lengths of resting, walking, eating and silk laying periods of early instar $D$. arcuata caterpillars in groups of 1,2, 4 and 5 individuals

3.6 Evidence for two hypotheses and predictions for the function of vibratory signalling in D. arcuata caterpillars 74

4.1 Life history and signal characteristics of non-gregarious early instar Drepana bllineata caterp1llars and gregarious early instar Drepana arcuata caterpillars. 


\section{LIST OF FIGURES}

2.1 Natural history of Scolytus multistriatus......................................................... 11

2.2 Phloem sandwich designs ...................................................................... 15

2.3 Preliminary vibration recordings of mealworm larvae underneath elm bark and

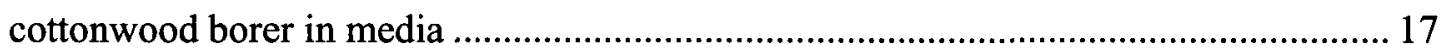

2.4 Steps involved in making a phloem sandwich ................................................ 21

2.5 Vibrations recorded from $S$. multistriatus larvae........................................... 24

3.1 Life history stages of Drepana arcuata ..................................................... 31

3.2 Previous experiments to test the spacing hypothesis ......................................... 36

3.3 Previous experiments to test the recruitment hypothesis ............................... 40

3.4 The vibratory repertoire of early instar Drepana arcuata ......................................55

3.5 Temporal and spectral properties of the four signals produced by early instar $D$.

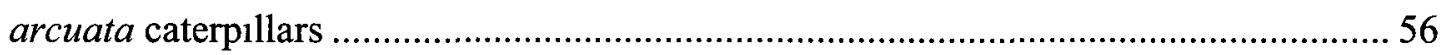

3.6 Signal and behaviour relationships for solitary D. arcuata and individuals in groups 61

3.7 Group size comparison of signal rates of $D$. arcuata early instar caterpillars.......... 64

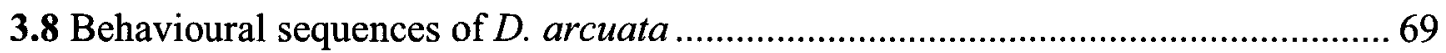

3.9 Signal escalation as an intruder approaches the nest of a solitary resident ............. 71

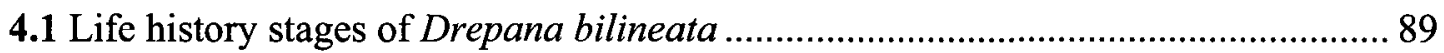

4.2 Leaf area preferred by early instar $D$. bilineata caterpillars ................................96

4.3 Body movements associated with buzz in early instar $D$. bilineata ..................... 98

4.4 Vibratory signals produced by early instar $D$. bilineata caterpillars ..................... 99

4.5 Signal/behavıour relationships for solitary D. bilineata and D. arcuata caterpillars

4.6 Signal rates of an early instar $D$. bllineata resident during a staged encounter..... 105 
CHAPTER ONE

\section{GENERAL INTRODUCTION}


Grouping is a widespread phenomenon that is observed in a broad range of organisms. In animals, groups range in size and scale from small bird cherry-oat aphids living only couple of millimetres apart on wheat seeds, to colonial bottlenose dolphins living together w1thin large home ranges (Quiroz et al. 1997; Gubbins, 2002). The term group often refers to individuals that live and move together with complex social functions, but they can be defined much more simply as a set of individuals that exist and interact in the same place for a period of time (Wilson, 2000). In that sense, the function of grouping can vary with respect to advantages for foraging, reproduction or predator avoidance (Krause \& Ruxton, 2002). Within some groups, spacing behaviour is important for resource competition and group cohesion (Wilson, 2000). At present, group spacing has been examıned for ecological studies (Clark \& Evans, 1954; Keelıng, 1995), practical applications (Petherick, 2007), and to answer fundamental questions of animal fitness and sociality (Hirsch, 2007). Implicit in any spacing behaviour is a mechanism to uphold a preferred inter-individual distance, by either attracting individuals from far away or by maintaining separation in close aggregations. Condor (1949) defines the area around an individual, where no other individuals are allowed to come, as individual distance. This area moves with the individual, regardless of the animal's location, and can be thought of as "personal space". The focus of my thesis is on the proximate mechanisms animals use to create and maintain personal space within groups.

There are several mechanisms that can be used to relay information between members in a group. Studies in spatial communication have focused on the visual, chemical and auditory modalities. Visual signals are favourable in either an acoustically noisy environment or an acoustically/chemically restricted environment, and have been 
suggested to play a role in group spacing of many bird (e.g. Beauchamp, 2007; Bajec \& Heppner, 2009) and fish species (reviewed in Krause \& Ruxton, 2002). Visual displays can also be used to mediate spacing between individuals occupying territories by advertising ownership of an area to competing conspecifics (e.g. Ord, 2008). Chemical signals are able to transmit spatial information to conspecifics without attracting attention to acoustically oriented predators, and are used to maintain inter-group spacing in mammal (eg. Scordato \& Drea, 2007) and insect aggregations (Greenfield, 2002). Chemical tracks laid out by ladybird beetle larvae are one of the few insect examples where chemicals are used to mediate spacing between individuals (Ruzicka \& Zemek, 2008). Alternatively, acoustic signals are advantageous when the communication pathway is interrupted and vision can be obstructed or chemical signals are not reliably transmitted. Acoustic spacing has been studied in many taxa, from primates (Palombit, 1992; Maynard Smith \& Harper, 2003), to insects (Greenfield, 2002). For example, groups of cooperatively foraging pied babblers use acoustic calls to maintain spatial organization when foliage obstructs visual signals (Radford \& Ridley, 2008). Although these are the most commonly cited modalities, other mechanisms may be important for animals within restricted environments where visual, chemical and auditory mechanisms are not available. Electrical and vibratory modalities are potential, yet unexplored mechanisms for spacing. Recent evidence with weakly electric fish living in murky water shows that electrical currents can be used to monitor the location of surrounding individuals (von der Emde et al., 1998; Hupe \& Lewis, 2008). Advancements in vibration-sensitive technology have fuelled a new interest in vibration-mediated behaviours, and vibratory communication is now thought to be widespread in many 
animals (Hill, 2008). This thesis will focus on the vibratory modality and will test hypotheses on vibratory-mediated spacing in holometabolous larvae from two different orders- Lepidoptera and Coleoptera.

\section{Vibratory communtcation}

It is now apparent that vibratory signals play a large role in communication systems across different taxa, from mammals to reptiles to insects (reviewed in Hill, 2008). Vibrations can be used in a variety of contexts including predator-prey interactions, matıng, and group communication (Hill, 2009). Most research on vibratory communication focuses on plant-borne signals produced by spiders and insects whose life histories are tightly tied with the plants they live on and consume (eg. Cokl \& VirantDoberlet, 2003; Cocroft \& Rodriguez, 2005). Vibrations are advantageous to plant dwelling insects because information can be accurately relayed over short distances, is restricted within the substrate and, is not easily detected by eavesdroppers. Also, unlike chemicals, vibrations are short term and do not leave a permanent signal on the substrate that could attract unwanted receivers like predators. For this reason, vibratory communication may be especially important for communication in insect groups that need to convey changing information within a restricted environment. For example, groups of treehopper nymphs use vibratory signals to elicit maternal predatory defence (Cocroft, 1999) whereas sawfly larvae use vibratory signals for cooperative foraging (Fletcher, 2008). Both examples demonstrate how signals are used in dynamic group behaviours. Currently we have no direct evidence for vibratory-mediated spacing in groups of lepidopteran larvae, but there are accumulating accounts of vibratory-mediated 
territorial behaviour in some caterpillar species that live solitarily on leaves. Vibratory signals are produced during territorial conspecific interactions in a tortricid moth (Sparganothis pilleriana in Russ, 1969), the cherry leaf roller (Caloptllia serotinella in Fletcher et al., 2006), and three drepanid moth species (Drepana arcuata, Drepana bilineata, and Oreta rosea in Yack et al., 2001; Bowen et al., 2008; Scott et al., 2010a). Although we have no examples of vibratory-mediated spacing in gregarious holometabolous larvae, many caterpillars and beetle grubs live in close proximity to one another and may require signals to maintain personal space within the group. This is fertile ground for exploration and will be the focus of this thesis. Vibratory-mediated spacing was studied using two larval systems; the bark beetle larvae Scolytus multistriatus that develop in aggregations under bark, and gregarious early instar caterpllars of Drepana arcuata that live together in silk shelters.

Beetle model system

The first species of interest is the smaller European elm bark beetle (Curculionidae: Scolytinae: Scolytus multistriatus Marsham, 1802). Adult beetles form reproductive pairs, burrow into the phloem layer of the bark, mate, and lay eggs in rows. Once hatched, the larvae develop alone in a collective of larval tunnels, called galleries, underneath the bark where they have limited room to avoid their siblings. In some species like S. multistriatus, larvae produce very defined and symmetrical larval galleries with little to no overlap. This display of organized close-range avoidance is unusual in beetle larvae (Tragardh, 1930) and is the reason I chose this species as a model for vibratorymediated spacing. Although vibratory signals have not been recorded in this species, I 
hypothesized that passive vibratory cues produced by chewing can be used by surrounding larvae to avoid unwanted encounters underneath the bark. In one of the few studies addressing avoidance mechanisms in beetle larvae, Saliba (1972) also suggested that cerambycid larvae (Cerambyx dux) modify their tunnel orientation in response to acoustic signals. However, at present there is no supporting evidence for this hypothesis. Therefore studies specifically addressing vibratory signals/cues produced by bark beetle larvae in groups are greatly needed.

\section{Caterpillar model system}

The second species of interest is the moth caterpillar, Drepana arcuata Walker 1855 (Drepanıdae) that forms small groups (2-7 indıviduals) in sılk shelters during the first and second instars (Yack lab, unpublıshed data). Living in close proximity to one another could increase competition for resources, and communication could, therefore, become important for spacing between group members. Late instar caterpillars of $D$. arcuata produce vibratory signals during territorial encounters with conspecifics (Yack et al. 2001; Scott et al., 2010b; Guedes et al., in review). In comparison, caterpillars in early instars produce four signals (mandible drumming, mandible scraping, buzz scraping and anal scraping) during routine activity in the nest (Yack lab, unpublished). I hypothesized that these vibratory signals are used to communicate with group members for the function of spacing, or alternatively for recruitment. To the best of my knowledge, early instar $D$. arcuata caterpillars are the only known example of vibratory signals produced by lepidopteran caterpillars in groups and this study is the first to test predictions for the function of vibratory signals in holometabolous larvae. 
Another caterpillar species that was studied in this thesis is the warty birch caterpillar (Drepana bilineata Packard 1864) that is a congener, and shares many life history traits with $D$. arcuata, yet is solitary in all larval stages. Therefore, this species was examined to test predictions associated with the hypotheses for signalling in $D$. arcuata. In testing predictions associated with the spacing hypothesis, it was necessary to document life history traits and signalling patterns of $D$. bilineata. Information collected from observations of this species was also used to test and formulate a new hypothesisthat vibratory signals in $D$. bilineata caterpillars are used to mediate space between caterpillars occupying individual leaf territories.

\section{Thesis objectives}

The original purpose of this thesis was to focus on bark beetle interactions and examine vibratory-mediated spacing in beetle larvae. However, due to unforeseen complicatıons in methodology (described herein), coupled with an opportunity to study spacing in another species, the focus was shifted to test hypotheses for the function of vibratory signals in lepidopteran larvae as well. Chapter two provides a summary of the methodology developed for recording vibratory signals in bark beetle larvae to test predictions associated with the hypotheses. Chapter three forms the bulk of the thesis and tests two hypothesis (spacing and recruitment) for the function of signalling in early instar D. arcuata caterpillars. The final chapter turns the focus to Drepana bilineata, that also produces vibratory signals but is solitary throughout development. This comparative chapter not only tests predictions for the function of signals in $D$. arcuata caterpillars, but also contributes novel information about this species. 
CHAPTER TWO

Potential vibratory spacing mechanisms in the smaller European elm bark beetle larvae (Scolytus multistriatus) 


\subsection{Introduction}

General bark beetle life history

Bark beetle larvae (Coleoptera: Curculionidae: Scolytinae) are excellent models to explore possible mechanisms for spacing since they spend their entire development in aggregations where they are unable to easily remove themselves from the group. There are similar underlying principles to the life cycle of most bark beetle species with slight differences in reproduction and development. Adult bark beetles use chemical signals from other adults and chemical cues from trees to travel from their natal tree to a new host (Wood, 1982). This process, known as colonization, involves large numbers of adults aggregating on one tree and subsequent intersexual acoustic communication used to coordinate reproductive activities (Jefferies \& Fairhurst, 1982). After mating, either one, or both of the parents burrow into the phloem layer of the bark to create the maternal tunnel where the female lays eggs. The ova are usually deposited in rows and once larvae hatch they tunnel outwards from the maternal tunnel to form a collective of larval tunnels, known as a gallery (Wood, 1982). Each species has a characteristic gallery pattern (Tragardh, 1930) and, to date, it is unknown why gallery patterns differ so much among species.

Bark beetle larvae living in close proximity within galleries are likely to encounter a variety of obstacles during development, such as competition from other larvae and predation. It is apparent from observations of gallery patterns, that despite restrictions in their movement, some larvae are able to avoid interactions with other phloem feeding larvae or tunnelling predators. For example, galleries produced by Scolytus multistriatus larvae have a characteristic radial pattern with no contact between 
neighbouring tunnels (Fig. 2.1). Such lack of contact suggests that this species uses mechanisms to space between nearby siblings and makes $S$. multistriatus an ideal model system to study spacing in groups of holometabolous larvae.

Sensory mechanisms available to bark beetle larvae

Due to the nature of the environment within the phloem layer of the tree, bark beetle larvae are limited in available mechanisms for communication with their neighbours. Tactile cues are unlikely as larvae of this species do not come into direct contact with each other during development (Chapman, 1910; personal observation). Visual cues are also improbable, both because of the undeveloped visual system of the larvae (Thomas, 1957), and the opacity of the bark tissue. Olfactory spacing could be possible using chemicals secreted into surrounding phloem, yet it would be difficult for larval semiochemicals to travel through the phloem at a consistent enough rate to provide reliable information. Byers (1989) suggested that larvae can detect changes in the chemical composition of the phloem around a tunnelling larva, and that approaching larvae might detect this chemical change using chemoreceptors. However, this mechanism would require larvae to come into contact with the damaged phloem within close range of a conspecific where avoiding interaction would be difficult. I hypothesized that bark beetle larvae monitor the locations of their neighbours using vibrations transmitted through the bark and respond by orienting their tunnels to avoid interaction. The proximity of neighbouring larvae and conductive properties of the bark would allow passive vibrations caused by chewing or movement to be detected by flanking siblings. Alternatively, the larvae may have a means of making intentional vibratory signals. 


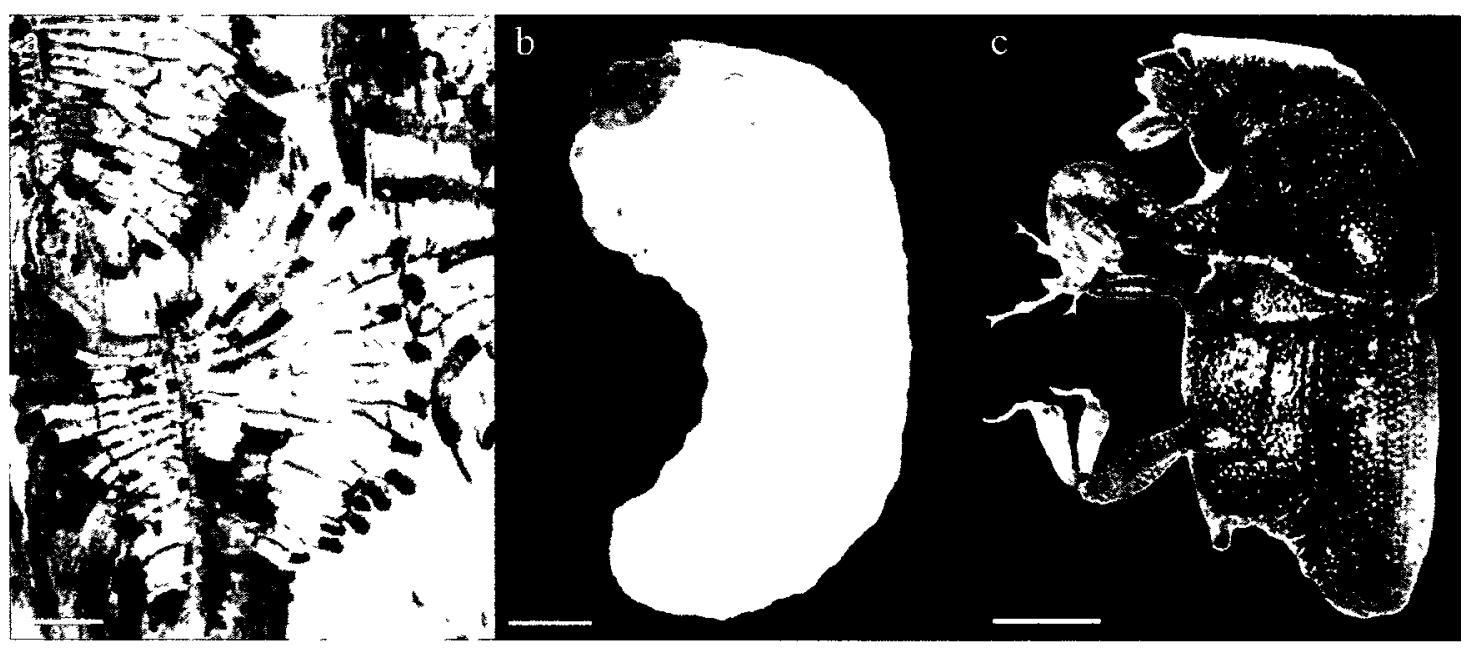

Figure 2.1 Natural history of Scolytus multsstriatus. (a) Exhausted gallery showing the characteristic radial pattern and an area where a larval tunnels avoided interaction with non-siblings (arrow). Scale bar, $3 \mathrm{~mm}$. (b) A late instar larva. Scale bar, $500 \mu \mathrm{m}$. (c) An adult male. Scale bar, $500 \mu \mathrm{m}$. 
The concept of bark beetle larvae using vibrations to maintain their own space underneath bark has been suggested a few times previously. In their discussion of competition among bark beetles de Jong \& Saarenmaa (1985), de Jong \& Grijpma (1986) and Byers (1989) suggested that scolytine larvae in the genera Ips and Dendroctonus are avoiding interaction by detecting the passive vibrations caused by movement or feeding of their neighbours. Furthermore, Saliba (1972) suggested that cerambycid larvae, Cerambyx dux, also change their tunnel orientation in response to vibrational sounds. In his study, larvae placed alone in tree bolts developed in straight tunnels whereas paired larvae created curved tunnels oriented away from each other, which could be the result of active spacing using vibrations. Although vibratory-mediated spacing in bark beetles has been suggested by the authors cited above, few studies have directly recorded vibrations produced by beetle larvae. Some large scolytine species, such as the larvae of palm weevils (Rhynchophorus sp.) produce airborne sounds so loud that they can be heard with the unaided ear (Mankin et al., 2008a). Laser doppler vibrometry has also been used to record movement and feeding sounds of cerambycid larvae, Anoplophora glabripennis, whose activity is not detectable with the unassisted ear (Mankin et al., 2008b). These examples demonstrate that some species of beetle larvae produce acoustic signals during their everyday activities, some of which can be detected with sensitive equipment. I predict that $S$. multistriatus larvae produce vibrations that are detectable by other larvae and are used to mediate spacing. 
Life history of the smaller European elm bark beetle, Scolytus multistriatus

Scolytus multistriatus was first documented in North America in the early twentieth century (Chapman, 1910). Previous studies of S. multtstriatus have focused on beetle populations from an ecological and control perspective (e.g. Hajek \& Dahlsten, 1985; Faccoli, 2001) and therefore, general life histories have been well documented. However, information about larval behaviour is lacking.

The massive decline of elm trees throughout North America can be attributed to the fungus (Ceratostomella ulmi) transmitted by adults of S. multistriatus which produces the commonly known Dutch elm disease (DED) (Wallace, 1940). After emergence from their natal tree, adults move to healthy elm trees and feed in twig crotches. In doing this they transmit fungal spores from an infected tree to a healthy one and continue the cycle of the DED fungus. The first adult flight time of the year occurs in May when daily temperatures become high enough to aid in their long-distance flights (Wood, 1982). Tree volatiles attract adult females to a dying or weakened elm tree where they select a location to begin tunnelling into the bark (Readio, 1935). Male adults are also attracted to the weakened tree through a combination of host cues and pheromonal cues from the females (Svihra \& Clark, 1980). Once males and females aggregate on the tree they perform an elaborate courtship ritual and mate in a nuptial chamber created by both sexes (for more details on courtship see Svihra \& Clark, 1980). The female then begins excavating an egg tunnel approximately $28 \mathrm{~mm}$ long with an average of 68 eggs per tunnel (Wallace, 1940). As she excavates the tunnel the female moves the frass backwards toward the tunnel entrance for the male to remove. When the egg tunnel is complete, the female carves out egg niches where she deposits the eggs and packs them 
with the excavated material. In most cases the male and female die within the gallery but adults will occasionally create an exit hole at the end of the tunnel (personal observation). Larvae hatch from a row of eggs and begin tunnelling perpendicular to the maternal tunnel. Larvae undergo five molts within a continuing outward tunnel, producing tunnels with an average length and width of $36 \mathrm{~mm}$ and $2 \mathrm{~mm}$, respectively (Fig. 2.1) (Wallace, 1940). Before pupation larvae create pupal cells at right angles to the larval tunnel.

Adults emerge from the bark through exit holes and continue their life cycle by locating a new host. During the entire process of larval development it is likely that $S$. multistriatus use spacing mechanisms to produce such a characteristically fan-shaped gallery with no contact between individuals.

\subsection{Objectives}

The objective was to test the hypothesis that the larvae of the smaller European elm bark beetle, Scolytus multistriatus, are using vibrations to mediate spacing by observing interactions between larvae while simultaneously recording vibrations from the phloem layer to determine if larvae produce vibrations. Preliminary investigation ruled out possible techniques for visualizing live activity of beetles under bark using thermal cameras, $\mathrm{x}$-ray, magnetic resonance imaging, and ultrasound. Instead I chose to develop a protocol using an older method with a phloem sandwich to monitor larvae. Phloem sandwiches date back to the 1930s and Kinn \& Miller (1981) have had success using phloem sandwiches for work on predators and parasitoids of Ips sp. (Fig. 2.2). However, no previous studies have combined acoustic recordings with phloem sandwich 

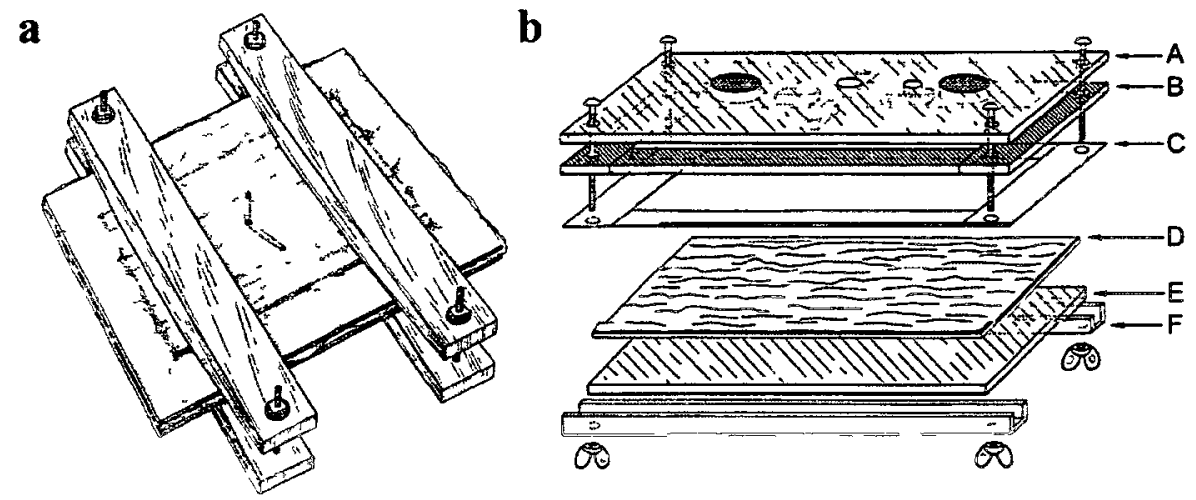

Figure 2.2 Phloem sandwich designs from Kaston \& Riggs (1937) (a), and Kinn \& Miller (1981) (b). (A) Plastic plate with two air vents; (B) Plastic spacer; (C) Layer of aluminum foil; (D) Phloem; (E) Lower plastic plate, intact; (F) U-brackets held in place with bolts. 
visualization. Consequently, most of my effort was spent developing a protocol using a modification of a phloem sandwich with modern vibration recording methods.

Development of a protocol for visualizing behaviour with vibration recordings proved to be more difficult than anticipated, and only preliminary data was obtained. As such, the second part of this chapter will combine methods, results and discussion to describe the development process and preliminary results.

\subsection{Methods, results and discussion}

Preliminary work was conducted between September 2008 and May 2009 to familiarize myself with the life stages of S. multistriatus, and develop a method for rearıng larvae. Details of this preliminary work are provided in Appendix 1.

\section{Preliminary vibration recordings with other beetle larvae}

The objective was to study the possible mechanisms used by larval bark beetles to communicate with one another while developing beneath tree bark. To test for a vibratory mechanism, a protocol was developed in January 2008 to visualize the larvae while recording vibrations produced during normal activity. At this time $S$. multistriatus beetles were unavailable, therefore, recording apparatus was tested using accessible beetle larvae that could be placed into bark in a similar way to $S$. multistriatus larvae. First, mealworm beetle larvae, Tenebrio molitor, were placed in an artificial tunnel in the phloem of a piece of Ulmus sp. bark, which had the outer bark previously sanded down (Fig. 2.3a). The larva was held in place by a small piece of plastic to secure it while the bark was rotated for recordings (Fig. 2.3bc). The beam of a laser vibrometer (velocity $20 \mathrm{~mm} / \mathrm{s}$; 

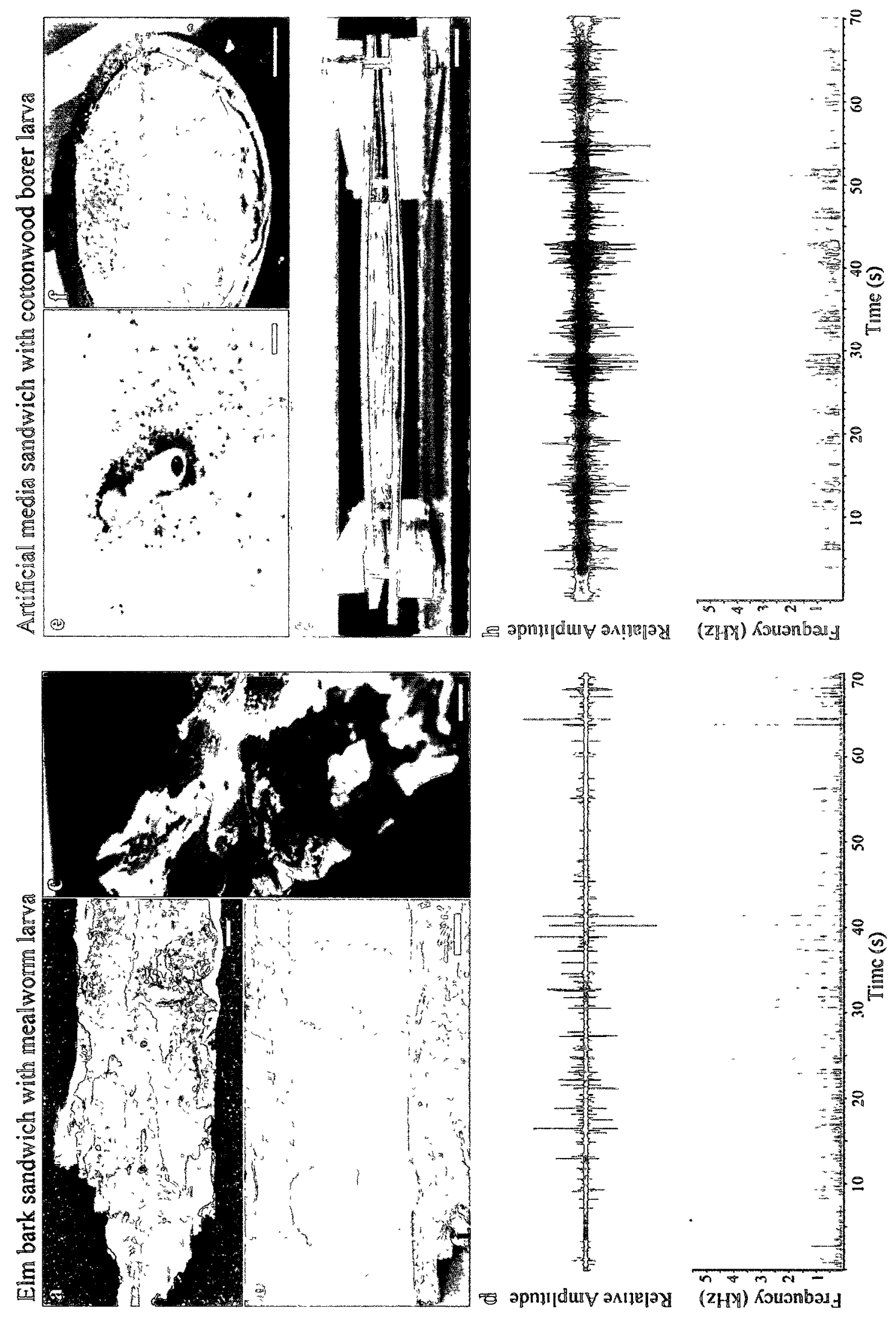
Figure 2.3 Vibration recordings of mealworm larvae underneath elm bark and cottonwood borer in artificial media. (a) Outer bark of elm sanded down for recording; black dots represent the end of the tunnel on opposite side. Scale bar, $5 \mathrm{~mm}$. (b) Phloem layer of elm bark with a mealworm larvae sandwiched into an artificially made tunnel. Scale bar, $1 \mathrm{~cm}$. (c) Laser beam focused on target on opposite side to larvae. Scale bar, $5 \mathrm{~mm}$. (d) Waveform and spectrogram of vibrations produced by moving mealworm larva under elm bark. (e) Cottonwood borer larvae in artificial media. Scale bar, $1 \mathrm{~cm}$. (f) Laser beam focused on target on opposite surface of medium. Scale bar, $3 \mathrm{~cm}$. (g) Media sandwich. Scale bar, $2 \mathrm{~cm}$. (h) Waveform and spectrogram of vibrations produced by moving cottonwood borer larva. 
high pass filter off; low pass filter $20 \mathrm{kHz}$; PVD-100, Polytec Inc., Irvine, CA, USA) was focused on the outer surface of the bark and recordings were transferred to a Marantz data recorder (PMD 671, D\&M Professional, Itasca, IL). All recordings were transferred from the data recorder to a laptop (HP Pavilion dv5, Hewlett Packard Inc, Mississauga, ON, Canada) for analysis. Vibrations produced by the larva's movement were faint but detectable as seen in Figure 2.3d. The second test specimen was a late-instar cottonwood borer larva, Plectrodera scalator, acquired from Insect Production Services (Fig. 2.3e) (Great Lakes Forestry Centre, Sault Ste. Marie, ON, Canada). This species was used to test if vibrations could be detected from artificial media, which was at that time a possible rearing media (Fig. 2.3f) (see Appendix 1). Larvae were placed individually into sandwiches of media and recordings were taken from the surface of the media with the laser vibrometer (Fig. 2.3g). Larval activity was easıly detected with the laser (Fig. 2.3h).

Collecting and rearing S. multistriatus larvae

Adult smaller European elm bark beetles, S. multistriatus, were collected from lindgren funnel traps with elm bark beetle lure (Item Number 300000098, Contech Enterprises Inc, Victoria, BC, Canada) on Carleton University property (Ottawa and Manotick, ON) in May, June and August 2009. Adults were used to test two natural methods of mating and oviposition. In the first method phloem sandwiches were created using a modified plate against the outer bark with a $10 \mathrm{~cm}$ hole drilled into it. Five males and five females were placed on the exposed bark and the hole was covered with a petri dish to create a mating chamber. The objective for using this method was to allow adults to mate and tunnel into the bark to lay eggs against the other plane of glass and allow 
larvae to be monitored when they began to develop. Within 24 hours of placing adults into the mating chamber some adults had excavated holes in the bark and tunnelled into the phloem area. However, after 5 days of observation tunnelling had stopped, adults were not laying eggs, and the adults eventually died in the phloem sandwiches. The remaining field collected adults were used in a second method where they were placed inside rearing chambers to mate and lay egg galleries on elm bolts $40-60 \mathrm{~cm}$ in length. Rearing chambers were housed under a $16: 8 \mathrm{LD}$ photoperiod at $21-26^{\circ} \mathrm{C}$ for 25 days to allow an appropriate length of time for mating, oviposition, gestation and partial development. This method of rearing was successful in creating two generations of beetle larva that were used for all subsequent phloem sandwich studies.

\section{Assembly of the phloem sandwich}

Elm bark bolts from the rearing chambers described above were examined for adult entrance holes that occur at the bottom of the natal tunnel (Fig. 2.4a). Using the location of the entrance hole, the surface area of the gallery area was approximated and the appropriate section bark and phloem containing S. multistriatus larvae were removed from the $\log$ and placed into a phloem sandwich (Fig. 2.4b). Developing a successful phloem sandwich technique required numerous trials to find a balance between the proper humidity necessary for the larvae, and a non-lethal concentration of anti-fungal and antibacterial solutions. A total of 12 phloem sandwiches were made with the last two being the only successful models with survival longer than 48 hours. In the final and most successful method a phloem sandwich was created with a piece of bark containing a gallery with mid-instar larvae which were removed from the tunnels, and $0.1 \%$ 


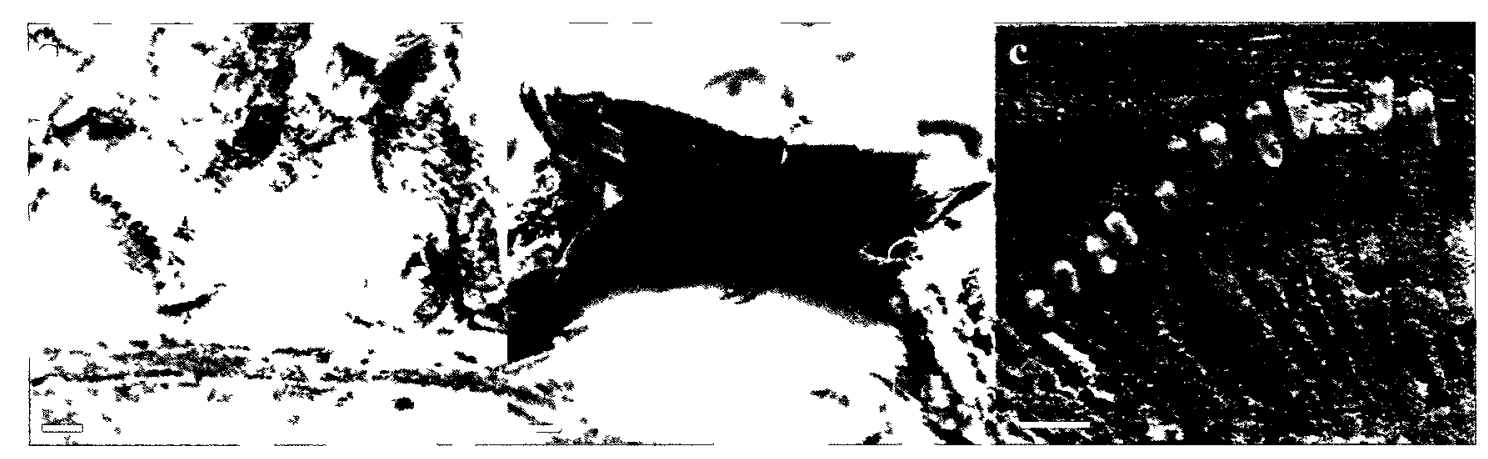

Figure 2.4 Steps involved in making a phloem sandwich. (a) Evidence of a beetle gallery from an entrance hole on the surface of an inoculated log. Scale bar, 3mm. (b) Log with bark partially removed showing the egg gallery. Scale bar, $5 \mathrm{~mm}$. (c) $S$. multistriatus larvae tunnelling in phloem sandwich photographed through a plane of plexiglass. Scale bar, $5 \mathrm{~mm}$. 
concentration of bleach (R.E.M Charette Ltd., Orleans, ON, Canada) was gently rubbed over the entire surface of the phloem, making sure not to disturb the packed frass within the tunnels. After a thorough coat of bleach was applied to the phloem, larvae were placed back into their same tunnels in the correct orientation and placed the glass plate onto the gallery. The sandwich was slowly tightened while observing the larvae with a microscope to ensure they made contact with the plate, but were not injured with too much pressure. To prevent larval desiccation, cotton or paper towels were placed in the space around the bark and wetted with $0.1 \%$ bleach daily.

\section{Vibration recordings and analysis of $S$. multistriatus larvae in a phloem sandwich}

Once a successful protocol was developed for sustaining $S$. multistriatus larvae in a phloem sandwich, the model was adapted to include vibration recording equipment to record any possible vibratıons produced by larval movement (i.e. tunnelling and chewing). The first task was to create video recordings of larval behaviour over varying lengths of time to test if tunnelling behaviour could be observed. Long term video recordings of 2, 4 and 8 hours of phloem sandwiches containing S. multistriatus larvae were made using a Sony HDR-XR520V Handycam (Tokyo, Japan) in ambient lighting and also in the dark using the night vision setting on the camera. Despite the small size of the larvae, the video showed when larvae were eating/tunnelling or resting (Fig. 2.4c). Next, vibration recording was attempted with the laser vibrometer using a split output into the microphone port of video camera and the data recorder. The laser vibrometer was focused on the bark through holes drilled into the plates of the phloem sandwich. All recordings were transferred from the data recorder to a laptop for temporal and spectral 
analysis using RavenPro Bioacoustics Research Program 1.4 (Cornell Laboratory of Ornithology, Ithaca, NY, USA)

For reasons yet to be confirmed, multiple vibration recordings of the larva could not collected. This provided little acoustic data to present in conjunction with the video. However, in one of the final attempts, vibrations were recorded from one tunnelling larva in a phloem sandwich (Fig. 2.5). Unfortunately, recordings of this trial were performed without video, therefore no trials of video and vibration were collected. Preliminary sound characterization of the vibrations is provided below. Upon reviewing the data, the only successful vibration recording resulted from a final modification of the recording design. In previous designs the recording apparatus focuses the laser through a hole drilled in the plate on the outer bark. In the final trial, larvae had tunnelled into the middle of the bark (so they were not visible from either side of the sandwich) and the plates were reversed and rotated to record through holes on the phloem side of the bark, in very close distance to the known larvae. It appears that vibrations can only be detected when the larvae are very close to the laser with little tissue in between. This information should be incorporated into the experimental design in future studies.

\section{Signal analysis}

Temporal and spectral characteristics of 10 signals from one successful trial were analyzed. Mean \pm SD signal duration was $12.6 \pm 14 \mathrm{~ms}$. Most of the signal energy occurred below $7 \mathrm{kHz}$, with peaks at $1518.6 \pm 106.4,2812.5 \pm 0$ and $6125 \pm 88.4 \mathrm{~Hz}$, respectively (Fig. 2.5). 
$\mathbf{a}$

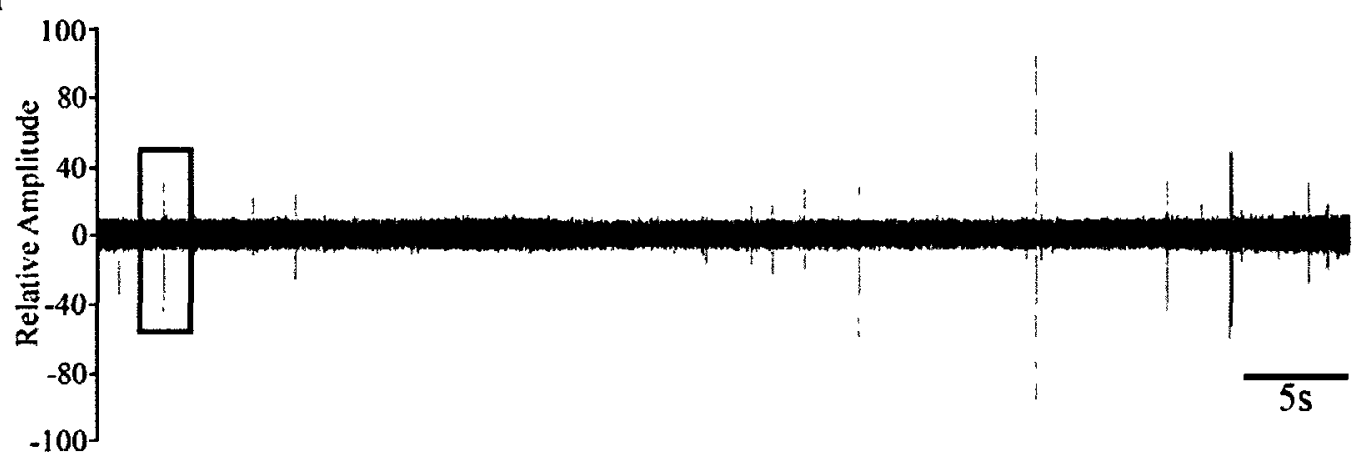

b

c
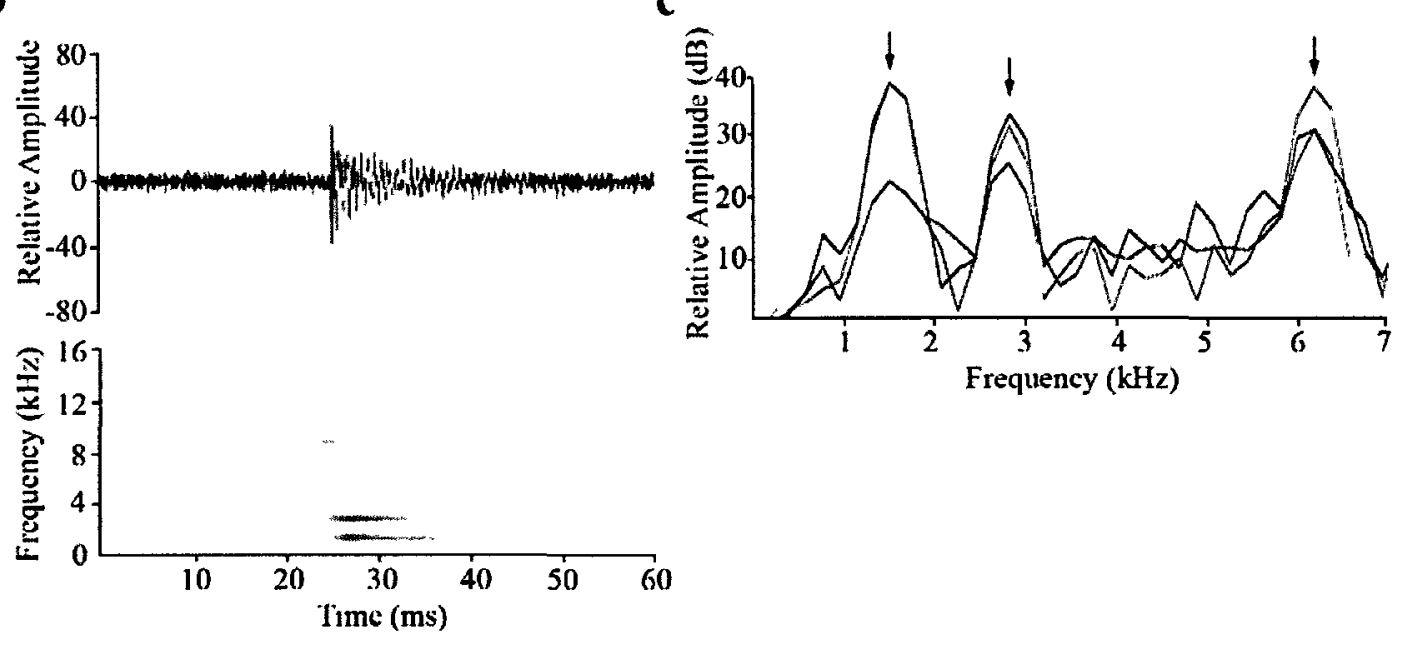

Figure 2.5 Vibrations recorded from phloem surrounding a $S$. multistriatus larva. (a) Waveform of a series of vibrations produced by the moving larva. (b) Waveform and spectrogram of an individual vibration taken from part (a) indicated by box. (c) Power spectra of vibrations showing peaks at 1518,2812 and $6125 \mathrm{kHz}$ as indicated by arrows. 


\subsection{Summary}

This research represents the first known attempt to test the mechanisms used by bark beetle larvae to space themselves in a sensory limited environment. Vibratory recordings in conjunction with behavioural observations are critical to provide support for the hypothesis that vibratory communication mediates spacing in larval bark beetles. Unfortunately, much of the time and resources were spent developing a method for recording vibrations in conjunction with visualizing behaviour, and further behavioural experiments could not be achieved in the scope the thesis. However, this work has great potential to pave the way for future research using the method of rearing larvae in elm bolts, creating a phloem sandwich and recording from the bark with a laser vibrometer.

The recordings that were obtained from S. multistriatus larvae do provide some evidence that vibratory signals/cues are available to developing larvae. The small amplitude of the vibrations, which added to the difficulty in obtaining recordings, may be useful to communicate with conspecifics in close proximity while avoiding detection by acoustically-orienting predators. These preliminary results offer positive support for the hypothesis that beetle larvae are using vibrations created by their neighbours to mediate spacing within galleries. Future projects should focus on improving rearing methods, and phloem sandwich techniques using modifications suggested in this chapter. Additional variations to the recording set up could include a recording array placed along the gallery to provide information about how vibrations travel across phloem and if vibrations are available to neighbouring larvae. Finally, experimental tests using artificial vibrators should be conducted to manipulate natural larval development and determine if larvae respond to vibrations in a meaningful way. 


\section{CHAPTER THREE}

The function of vibratory signals in gregarious instars of the masked birch caterpillar, Drepana arcuata (Drepanidae) 


\subsection{Introduction}

The masked birch caterpillar, Drepana arcuata (Drepanidae) is gregarious during its first and second instars, living together within silk nests and producing a complex repertoire of vibratory signals. I will be testing the hypothesis that gregarious $D$. arcuata caterpillars are using vibratory signals to mediate spacing within the nest. In addition, I will test an alternative hypothesis- that signals are used for recruitment. In the introduction to this chapter group living in caterpillars and the possible mechanisms used to communicate within groups will be discussed first. Next some of the recent literature describing examples of caterpillars using vibrations to defend territories from conspecifics will be summarized. Lastly I will explain what is currently known about vibratory communication in $D$. arcuata and discuss the hypotheses and objectives that will be addressed in this chapter.

\section{Group living}

Many species of caterpillars form groups at some point in their development and often groups occur during early instars as a result of eggs being laid close together (Stamp, 1980). Approximately 5\% of North American butterfly species and $7 \%$ of moth species form aggregations during their development (Stamp, 1980; Hebert, 1983). Some of the suggested advantages to group living for caterpillars include feeding facilitation, predator defence, and enhanced thermoregulation and/or microclimate (Reader \& Hochuli, 2003; Denno \& Benrey, 1997; Bryant et al., 2000). Yet group living may only provide benefits during early instars, which explains why most gregarious species become solitary during later development (Fitzgerald, 1993). Regardless of which social 
force is bringing caterpillars together, communication among individuals in groups is extremely important.

Although little is known about mechanisms used for communication within larval groups, chemical and tactile mechanisms have been shown to aid in some aspects of caterpillar group behaviour. Processionary behaviour seen in groups of Hylesia lineate (Saturniidae) caterpillars is an excellent example of both chemical and tactile communication. Caterpillars use pheromones laid down by the anal segments of the preceding caterpillar, in conjunction with physical contact between the head and abdomen of adjacent caterpillars, to move forward in a fluid line (Fitzgerald \& PescadorRubio, 2002). Similar trail marking behaviours have been seen in two lasiocampid caterpillars; Malacosoma americanum and Gloveria sp. (Fitzgerald \& Visscher, 1995; Fitzgerald \& Underwood, 1998). Currently there are no examples of vibratory sıgnalling in lepidopteran larval groups. However, there is one documented hymenopteran species, Perga affinis (Pergidae), whose gregarious larvae communıcate with vibratory signals for group movement and cohesion while foraging (Fletcher, 2008) but there is no published information on the function of vibratory signals in caterpillar groups.

\section{Vibratory signalling in caterpillars}

Vibratory signals play a role in ant-caterpillar mutualisms in some Riodinidae and Lycaenidae caterpillars (DeVries, 1990; Travassos \& Pierce, 2000), and these are currently the only example of interspecific vibratory communication in caterpillars. However, there have been a number of studies of late instar caterpillars using vibratory signals in conspecific territorial disputes. Vibratory interactions between competing 
conspecifics have been reported in a tortricid moth (Sparganothis pilleriana in Russ, 1969), the cherry leaf roller (Caloptilia serotinella in Fletcher et al., 2006), the warty burch caterpillar (Drepana bilineata in Bowen et al., 2008), and the rose hook-tip moth (Oreta rosea in Scott et al., 2010a). In addition, late instar caterpillars of the masked birch caterpillar (Drepana arcuata) produce vibratory signals during territorial interactions with conspecifics, and are able to discriminate, and filter out, irrelevant abiotic sounds of wind and rain to focus solely on conspecific vibrations (Yack et al., 2001; Guedes et al., in review). In the examples above, territorial disputes may be a form of long distance spacing to avoid conflict over resources. With increasing evidence of vibratory communication in solitary caterpillars, the possibility exists that vibratory signals could also serve an important role for communication between group members. Vibratory signals could be beneficial during group interactions to enhance cooperative behaviour and/or mediate spacing between individuals. To the best of my knowledge, the only known example of vibratory signalling in caterpillar groups is in gregarious early instars of the masked birch caterpillar, Drepana arcuata (Yack lab, unpublished data).

\section{Drepana arcuata}

The masked birch caterpillar, Drepana arcuata (Drepanidae), is commonly found on birch trees (Betula sp.) throughout northeastern North America (Rose \& Lindquist, 1997). Adults lay eggs in rows on leaves and newly hatched caterpillars form groups of 2 to 5 individuals within silk shelters for their first and second instars (Yack et al., 2001; Yack, unpublished data) (Fig. 3.1a-c). Aggregations dissolve during the third instar and caterpillars live alone within silk shelters on individual leaves until pupation (Yack et al., 
2001) (Fig. 3.1d). Caterpillars produce vibrational signals during all stages of development (Yack et al., 2001; Timbers 2005; Lynes 2006). Early instar caterpillars produce four vibratory signals (buzz scrape, mandible scrape, mandible drum and anal scrape) and late instars produce three vibratory signals (mandible drum, anal scrape and mandible scrape) (Yack et al., 2001; Timbers, 2005; Lynes, 2006). While the function of territorial signalling in late instars has been tested (see above), vibratory signalling in early instars is a novel topic to explore with respect to its possible role in group spacing. The group structure and vibratory signals of $D$. arcuata early instar larvae differs from late instars in a few important ways. First, while late instar caterpillars are non-gregarious and occupy an entire leaf, early instar caterpillars tend to live in groups in silk shelters. Second, the vibratory repertoire differs amongst instars, with caterpillars producing four signals during early instars and three signals during late instars. Third, signalling appears to be made in different contexts. For example, early instar caterpillars signal while feeding (Matheson, unpublished data), and late instars do not. Also, late instar caterpillars only signal to the approach of a conspecific, whereas during early instars caterpillars signal during routine activities within the nest (Yack et al., 2001; Timbers, 2005; Lynes, 2006). With no equivalent literature about vibratory signalling in gregarious holometabolous larvae, the suggested function of these signals produced in early instars is puzzling. Therefore the focus of my research is to test the function of vibratory signals in groups of $D$. arcuata caterpillars. To provide a platform for my specific thesis objectives, I will summarize the proposed hypotheses for the function of signalling below and briefly describe what has already been done by students of Dr. Yack that has led to my current research. 


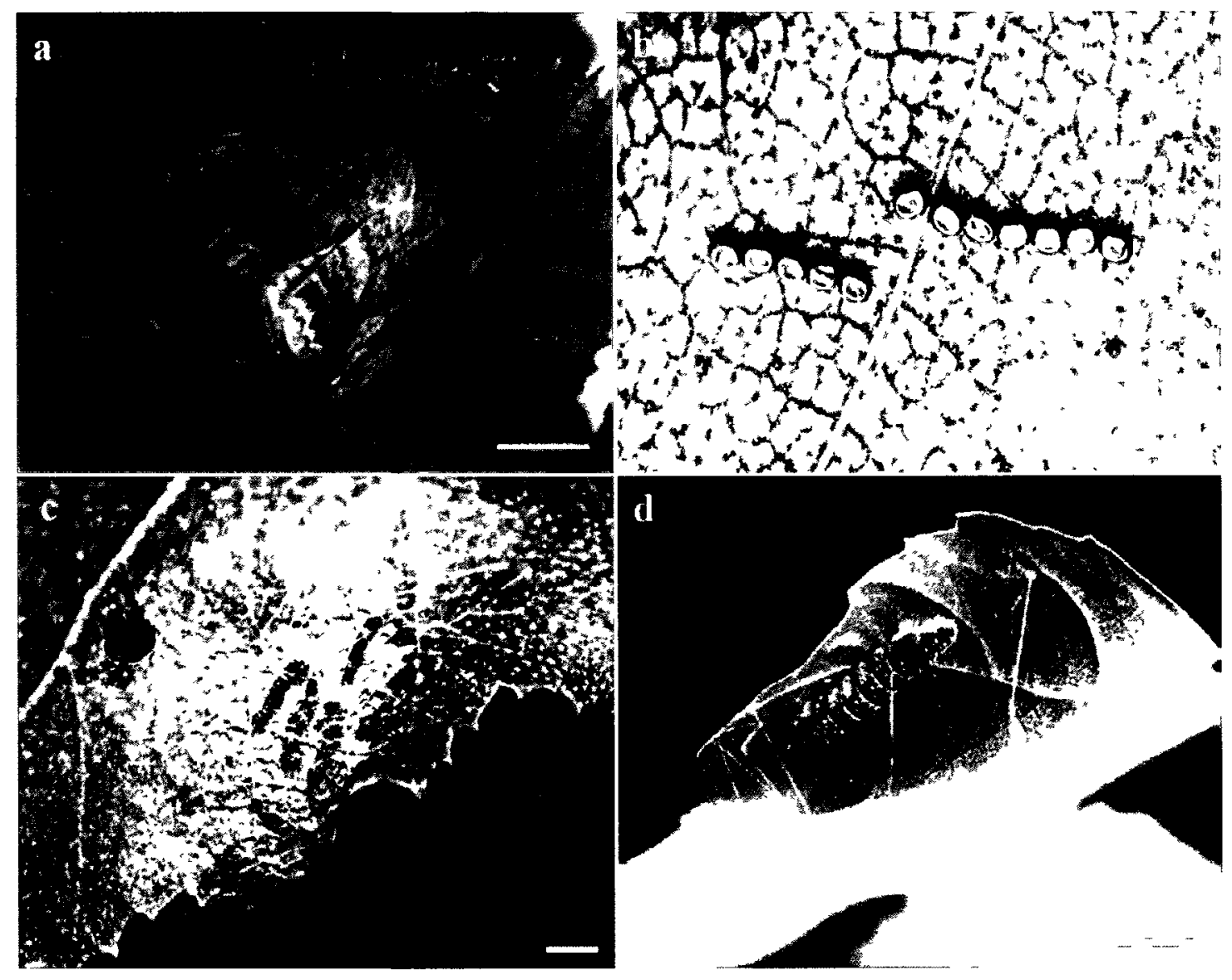

Figure 3.1 Life history stages of Drepana arcuata. (a) A pair of adults mating. Scale bar, $1 \mathrm{~cm} \mathrm{(b)} \mathrm{Rows} \mathrm{of} \mathrm{eggs} \mathrm{on} \mathrm{the} \mathrm{underside} \mathrm{of} \mathrm{a} \mathrm{birch} \mathrm{leaf.} \mathrm{Scale} \mathrm{bar,} \mathrm{3mm} \mathrm{(c)} \mathrm{Early} \mathrm{instar}$ larvae in a silk shelter. Scale bar, $2 \mathrm{~mm}$. (d) A solitary late instar larvae in a silk shelter. Scale bar, $8 \mathrm{~mm}$. Photo credit (a) and (b): Jayne Yack. Photo credit: (c) and (d) Sarah Matheson. 


\subsection{Hypotheses for the function of vibratory signals in early instar $\mathrm{D}$. arcuata}

After reviewing the literature on caterpillar group behaviour, vibratory signalling in insects, and the function of communication in animal groups, four hypotheses were developed to examine the function of vibratory signalling in gregarious early instar $D$. arcuata caterpillars. The hypotheses are described below under general subheadings.

\section{Enhancing feeding}

The first hypothesis is that caterpillars are producing vibratory signals to enhance feeding. This can be done in two ways; by acting as a vibrotome while feeding or by preparing the leaf for consumption. Some ant species have a behavioural adaptation while feeding where they produce vibratıons with a specialized organ on their gaster which vibrates the leaf and changes the physical characteristics of the leaf allowing the mandibles to cut the leaf with ease (Tautz et al., 1995). The justification for rejecting this hypothesis with respect to $D$. arcuata is that they do not produce signals exclusively whlle feeding and so signals must serve an additional function (Matheson, personal observation). Another possibility is that caterpillar vibrations are the result of body movements to prepare the leaf for consumption. Leaf hairs, trichomes, and cuticular waxes all pose problems for early instar caterpillars (Zalucki et al., 2002), and removal of these obstacles may make feeding easier. Caterpillars do produce anal scrape signals while feeding (personal observation) but caterpillars typically feed in a position where they are oriented with their head toward the edge of the feeding scar and the rest of their body on the skeletonised leaf. In this position, scraping the anal segment against the leaf 
would not prepare the leaf for feeding. Also, the complexity of the vibratory repertoire makes this hypothesis unlikely.

\section{Predator defence}

The next hypothesis is that vibratory signals of $D$. arcuata caterpillars have an antipredator function to warn of defences or recruit help. Drepana arcuata caterpillars do not have any obvious defences that would protect them from predators, so vibrations could be used instead to deter predator attacks. However, previous experiments found that caterpillars became silent when the nest was disturbed with a paintbrush and when a predatory spider was placed on the leaf, rather than signalling to the attacker (Yack \& Matheson, unpublished data). Vibratory signals could have a predator defence function in a similar way to those produced in mutualıstic interactions between lycaenid and riodinid caterpillars and ants (DeVries, 1990; Travassos \& Pierce, 2000). In these interactions, ants protect the caterpillars from predators in exchange for a sucrose reward. However, there are no observations of relationships between $D$. arcuata caterpillars and ants which provided another reason to dismiss the antipredator hypothesis.

\section{Conspecific communication}

The final two hypotheses both pertain to the idea that vibratory signals function to communicate between conspecifics. Whereas late instars produce signals only during territorial disputes, early instars live together and signal regularly during routine activities. Observations of signalling within gregarious groups led to the hypothesis that D. arcuata signals function to mediate spacing within the nest. An alternative hypothesis 
is that signals function to recruit conspecifics to the nest. Both hypotheses will be discussed individually below with corresponding predictions and preliminary evidence from previous experiments (Timbers, 2005; Lynes, 2006).

Signals function to space

The primary hypothesis tested is that vibratory signals in early instar $D$. arcuata function to space individuals within the nest. More specifically, vibrations could be used to convey spatial information to conspecifics in the nest. To the best of my knowledge, there are no examples in the literature demonstrating communication in holometabolous insect groups for within-group spacing. However, there are some studies from other taxa that demonstrate inter-Individual spacing. For example, in some bird groups the 'chuck' or 'kek' call functions to regulate spacing by advertising the signaller's position to prevent a group member from moving toward the signaller and entering into conflict (Radford, 2004; Radford \& Ridley, 2008). Also, in many schooling fish species, the lateral line system is used as a permanent mechanism to prevent individuals from swimming into one another (reviewed in Krause \& Ruxton, 2002). Using evidence from other taxa we can draw parallels to $D$. arcuata larvae that could be demonstrating similar spacing behaviour using vibratory signalling.

The predictions for the spacing hypothesis in $D$. arcuata are:

1. Larvae maintain regular inter-individual distance in the nest

2. Signal rates increase as a conspecific approaches an individual's personal space 
3. An individual that is moving (changing position in the nest) should signal while moving to indicate its position

4. Signal rates are lower in solitary individuals than individuals in groups

5. Signal rates of undisturbed gregarious early instar caterpillars are higher than undisturbed non-gregarious late instar caterpillars

6. Signal rates of undisturbed gregarious early instar D. arcuata caterpillars are higher than undisturbed non-gregarious early instar $D$. bilineata caterpillars

There is already some preliminary support for the spacing hypothesis from previous unpublished studies of $D$. arcuata caterpillars from the Yack lab (Timbers, 2005; Lynes, 2006). Two predictions that have been previously tested are (a) larvae maintain regular inter-ındıvidual distance in the nest, and (b) signal rates increase as a conspecific approaches an individual's personal space. The first prediction was tested by measurıng the average inter-1ndividual distances of caterpillars on leaf sprigs while resting or eating in the nest. Results showed that caterpillars maintained a regular inter-individual distance of 0.5 to $2.5 \mathrm{~mm}$, which supports the prediction that caterpillars maintain a preferred "personal space" in the nest (Lynes, 2006) (Fig. 3.2a). To test the second prediction, a conspecific intruder was placed on a leaf containing an established nest and signal rates of buzz scraping, mandible scraping, mandible drumming and anal scraping were calculated at time intervals as the intruder approached and entered the nest. Signal rates increased as the intruder approached the personal space of the residents in the nest, 

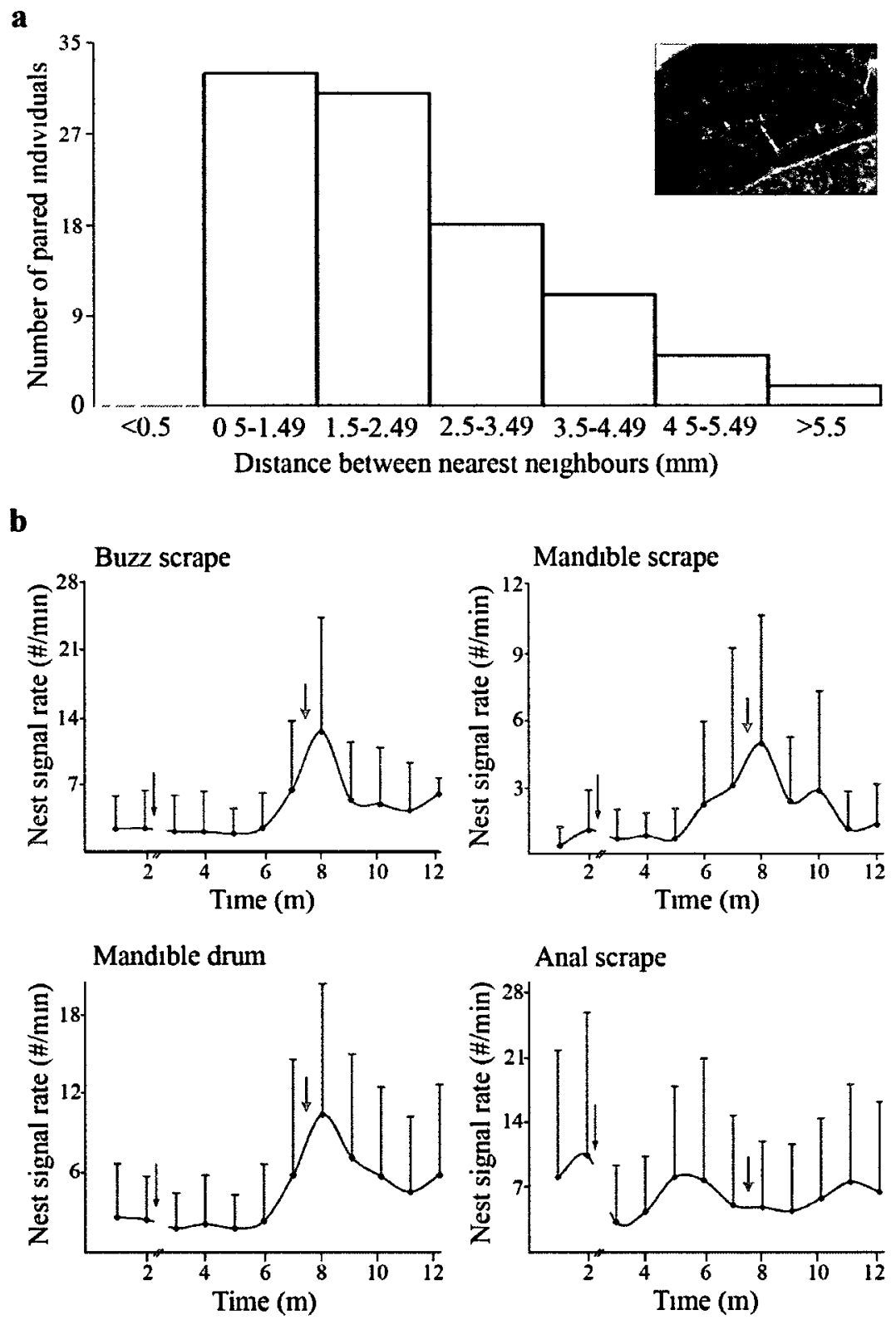

Figure 3.2 Previous experiments to test the spacing hypothesis. (a) Distance between paired individuals in the nest. Caterpillars showed regular inter-individual spacing of 0.5 $2.5 \mathrm{~mm}$ from each other. Inset is a picture showing resting caterpillars in a nest and an arrow measuring distance between individuals. (b) Signal rates of residents as an intruding caterpillar approaches the nest. Black arrows represent the time when the intruder was placed on the leaf. Red arrows indicate the point when the intruder entered the nest. 
except anal scraping while feeding which most likely decreased because feeding stopped (Timbers, 2005) (Fig. 3.2b).

Both of the above mentioned studies provide support for the spacing hypothesis and given that this behaviour has never been reported for larvae in any species before, it was necessary to increase the sample size of some of the previous tests and, to test further predictions to provide additional support that signals function for spacing. I will be retestıng the prediction that signal rates increase as a conspecific approaches an individual's space, as well as testing the remainder of the predictions. I will do this by quantifying signals and behaviours of undisturbed nests and by performing manipulations by introducing a conspecific to the leaf with a solitary individual. Further detail is provided in the description of my thesis objectives (below).

Signals function to recruit

An alternative hypothesis for the function of vibratory signals in $D$. arcuata caterpillars is that signals function to recruit conspecifics to join the nest. The Australian sawfly, Perga affinis, is the only documented example of vibratory recruitment in groups of holometabolous larvae. This species of sawfly forages in groups and when a larva gets separated from the group, it begins tapping its abdomen against the plant which produces a vibratory signal. The group of sawflies respond by signalling together to 'recruit' the separated larva back to the group (Fletcher, 2008). Although D. arcuata would not need to rejoin the group because they do not leave the nest to forage collectively, they do live gregariously and could be using vibratory signals to communicate to roaming conspecifics looking to join a nest. As discussed in the introduction, there are advantages 
associated with group living for caterpillars and signals functioning to recruit individuals to the nest may be used to initiate or increase group size.

The predictions for the recruitment hypothesis are:

1. Caterpillar groups are the result of active group formation and not from incidental environmental gatherings

2. Individuals will join a signalling (occupied) nest more than a non-signalling (empty) nest

3. Signal rates are higher in solitary individuals than individuals in groups

4. Signal rates of undisturbed gregarious early instar caterpillars are higher than undisturbed non-gregarious late instar caterpillars

5. Signal rates of undisturbed gregarious early instar $D$. arcuata caterpillars are higher than undisturbed non-gregarious early instar D. bilineata caterpillars

Two experiments were previously conducted to test predictions associated with the recruitment hypothesis. These predictions are (a) caterpillar groups are the result of active group formation and not from incidental environmental gatherings and (b) individuals join a signalling (occupied) nest more than a non-signalling (empty) nest. To test that groups are not the result of incidental gatherings, individual larvae were placed on separate leaves of a birch sprig containing 6 leaves and group size was recorded at time intervals. After 24-48 hours, caterpillars that had been placed on individual leaves had formed groups of two to four individuals, demonstrating that caterpillars actively form groups (Timbers, 2005) (Fig. 3.3a). The nest location was also recorded and results showed that $47 \%$ and $38 \%$ of caterpillar groups were located on the leaf side or tip, 
respectively (Timbers, 2005) (Fig 3.3b). The result that caterpillars form groups after 24 hours supports the idea that caterpillars actively seek one another out. However, the results that caterpillars form groups on specific areas of the leaf may indicate a preference for a particular area of resource and a secondary adaptation to deal with living in proximity to others. The second prediction, that caterpillars join signalling nests more than silent nests was tested by introducing a solitary caterpillar to a leaf containing a nest that was either occupied by 2-3 residents, representing the signalling condition, or a nest that lacked residents to represent a silent condition. There was no statistical difference to show that caterpillars preferred one condition over the other (Fig. 3.3c) indicating that vibratory signals may not influence a roaming caterpillar's decision to join a nest (Tumbers, 2005).

The alternative hypothesis that signals function for recruitment had mixed support from the previous studies described above. While caterpillars actively formed groups, they did so on particular areas of the leaf. Therefore signalling may not be used to form groups if caterpillars are searching for specific locations in the first place. Once again, given that this behaviour has never been reported before it is necessary to test the remaining predictions by quantifying signals and behaviours of undisturbed nests. Based on the preliminary positive support for the spacing hypothesis and weak support for the recruitment hypothesis, the objective was to complete the untested predictions and further test the spacing hypothesis. The spacing and recruitment hypotheses discussed above are summarized in Table 3.1 with corresponding predictions. 
a

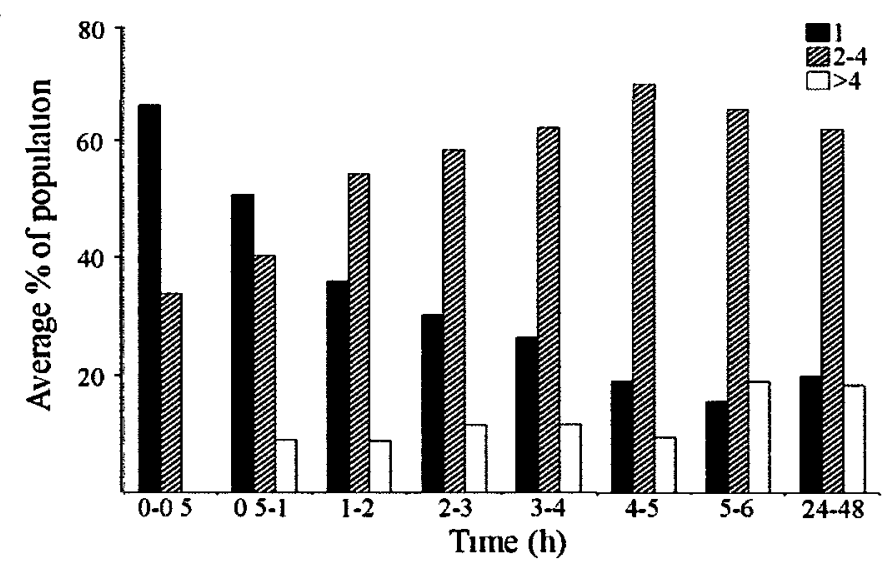

b
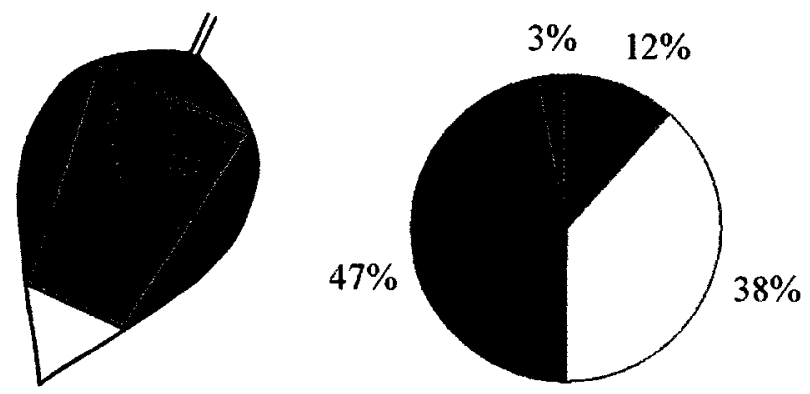

c

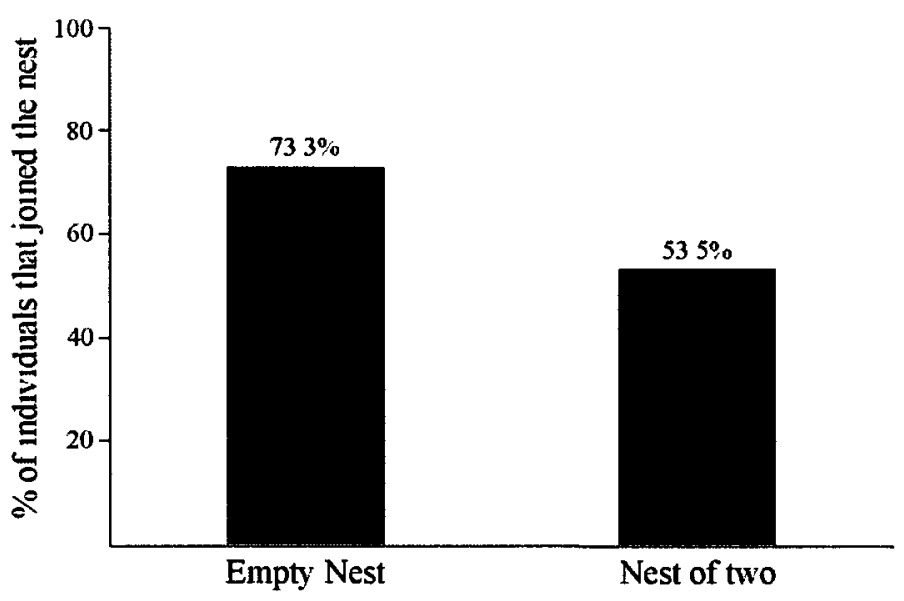

Figure 3.3 Previous experiments to test the recruitment hypothesis (a) Distribution of group sizes of $D$. arcuata after being individually placed on 6 separate leaves of a birch sprig. (b) Area of leaf that caterpillars formed nests. (c) Percentage of individuals who joined an empty or occupied nest after being introduced to a leaf. 
Table 3.1 Two hypotheses, and corresponding predictions, explaining the function of vibratory signalling in early instar $D$. arcuata caterpillars. Predictions in italics were tested with previous research. $\mathrm{S} 1=$ spacing prediction $1, \mathrm{R} 1=$ recruitment prediction 1 , and so on.

\begin{tabular}{ll}
\hline $\begin{array}{c}\text { Signals function to space individuals in } \\
\text { the nest }\end{array}$ & $\begin{array}{c}\text { Signals function to recruit individuals } \\
\text { to the nest }\end{array}$ \\
\hline $\begin{array}{l}\text { S1. Larvae maintain regular inter- } \\
\text { individual distance in the nest }\end{array}$ & $\begin{array}{l}\text { R1. Caterpillar groups are the result of } \\
\text { active group formation and not from } \\
\text { incidental environmental gatherings }\end{array}$ \\
\hline $\begin{array}{l}\text { S2. Signal rates increase as a conspecific } \\
\text { approaches an individual's personal } \\
\text { space }\end{array}$ & $\begin{array}{l}\text { R2. Individuals will join a signalling } \\
\text { (occupied) nest more than a non- } \\
\text { signalling (empty) nest }\end{array}$ \\
\hline
\end{tabular}

S3. An individual that is moving (changing position in the nest) should signal while moving to indicate its position

R3. Signal rates are higher in solitary individuals than individuals in groups
S4. Signal rates are lower in solitary individuals than individuals in groups
R4. Signal rates of undisturbed gregarious early instar caterpillars are higher than undisturbed non-gregarious late instar caterpillars
S5. Signal rates of undisturbed gregarious early instar caterpillars are higher than undisturbed non-gregarious late instar caterpillars
R5. Signal rates of undisturbed gregarious early instar D. arcuata caterpillars are higher than undisturbed non-gregarious early instar $D$. bulineata caterpillars

S6. Signal rates of undisturbed gregarious early instar $D$. arcuata caterpillars are higher than undisturbed non-gregarious early instar $D$. bulineata caterpillars 


\subsection{Chapter objectives}

There are two primary strategies used to collect data to test predictions: (a) monitoring activity associated with signals, and (b) experimental manipulations by introducing conspecifics to established nests.

\section{Nest observations}

Most of the previous research tested predictions by taking intermittent measurements of either group size or distribution or by manipulating nest behaviour by introducing a conspecific. None of the experiments had continuously observed undisturbed nests to document natural group interactions. By recording video and vibratory signals of groups of varying nest sizes over 30 minute undisturbed trials, the vibratory repertoire and behaviours of caterpillars were characterized and then the following four predictions relating to the spacing (S) or recruitment (R) hypotheses were tested:

S3. An individual that is moving (changing position in the nest) should signal to indicate its position. This prediction was tested by calculating the signal rate of each of the four signals independently with each type of observed behaviour to determine if signals are associated with movement. The signal/state rates between solitary individuals and individuals in groups were also tested to see if solitary individuals did not signal while moving because they do not need to communicate spatial information to conspecifics.

S4. Signal rates are lower in solitary individuals than individuals in groups. This prediction was tested by comparing signal rates of each signal type between solitary 
individuals and individuals in a group to determine if there is a relationship between signal amount and group size.

S5/R4. Signal rates of undisturbed gregarious early instar caterpillars are higher than undisturbed non-gregarious late instar caterpillars. This was tested by comparing overall signal rates of solitary caterpillars in gregarious early instars with solitary caterpillars in non-gregarious late instars to determine if signals are used for spacing and/or recruitment between conspecifics.

R3. Signal rates are higher in solitary individuals than individuals in groups. This prediction was tested by comparing signal rates of each signal type between solitary individuals and individuals in a group to determine if there is a relationship between signal amount and group size if solitary individuals have more need to recruit.

\section{Nest manipulations}

Previous studies showed that signalling rates of buzz scraping, mandible drumming and mandible scraping increased over time as an intruder approached an individual's personal space. This chapter will retest this phenomenon with video recordings of behaviours and vibratory signals during interactions between solitary residents and an introduced conspecific to test the following prediction:

S2. Signal rates increase as a conspecific approaches an individual's personal space. This prediction was tested by measuring the relationship of the inter-individual distance and the resident's signal rate to determine if signals escalate as the intruder approaches the personal space of the resident. 


\section{Comparison with Drepana bilineata}

The remaining two predictions will employ the comparative method to test the prediction that signalling in a gregarious species will be higher than signalling in a nongregarious congener species. The prediction is:

S6/R5. Signal rates of undisturbed gregarious early instar $D$. arcuata caterpillars are higher than undisturbed non-gregarious early instar $D$. bilineata caterpillars. A higher signal rate for gregarious caterpillars demonstrates that signallıng functions for conspecific communication within the nest, regardless if it is for spacing or recruitment. This prediction is tested with 30 minute undisturbed recordings of video and vibratory signals of solitary $D$. bilineata caterpillars who have similar life history traits but are solitary during all instars. While these trials were being conducted, the scope of the project expanded to include analysis of signals and behaviours that have never been documented for this species. The results of this study are provided in chapter four.

\subsection{Methods}

Animals and experimental setup

Caterpillars of Drepana arcuata (Drepanidae) were reared from eggs obtained from moths collected at sheets illuminated with $15 \mathrm{~W}$ ultraviolet collecting lights (Bioquip, Rancho Dominguez, California) in August 2009 and 2010 at the Queen's Unıversity Biological Station (Lake Opinicon, Ontario, Canada, 44³3'55.34”N $\left.76^{\circ} 19^{\prime} 26.59^{\prime \prime} \mathrm{W}\right)$. Larvae were reared indoors on cuttings of birch (Betula sp.) at Carleton University under a $16: 8 \mathrm{LD}$ photoperiod at $21-26^{\circ} \mathrm{C}$. First instar larvae (1-3 days old) 
were used for all trials to represent the early instar condition, as both first and second instars are gregarious and produce the same vibratory signals.

To create established nests for both the observation and manipulation trials, five newly hatched larvae were placed singly on five leaves of a birch sprig and left undisturbed for a minimum of 12 hours. This allowed caterpillars to form groups of natural size and location on the leaf. After 12 hours, sprigs were visually inspected and a single group containing 1 to 5 individuals was selected for observation. The individuals in all remaining groups on the sprig were removed and introduced to a new sprig for use in subsequent trials.

Vibration recordings and stgnal analysis

Vibratory signals were recorded from solitary caterpillars and groups using a laser-doppler vibrometer (PVD-100, Polytec Inc., Irvine, CA, USA) with the beam of the laser focused on a circle of reflective tape ( $2 \mathrm{~mm}$ diameter) attached to the upper surface of the leaf approximately $1-2 \mathrm{~cm}$ from the nest. Signals detected by the laser (velocity $20 \mathrm{~mm} / \mathrm{s}$; high pass filter off; low pass filter $20 \mathrm{kHz}$ ) were recorded to a Marantz data recorder (PMD 671, D\&M Professional, Itasca, IL) at a sampling rate of $48 \mathrm{kHz}$. In conjunction with vibration recordings, all trials were videotaped using a Sony HDRXR520V Handycam (Tokyo, Japan) with the digital output from the laser vibrometer plugged into the microphone port. All trials were performed within an acoustic chamber (C-14A MR, Eckel Industries Ltd., Cambridge, MA, USA) to prevent extraneous noise. Preliminary observations indicated that caterpillars produce four unique vibratory signals which were analyzed for temporal/spectral characteristics and signal amplitude 
using RavenPro Bioacoustics Research Program 1.4 (Cornell Laboratory of Ornithology, Ithaca, NY, USA). An overall mean \pm SD of signal duration and relative amplitude for each signal type was calculated using means of signal duratıons and amplitudes from 100 different signals ( 25 from each signal type) from 5 different individuals. Signal amplitudes were calculated by measuring peak to peak values in RavenPro and converting them to volatges with a conversion factor from a calibration curve. The calibration curve was created from a laser recording of a $1 \mathrm{~V}$ peak to peak sine wave produced by a minishaker (Type 4810 , Bruel \& Kjaer, Naerum Denmark) receiving the signal from a function generator (WW5061, Tabor Electronics, Tel Hanan Isreal). Signal voltages were then converted into velocity using a conversion factor provided in the laser vibrometer manual (Polytec Inc.). Spectral values of frequency range and mean \pm SD peak frequencies were calculated from 9 signals of each signal type from 3 individuals using a 1024 hanning window in RavenPro.

Set-up for video recordings and video analysis

Nest observation trials were performed by recording vibrations and video of established nests to gain a greater understanding into the behaviour of $D$. arcuata and to test predictions for the spacing and recruitment hypotheses. A randomly selected nest containing 1-5 residents was positioned in the recording apparatus described above and left isolated for approximately 5 minutes. In total, 38 half-hour nest observation trials were examined, comprised of 9 replicates each for groups of 2 and 4 individuals, and 10 replicates each with solitary individuals and groups of 5 individuals. Nest observation trials were used to analyze multiple characteristics of $D$. arcuata behaviour including (a) 
signal/behaviour relationships, (b) signal rates across group sizes, (c) signal rates across instars and, (d) behaviour patterns.

To calculate individual signal rates and signal/behaviour relationships, signalling behaviour had to be characterized for each individual within the group. This was done by creating time sequenced files of individual vibratory signals and behaviours using JWatcher Video 1.0 (Blumstein et al., 2010). Initial observations were made to categorize routıne caterpillar activity into four behavioural states (eating, resting, walking, and laying silk) and signals into four signal types (buzz scrape, mandible scrape, anal scrape and mandible drum). Video recordings of each trial were then viewed at reduced speed and individual behaviours and vibratory signals were time marked using designated keys of a keyboard. This method provided a time sequenced list of traits that could be analysed separately for each individual in the nest. Data files from JWatcher were exported into Microsoft Excel for analysis.

\section{Signal/behaviour relationships}

Signal rates of buzz scraping, mandible scraping, anal scraping and mandible drumming were calculated for walking, resting, eating and laying silk to test the prediction that an individual that is moving, and therefore changing its spatial position in the nest, will signal while moving to communicate spatial information to nest mates (S3). For all trials, signal rates produced by each individual were calculated by measuring the number of signals during each behavioural state. Within each behavioural state, signal rates of all four signals were compared with a Kruskal-Wallis test using JMP8 statistical software. If a significant difference was found, pair-wise post-hoc testing was performed 
with a Mann-Whitney $U$ test. To test if solitary individuals do not signal while moving because they have no one to communicate information to, signals/state relationships were also calculated separately for solitary individuals.

Signal rates across group sizes

Both the spacing and recruitment hypotheses have predictions regarding relationships with signal rates and group size. S4 predicts that signal rates are lower in solitary individuals than individuals in groups, because spacing would be less important when the caterpillar is alone. In contrast, $\mathrm{R} 3$ predicts that signal rates per individual would be higher in a solitary individual than for an individual in a group because the need to recruit conspecifics to join the nest is higher when the caterpillar is alone. To test both predictions, individual signal rates (\#/min) were compared between solitary caterpillars and caterpillars in groups under undisturbed conditions. Unlike the signal/state rates described above that divided signalling into different behaviours, signal rates in this analysis were calculated using all behaviour states combined. The group signal rate was a grand mean of individual signal rates from caterpillars in groups of 2, 4 and 5. The signal rates of a solitary caterpillar and caterpillars in groups were compared with a MannWhitney U test using JMP8 statistical software. Values of signal rates of solitary individuals were also used to test the prediction that signal rates of solitary gregarious $D$. arcuata are higher than solitary non-gregarious D. bilineata caterpillars (S6 and R5). Results of the latter prediction will be presented in chapter four. 
Signal rates between undisturbed early instars and late instars

To test the prediction that signal rates of gregarious early instars are higher than non-gregarious late instars (S5), a comparison was made of average indıvidual sıgnal rates of all signals between undisturbed solitary first instar caterpillars and undisturbed solitary late instar caterpillars. Vibratory signal types differ between early and late instars and so a comparison could only be made with respect to the abundance of signalling in general without reference to the types of signals. Signal rates of late instars were calculated from videos taken for a prior study (Guedes et al., in review). Fifteen minutes (across 25 solitary individuals) of video footage of undisturbed behaviour was used to calculate the signal rate of late instar D. arcuata caterpillars. Signal rates were compared with a Mann-Whitney U test using JMP8 statıstıcal software.

\section{Behaviour patterns}

Although none of the predictions required documentation of behaviour patterns of indıviduals in the nest, it was important to characterize the general activity of caterpillars. For example, to understand any relationship between signalling and movement, we must have some idea of how often, and in what pattern, movement occurs. First, calculations were made of the mean \pm SD length of a behaviour bout (a period of one behaviour that is bound by two different behaviours) for all four behavioural states (walking, resting, eating, laying silk) for each of the four group sizes $(1,2,4,5)$. Behaviour lengths were compared across group sizes with a Kruskal-Wallis test using JMP8 statistical software. If a significant difference was found, pair-wise post-hoc testing was performed with a Mann-Whitney $U$ test. This information was used to determine if group size is related to 
the duration of an activity. For example, feeding lengths could decrease with increasing group size if there are space limitations at the feeding scar. Relationships between behaviour lengths and group sizes could have implications on the spacing hypothesis, if an increase in group numbers results in decreased activity per individual because of crowding or interference. Second, I calculated behavioural sequences of individuals across all group sizes to uncover patterns surrounding behavioural transitions. Preliminary observations indicated that caterpillars move frequently within the nest and do not remain fixed in one spot where they carry out all their activity. Instead, patterns were observed such as moving from a non-feeding location to the feeding spot and returning to a non-feeding location afterward. If caterpillars are moving from location to location often, evidence to support the prediction that a moving individual w1ll signal while moving (S3) to communicate to nest mates, is highly relevant. Behaviour sequences were determined by calculating how often each behaviour preceded or followed one another using time sequenced trial sheets. Pair-wise comparisons of the preceding and following behaviours were calculated with either Mann-Whitney U or Tukey-Kramer HSD tests using JMP8 statistical software.

\section{Nest manipulation and analysis}

Joining trials were used to examine how a solitary individual reacts as a conspecific approaches its personal space. Trials were conducted immediately following the nest observation trials (see above) while the leaf was still positioned in the recording apparatus. Joining was simulated by placing a single larva on the leaf at a distance of 3 -

$5 \mathrm{~cm}$ from the nest. The intruder was an established caterpillar selected from another birch 
sprig and placed in isolation for 5 minutes before the trial began. In all 9 trials placement of the intruder on the leaf did not cause the resident to signal immediately, therefore, I am confident that signalling as the intruder approached was in response to the caterpillar and not my disturbance. Recordings were made for 20 minutes after the introduction of the conspecific. Nine trials with solitary residents were performed and 6 were used for analysis. Time sequenced files of individual vibratory signals and behaviours of the resident and intruder were created using the same method as described for nest observation trials. The joining trials were used to test the prediction that signal rates of the resident increase as a conspecific approaches its personal space (S2). To test this prediction I calculated the signal rates of both the resident and intruder as the intruder approached the nest. Signal rates (\#/mın) were calculated for each $1 \mathrm{~mm}$ interval from $11 \mathrm{~mm}$ to the point of contact. Prelıminary observations indicated that signalling of the resident began at approximately $1 \mathrm{~cm}$ which gave rationale for beginning measurements at $11 \mathrm{~mm}$. Regression analysis was performed on signal distance and signal rate to determine if signalling is related to how close the caterpillars are to each other. Overall mean $\pm \mathrm{SD}$ signal rates were also calculated for both the resident and intruder during the time the intruder was within $11 \mathrm{~cm}$ of the resident. This was used to determine if the resident signals more than the intruder, because it is defending its personal space. In the course of analysis, further measurements of the following were taken of (i) distance between intruder and resident at the first signal of the resident, (ii) type of first signal of the resident, and (iii) behaviour of the resident while signalling (walking, resting, eating or laying silk). Information such as signal distance is important for understanding if 
residents are signalling to a conspecific to advertise their location in the nest or to recruit the individual to the nest.

\subsection{Results}

Signal analysis

Previous studies in the Yack lab identified four signals associated with different body movements: buzz scraping, mandible scraping, mandible drumming, and anal scraping. I have further characterized the temporal and spectral components of these signals to identify differences in signals that could be meaningful to the receiver. Signal characteristics will be described below with respect to the behavioural movements associated with the signal and a general statement about the temporal and spectral properties of the signal. Values are provided in Table 3.2.

Buzz scrape. A buzz scrape is produced when the caterpillar tremulates its body while anal scraping (Fig 3.4a). Tremulation is a fast oscillation of the body that does not require any body parts striking the leaf surface to produce a vibration. An anal scrape is produced when the caterpillar contracts its anal segments anteriorly and scrapes a chintinous modified anal seta across the leaf surface (Fig. 3.4b inset). Mean \pm SD duration and amplitude of a buzz scrape is $431 \pm 11 \mathrm{~ms}$ and $0.019 \pm 0.009 \mathrm{~mm} / \mathrm{s}$, respectively. Buzz scrapes are broadband with a primary peak frequency at $250.0 \pm 46.5 \mathrm{~Hz}$.

Mandible scrape. Caterpillars produce a mandible scrape signal by scraping their mandibles laterally against the leaf surface (Fig 3.4a). Mandible scrapes have a mean \pm SD duration and amplitude of $53 \pm 13 \mathrm{~ms}$ and $0.029 \pm 0.01 \mathrm{~mm} / \mathrm{s}$, respectively. Mandible scrapes are broadband with a primary peak frequency at $1359.4 \pm 137.3 \mathrm{~Hz}$. 
Mandible drum. A mandible drum is produced when the caterpillar vertically strikes the leaf surface with the mandibles (Fig 3.4a). The mean \pm SD duration and amplitude of mandible drums is $26 \pm 70 \mathrm{~ms}$ and $0.022 \pm 0.012 \mathrm{~mm} / \mathrm{s}$, respectively. Mandible drums are broadband with a primary peak frequency at $416.69 \pm 15.6 \mathrm{~Hz}$.

Anal scrape. Anal scraping occurs during a buzz scrape but also occurs independently. As described above, anal scraping occurs when the caterpillar contracts its anal segments and scrapes a modified anal seta across the leaf surface (Fig 3.4b). Mean \pm SD signal duration and amplitude of anal scrapes is $262 \pm 38 \mathrm{~ms}$ and $0.019 \pm 0.009 \mathrm{~mm} / \mathrm{s}$, respectively. Anal scrapes are broadband with a primary peak frequency at $1546.8 \pm 69.8 \mathrm{~Hz}$.

Each signal produced by early instar $D$. arcuata caterpillars has a unique combination of temporal, spectral and amplitude properties that may be used to define it from the other signals. 
Table 3.2 Temporal/spectral characteristics and amplitude of four vibratory signals produced by early instar $D$. arcuata caterpillars. $\mathrm{n}=$ number of signals analyzed, $\mathrm{N}=$ number of individuals that signals were taken from, $\mathrm{P}=$ primary peak frequency, $\mathrm{S}=$ secondary peak frequency.

Temporal

Signal Duration \pm SD (ms)

Buzz Scrape

$431 \pm 11$

$262 \pm 38$

$25 \quad 5$

Anal Scrape

Mandible Scrape

$53 \pm 13$

$26 \pm 70$

Mandible Drum

$25 \quad 5$

$25 \quad 5$

(P) $1359.4 \pm 137.3$

(S) $2276.8 \pm 129.4$

(P) $416.69 \pm 15.6$

(P) $250.0 \pm 46.5$

(S) $453.1 \pm 40.6$

(S) $474.2 \pm 41.6$

(P) $1546.8 \pm 69.8$

93

$0.019 \pm 0.009$

Relative Amplitude

Velocity \pm SD (mm/s)

n N


a
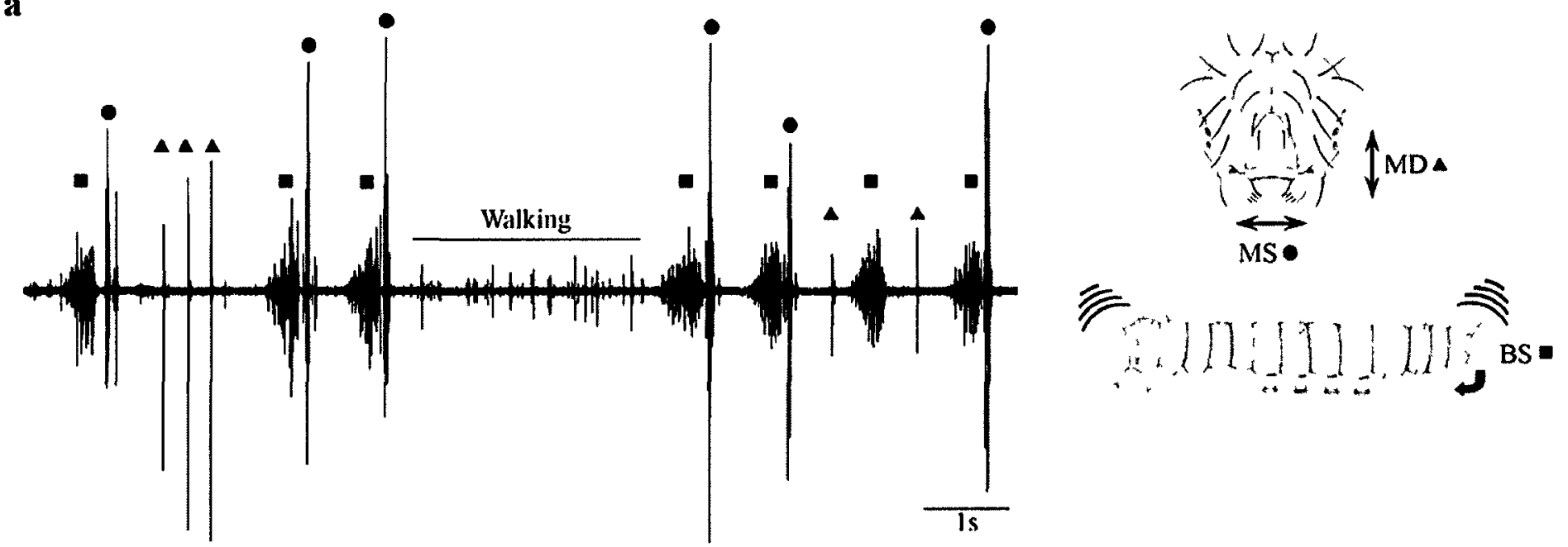

b
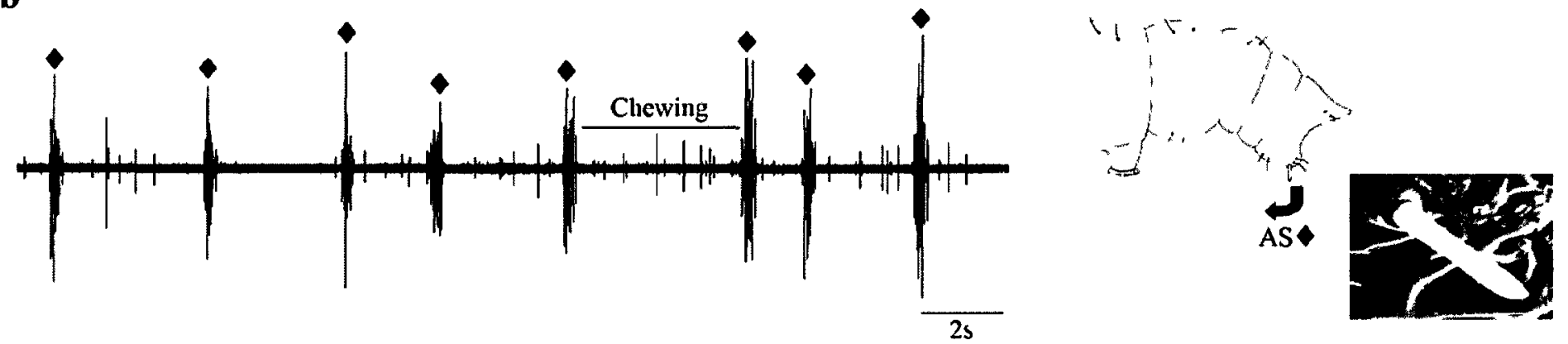

Figure 3.4 The vibratory repertoire of early instar Drepana arcuata. (a) Waveform of three vibratory signals produced while walkıng with schematics of movements associated with signalling. (b) Waveform of signals produced while feeding with schematic of movement associated with signalling and an inset of the anal oar (Scale bar, 10 $\mu \mathrm{m}$ ). Signals and corresponding symbols are: MS- mandible scrape, circle. MD- mandible drum, triangle. BS- buzz scrape, square. AS- anal scrape, diamond. Drawing and photo credit: Jayne Yack. 


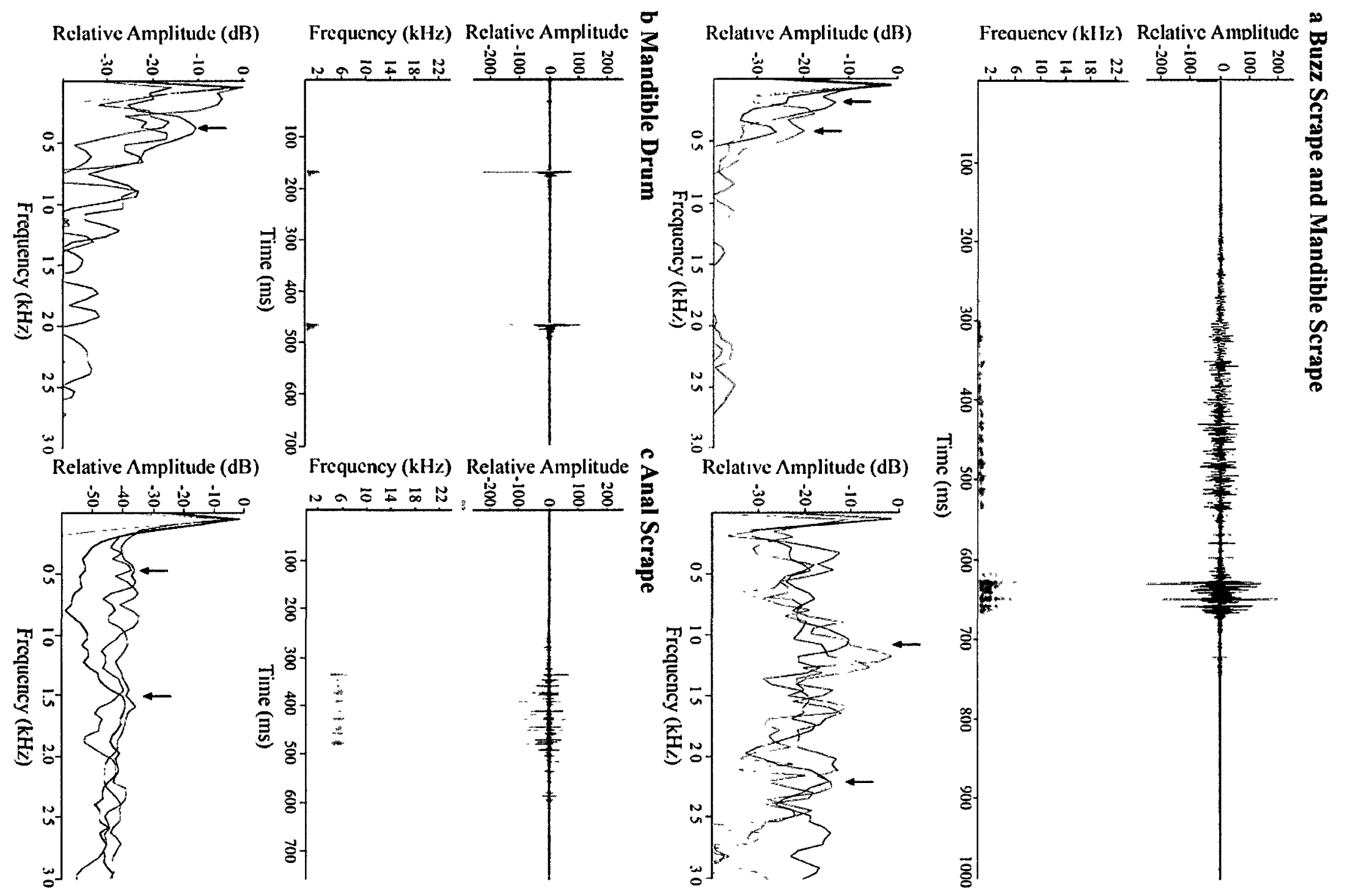


Figure 3.5 Temporal and spectral properties of the four signals produced by early instar D. arcuata caterpillars. (a) Buzz scrape (left) and mandible scrape (right) produced in sequence with separate power spectra below. (b) Two separate mandible drums with power spectrum below. (c) An anal scrape with power spectrum below. The power spectrum is displayed for the top $60 \mathrm{~dB}$ because anal scrapes are much lower in amplitude than the background noise. For all power spectra the background noise is represented in black. 


\section{Signal/behaviour relationships}

Signal rates were calculated for each of the vibratory signals (buzz scrape, mandible scrape, anal scrape, mandible drum) produced by $D$. arcuata caterpillars during each of the four behavioural states (resting, walking, eating, laying silk) while in their nest. Relationships between signals and behaviours were used to test the prediction that moving caterpillars signal to inform conspecifics of changing locations (S3). Each signal/state relationship was analyzed for solitary individuals and also from a grand mean of all group sizes, not only test to the prediction above, but also to test if solitary individuals will not signal while moving because they have no one with which to communicate spatial information. Signal rates are provided in Table 3.3 and a description of signal comparisons is provided for each signal below.

Buzz scrape. Buzz scraping is clearly associated with walking, regardless if an individual is on its own, or in a group. There is a significant difference in buzz scraping rates among the four behavioural states, for both solitary individuals and individuals in groups (Kruskal-Wallis $\chi^{2}=55.48, \mathrm{P}<0.0001$ and $\chi^{2}=280.27, \mathrm{P}<0.0001$, respectively) (Table 3.3). Post-hoc testing showed that the rate of buzz scraping during walking is significantly higher than during resting, eating and laying silk in solitary individuals (Mann-Whitney $\mathrm{P}<0.001$ for all pairs) (Fig 3.6a) and individuals in groups (MannWhitney $\mathrm{P}<0.0001$ for all pairs) (Fig 3.6b).

Mandible scrape. Mandible scraping is associated with walking in individuals in groups. The rate of mandible scraping is not significantly higher during any behavioural state in solitary individuals but is significantly different among states in groups (KruskalWallis $\chi^{2}=5.48, \mathrm{P}=0.14$ and $\chi^{2}=66.55, \mathrm{P}<0.0001$, respectively) (Table 3.3). Post-hoc 
testing showed that for individuals in groups, the rate of mandible scraping during walking is significantly higher than during resting, eating and laying silk (Mann-Whitney $\mathrm{P}=0.0004, \mathrm{P}<0.0001$ and $\mathrm{P}<0.0001$, respectively)(Fig 3.6b).

Anal scrape. Anal scraping is clearly associated with eating regardless if and individual is on its own, or within a group. The rate of anal scraping is significantly different among the four behavioural states, for both solitary individuals and individuals in groups (Kruskal-Wallis $\chi^{2}=43.64, \mathrm{P}<0.0001$ and $\chi^{2}=408.81, \mathrm{P}<0.0001$, respectively) (Table 3.3). Post-hoc testing showed that in solitary individuals and individuals in groups, anal scraping signal rates are significantly higher during eating than during resting, walking and laying silk (Mann-Whitney $\mathrm{P}<0.001$ for all pairs) (Fig 3.6).

Mandible drum. There is no clear association between mandible drumming and a specific behaviour. The rate of mandible drumming is significantly different among states, for both solitary individuals and individuals in groups (Kruskal-Wallis $\chi^{2}=9.3882$, $\mathrm{P}=0.0246$ and, $\chi^{2}=47.2246, \mathrm{P}<0.0001$, respectively) (Table 3.3). However, post-hoc testing showed that for solitary individuals, mandible drumming was only significantly higher during walking than while laying silk (Mann-Whitney $\chi^{2}=6.5587, \mathrm{P}=0.0104$ ) (Fig 3.6a). In groups, mandible drumming signal rates are significantly higher during walking than while eating and laying silk (Mann-Whitney $\mathrm{P}<0.001$ for both pairs) but not higher during walking than resting (Mann-Whitney $\left.\chi^{2}=0.8223, \mathrm{P}=0.3645\right)($ Fig 3.6b). Therefore, no association can be made for mandible drumming and a particular behaviour. 
Table 3.3 Signal rates \pm SD (\#/min) of signals produced per behavioural state by individual early instar $D$. arcuata caterpillars as solitary individuals $(\mathrm{S})$ or in groups $(\mathrm{G})$. Values in bold represent significant signal/state associations. Buzz scraping and mandible scraping were significantly higher during walking than during other behavioural states. Anal scraping was significantly higher during eating than during other behavioural states.

\begin{tabular}{ccccccccc} 
& \multicolumn{2}{c}{ Buzz Scrape } & \multicolumn{2}{c}{ Mandible Scrape } & \multicolumn{2}{c}{ Anal Scrape } & \multicolumn{2}{c}{ Mandible Drum } \\
\cline { 2 - 8 } & $\mathrm{S}$ & $\mathrm{G}$ & $\mathrm{S}$ & $\mathrm{G}$ & $\mathrm{S}$ & $\mathrm{G}$ & $\mathrm{S}$ & $\mathrm{G}$ \\
\hline Resting & $1.68 \pm 3.79$ & $1.76 \pm 3.11$ & $0.09 \pm 0.38$ & $0.33 \pm 1.09$ & $\mathbf{0 . 0 8} \pm 0.29$ & $\mathbf{0 . 0 2} \pm 0.14$ & $0.77 \pm 2.33$ & $0.62 \pm 2.4$ \\
Walking & $\mathbf{6 . 5} \pm \mathbf{3 . 8 3}$ & $\mathbf{4 . 9 3} \pm \mathbf{4 . 8}$ & $\mathbf{0 . 2 9} \pm 0.97$ & $\mathbf{1 . 0 2} \pm \mathbf{2 . 4 2}$ & $\mathbf{0 . 3 6} \pm 0.87$ & $\mathbf{0 . 1 1} \pm 0.57$ & $1 \pm 1.99$ & $1.32 \pm 4.01$ \\
Eating & 0 & $0.06 \pm 0.32$ & 0 & $0.01 \pm 0.03$ & $\mathbf{1 1 . 4 8} \pm \mathbf{7 . 5 5}$ & $\mathbf{5 . 8 5} \pm \mathbf{5 . 9 4}$ & 0 & $0.03 \pm 0.24$ \\
Laying Silk & $0.29 \pm 1.39$ & $0.44 \pm 2.44$ & 0 & $0.01 \pm 0.05$ & $2.66 \pm 4.08$ & $1.41 \pm 2.93$ & 0 & 0
\end{tabular}


a Solitary individual
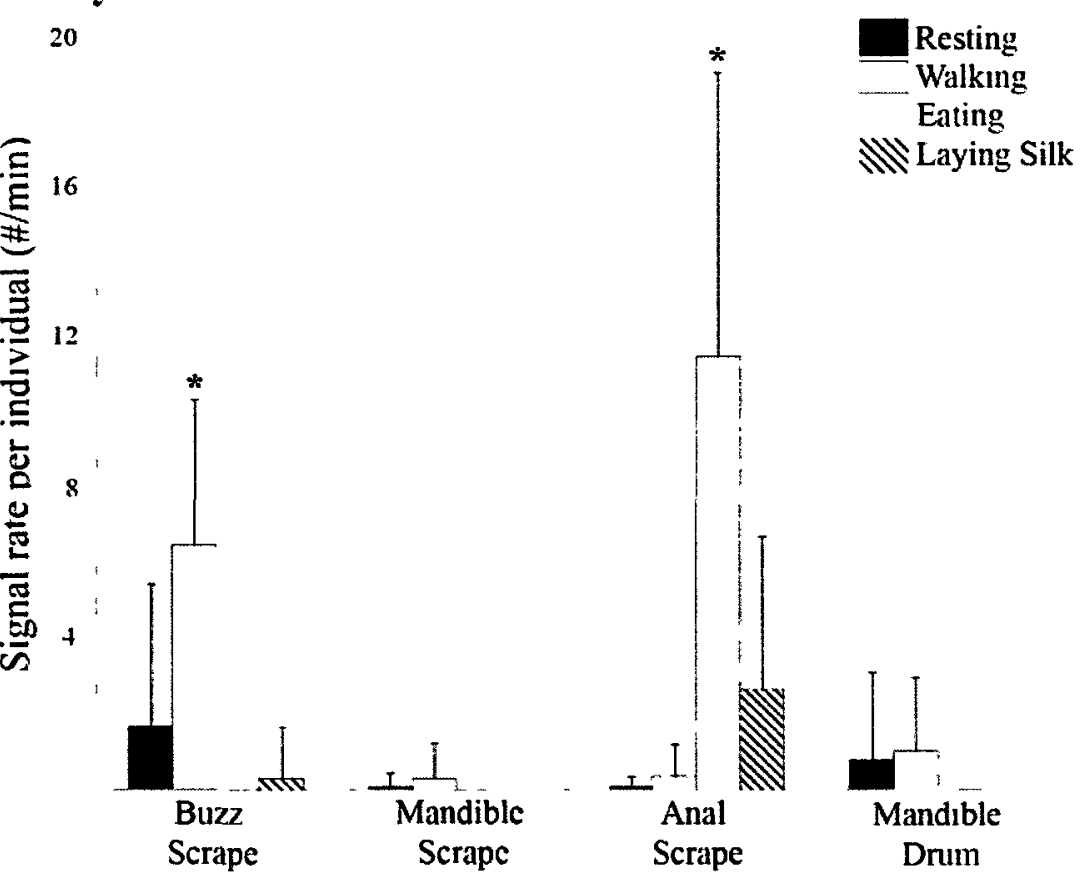

b Individual in a group
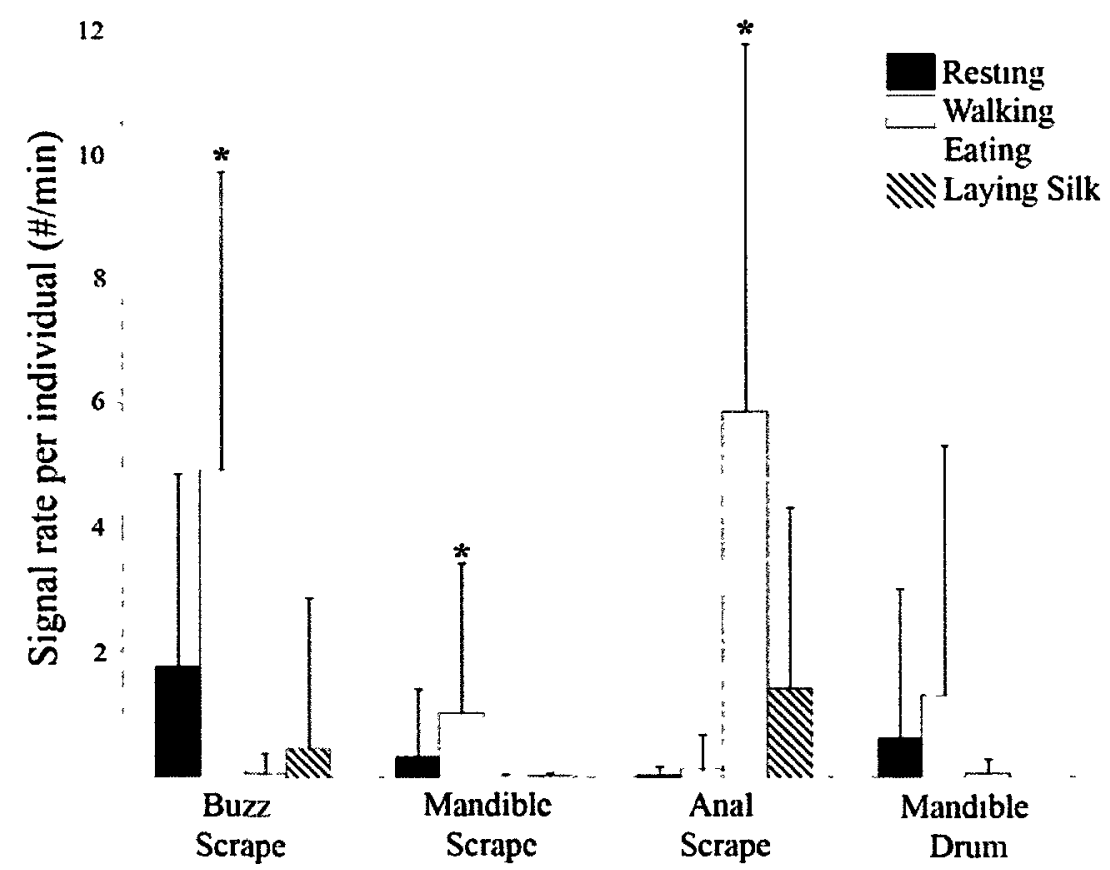

Figure 3.6 Signal and behaviour relationships for solitary D. arcuata (a) and individuals in groups (b). Asterisks indicate significant signal/behaviour relationships. Buzz scraping is significantly associated with walking and anal scraping is significantly associated with feeding regardless of the group size. 


\section{Signal rates across group sizes}

Individual signal rates were calculated for each of the vibratory signals (buzz scrape, mandible scrape, anal scrape, mandible drum) produced by solitary early instar $D$. arcuata caterpillars and individuals in groups (Table 3.4). Comparing signal rates across group sizes tests the spacing prediction that signal rates are lower in solitary individuals than individuals in groups (S4) and the recruitment prediction that signal rates are higher in solitary individuals than individuals in groups (R3). Signal rates were calculated for each group size, but comparison between signalling of solitary individuals and groups used averages from groups of 2, 4 and 5 individuals to represent "group" signal rates.

There is no significant difference of buzz scrape, mandible scrape and mandible drum signal rates between solitary individuals and individuals in groups (Mann-Whitney U, $\chi^{2}=0.0834, \mathrm{P}=0.7728 ;$ Mann-Whitney $\mathrm{U}, \chi^{2}=2.3428, \mathrm{P}=0.1259$; Mann-Whitney $\mathrm{U}$, $\chi^{2}=0.0053, \mathrm{P}=0.9417$, respectively) (Fig 3.7). These results do not support the predictions that signalling will be different in solitary individuals because of less need for spacing or a higher need for recruitment. There is a significant difference between anal scrape signal rates of solitary individuals and individuals in groups (Mann-Whitney $\mathrm{U}, \chi^{2}=7.1707$, $\mathrm{P}=0.0074$ ). Post-hoc testing showed that the rate of anal scraping is higher for solitary individuals than for individuals in groups of 2,4 and 5 (Mann-Whitney $\mathrm{P}=0.0683$, $\mathrm{P}=0.0188$ and $\mathrm{P}=0.0049$, respectively) (Fig 3.7) which supports the recruitment prediction that signal rates are higher in individuals than groups (R3). 
Table 3.4 Individual signal rates of solitary early instar $D$. arcuata caterpillars and individuals in groups. There is a significant difference between anal scrape rates in solitary individuals and individuals in groups. $\mathrm{N}=$ number of individuals that rates were measured from.

Signal Rate \pm SD (\#/min)

\begin{tabular}{ccc}
\cline { 2 - 3 } & Solitary Individuals & Individuals in Groups \\
& $\mathrm{N}=10$ & $\mathrm{~N}=99$ \\
\hline Buzz Scrape & $1.42 \pm 1.42$ & $1.12 \pm 1.07$ \\
Mandible Scrape & $0.09 \pm 1.16$ & $0.19 \pm 0.33$ \\
Anal Scrape & $\mathbf{3 . 5 1} \pm \mathbf{2 . 8 6}$ & $\mathbf{1 . 2 6} \pm \mathbf{1 . 6}$ \\
Mandible Drum & $0.56 \pm 0.93$ & $\mathbf{0 . 4 9} \pm 1.09$
\end{tabular}




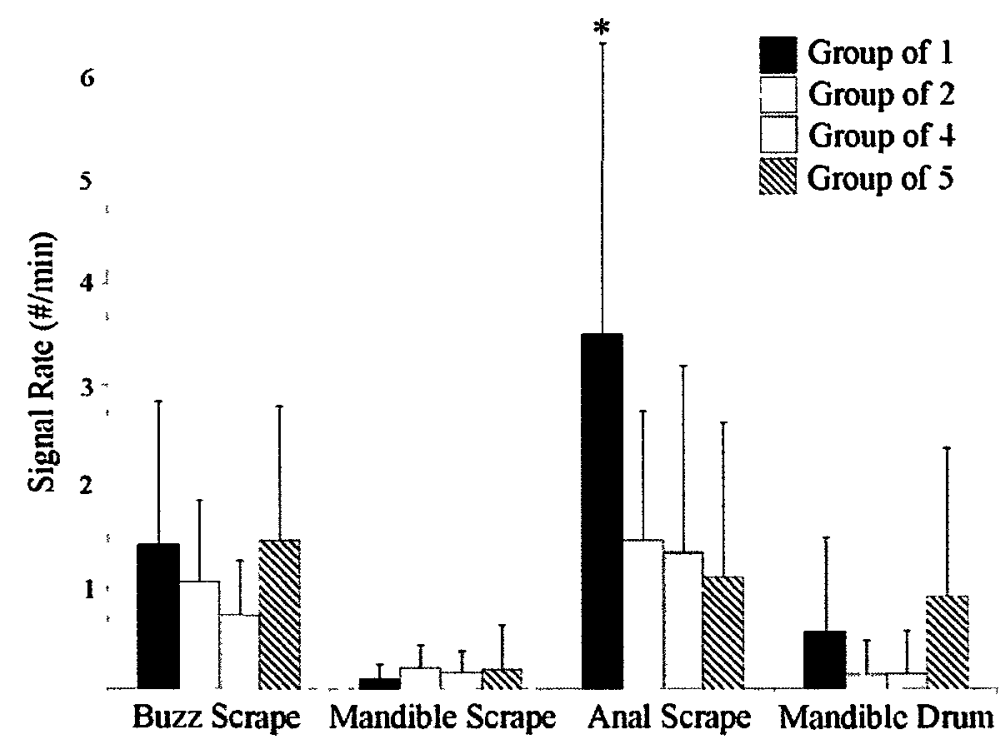

Figure 3.7 Group size comparison of signal rates of $D$. arcuata early instar caterpillars. Buzz scrape, mandible scrape, and mandible drum signal rates did not differ between solitary individuals and individuals in groups. Solitary individuals have higher anal scraping rates than individuals in groups. 
Signal rates between undisturbed early instars and late instars

To test the predictions that signal rates of gregarious early instars are higher than non-gregarious late instars to function for either spacing (S5) or recruitment (R4), the average signal rate of all signals for undisturbed solitary first instar caterpillars and undisturbed solitary late instar caterpillars were calculated. The mean \pm SD signalling rate of solitary early instar caterpillars was $5.6 \pm 3.7 \# /$ min whereas solitary late instar caterpillars have a mean signalling rate of $0 \# / \mathrm{min}$. Solitary early instars have a significantly higher signalling rate than late instars (paired $t$-test, one-tailed $\mathrm{P}=0.0005$ ).

\section{Behaviour patterns}

Early instar $D$. arcuata caterpillars exhibit four behavioural states during their daily activity: resting, walkıng, eating and laying silk. Other behaviours such as excretion and moulting do occur but were not examined because of their instantaneous and intermittent nature. Behaviour lengths of bouts of all four behavioural states (walking, restıng, eating, laying silk) for each of the four group sizes $(1,2,4,5)$ were calculated to determine if group size has an effect on the duration of an activity per individual. Relationships between behaviour lengths and group sizes could have implications for the spacing hypothesis, if feeding lengths decrease and group size increases. To understand the relationship between signalling and movement, we must have some idea of the pattern of movement of individuals. Behaviour sequences were determined by calculating how often each behaviour preceded or followed one another to determine if there were patterns associated with behaviours such as walking. Although these results do not 
formally test predictions, information from this analysis will be used to interpret other results such as associations between signalling and behaviours.

Behaviour lengths

There was no relationship between group size and individual caterpillars resting or silk laying periods (Kruskal-Wallis $\chi^{2}=6.03, \mathrm{P}=0.11$; Kruskal-Wallis $\chi^{2}=6.81, \mathrm{P}=0.078$, respectively) (Table 3.5). There was a significant difference between the length of eatıng and walking periods across group sizes (Kruskal-Wallis $\chi^{2}=12.2935, \mathrm{P}=0.0062$; KruskalWallis $\chi^{2}=10.81, \mathrm{P}=0.013$, respectively) (Table 3.5 ). In a post-hoc pairwise comparison of eating lengths, there was a significant difference between solitary individuals and individuals in groups of 4 (Mann-Whitney $\left.U \chi^{2}=4.4108, P=0.0357\right)$. However, eating lengths of solitary individuals and individuals in groups of 5 were not statistically different (Mann-Whitney $\left.U \chi^{2}=1.4441, \mathrm{P}=0.2295\right)$, indıcatıng that there may be a sampling issue rather than a biological trend. Simlarly, post-hoc pair-wise comparison of walking lengths showed a significant difference between walking lengths in solitary individuals and groups of 4 (Mann-Whitney $U \chi^{2}=8.65, P=0.003$ ) but this difference was not upheld with solitary individuals and groups of 5 (Mann-Whitney $U \chi^{2}=1,33, P=0.25$ ) indicating that there may once again be a sampling issue rather than a biological trend. There is no relationship between group size and individual caterpillar lengths of walking, resting, eating and laying silk during routine activity. 
Table 3.5 Average lengths of resting, walking, eating and silk laying periods of early instar D. arcuata caterpillars in groups of $1,2,4$ and 5 individuals. There is no significant difference between behaviour lengths across group sizes. $n=$ number of behaviour periods analyzed, $\mathrm{N}=$ number of individuals that behaviour lengths were measured from.

\section{Behaviour Lengths \pm SD (s)}

\begin{tabular}{|c|c|c|c|c|}
\hline Group Size & Resting & Walking & Eating & Laying Silk \\
\hline 1 & $\begin{array}{c}391.30 \pm 422.76 \\
(n=23, N=10)\end{array}$ & $\begin{array}{c}111.04 \pm 227.43 \\
(\mathrm{n}=39, \mathrm{~N}=10)\end{array}$ & $\begin{array}{c}401.44 \pm 294.21 \\
(n=11, N=9)\end{array}$ & $\begin{array}{l}72.35 \pm 42.38 \\
(\mathrm{n}=25, \mathrm{~N}=5)\end{array}$ \\
\hline 2 & $\begin{array}{c}343.29 \pm 375.83 \\
(n=61, N=18)\end{array}$ & $\begin{array}{c}64.45 \pm 78.83 \\
(n=64, N=18)\end{array}$ & $\begin{array}{c}374.58 \pm 225.69 \\
(n=20, N=17)\end{array}$ & $\begin{array}{c}32.89 \pm 24.05 \\
(\mathrm{n}=5, \mathrm{~N}=2)\end{array}$ \\
\hline 4 & $\begin{array}{c}516.22 \pm 527.70 \\
(\mathrm{n}=88, \mathrm{~N}=35)\end{array}$ & $\begin{array}{c}46.24 \pm 48.69 \\
(n=125, N=32)\end{array}$ & $\begin{array}{c}237.13 \pm 285.55 \\
(\mathrm{n}=52, \mathrm{~N}=32)\end{array}$ & $\begin{array}{l}55.87 \pm 40.24 \\
(n=30, N=7)\end{array}$ \\
\hline 5 & $\begin{array}{l}391.30 \pm 422.76 \\
(n=106, N=45)\end{array}$ & $\begin{array}{c}77.50 \pm 117.37 \\
(n=134, N=42)\end{array}$ & $\begin{array}{c}280.09 \pm 187.90 \\
(n=56, N=37)\end{array}$ & $\begin{array}{l}71.55 \pm 71.04 \\
(n=14, N=4)\end{array}$ \\
\hline
\end{tabular}


Behaviour sequences

Resting periods are preceded by walking $88.68 \%$ of the time, by eating $10.85 \%$ of the time and by laying silk only $0.47 \%$ of the time. Resting perıds are followed by walking, eating and laying sılk $89.9 \%, 9.13 \%$ and $0.96 \%$ of the time, respectively. There is a significant pattern of resting bound by walking (Tukey-Kramer HSD, $\mathrm{P}<0.0001$ for all pairs) (Fig 3.8a).

Eating periods are preceded by walking, resting and laying silk $75.68 \%, 19.82 \%$ and $4.5 \%$ of the time, respectively. Eating periods are followed by walking, resting and laying silk $80.34 \%, 17.09 \%$ and $2.56 \%$ of the time, respectively. There is a significant pattern of eating bound by walking (Tukey-Kramer HSD, $\mathrm{P}<0.0001$ for all pairs) (Fig $3.8 \mathrm{~b})$.

Silk laying perıods are preceded by walking $80.56 \%$ of the time and eating $19.44 \%$ of the time. Silk laying periods are followed by walking, eating and resting $71.43 \%, 24.29 \%$ and $4.29 \%$ of the time, respectively. There is a significant pattern of walking occurring before silk laying (Mann-Whitney, $\mathrm{P}=0.0408$ for walking and eating and $\mathrm{P}=0.0132$ for walking and resting) and non-significant trend of walking occurring after silk laying (Tukey-Kramer HSD, $\mathrm{P}=0.1465$ for walking and eating and $\mathrm{P}=0.0202$ for walking and resting) (F1g 3.8c).

Walking periods are preceded by resting, eating, and laying silk $52.89 \%, 27.82 \%$ and $19.28 \%$ of the time, respectively. Walking periods are followed by resting, eating and laying silk $53.01 \%, 26.78 \%$ and $20.22 \%$ of the tıme, respectively. There is a significant pattern of resting occurring before walking (Tukey-Kramer HSD, $\mathrm{P}=0.0224$ for resting 
$\mathbf{a}$
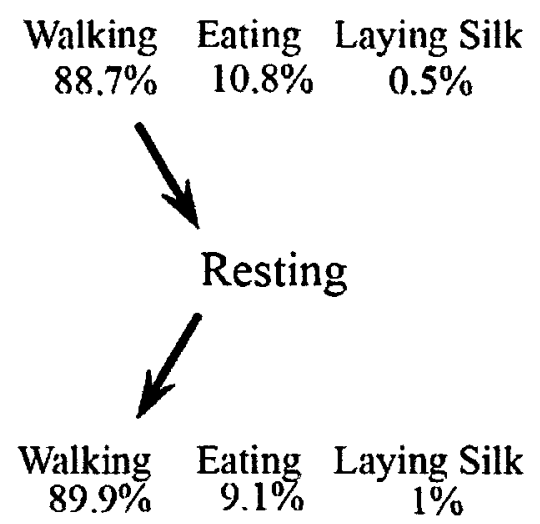

c
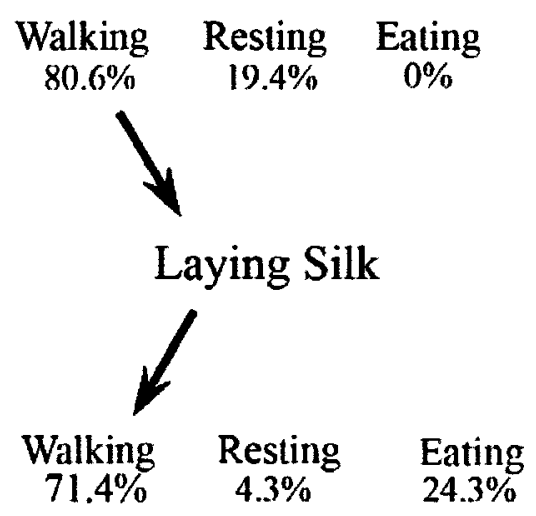

b

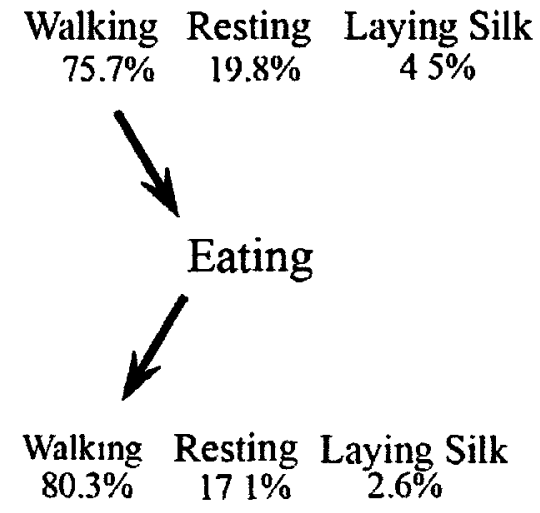

d

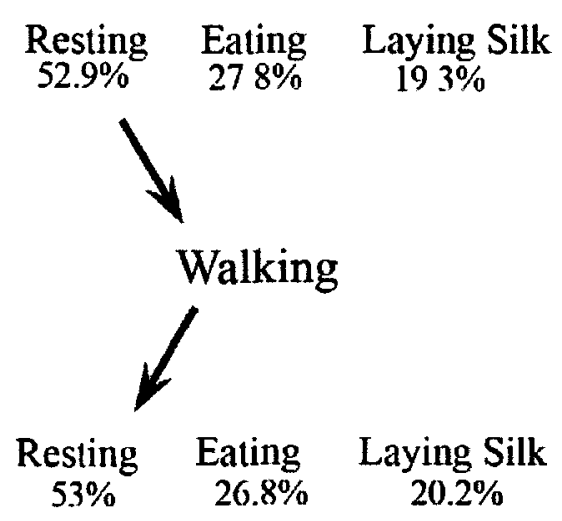

Figure 3.8 Behavioural sequences of $D$. arcuata (a) resting (b) eating (c) silk laying and (d) walking during routine activity. Values are the percentage of occurrences that the focal behaviour was preceded or followed by the indicated behaviour. The predominant sequence is indicated by bold arrows. 
and laying silk and $\mathrm{P}=0.0336$ for resting and eating) and a significant pattern of resting following walking (Tukey-Kramer HSD, $\mathrm{P}=0.0320$ for resting and laying silk and $P=0.0315$ for resting and eating) (Fig 3.8d).

Behavioural sequences confirm patterns noted during observational trials and reveal that $D$. arcuata caterpillars move from resting locations to eat or lay silk and then back to a resting spot. Signal relationships found with walking may be important in group communication to convey spatial information to conspecifics as individuals move around the nest.

\section{Nest manipulation analysis}

Signal rates as intruder approaches resident

Regression analysis was used to calculate the relationship of the distance between the resident and intruder and both resident and intruder signal rates. This analysis tested the spacing prediction that individual signal rates of a resident increase as a conspecific approaches its personal space (S2). Buzz scraping and mandible scraping of the resident increased as the intruder approached the nest $\left(\mathrm{R}^{2}=0.28\right.$ and $\mathrm{R}^{2}=0.43$, respectively) (Fig. 3.9a). Mandible drumming rates did not change as the intruder approached the nest $\left(\mathrm{R}^{2}=0.01\right)$. Residents did not anal scrape in any of the trials. Buzz scraping and mandible scraping of the intruder increased as the intruder approached the nest $\left(\mathrm{R}^{2}=0.4\right.$ and $\mathrm{R}^{2}=0.25$, respectively) (Fig. 3.9b). Intruders did not mandible drum or anal scrape in any of the trials. The overall mean $\pm \mathrm{SD}$ signal rates of the resident and intruder, while the resident was with $11 \mathrm{~mm}$ of the intruder, were $0.48 \pm 0.45 \# / \mathrm{sec}$ and $0.12 \pm 0.24 \# / \mathrm{sec}$, 


\section{a Resident Signal Escalation}

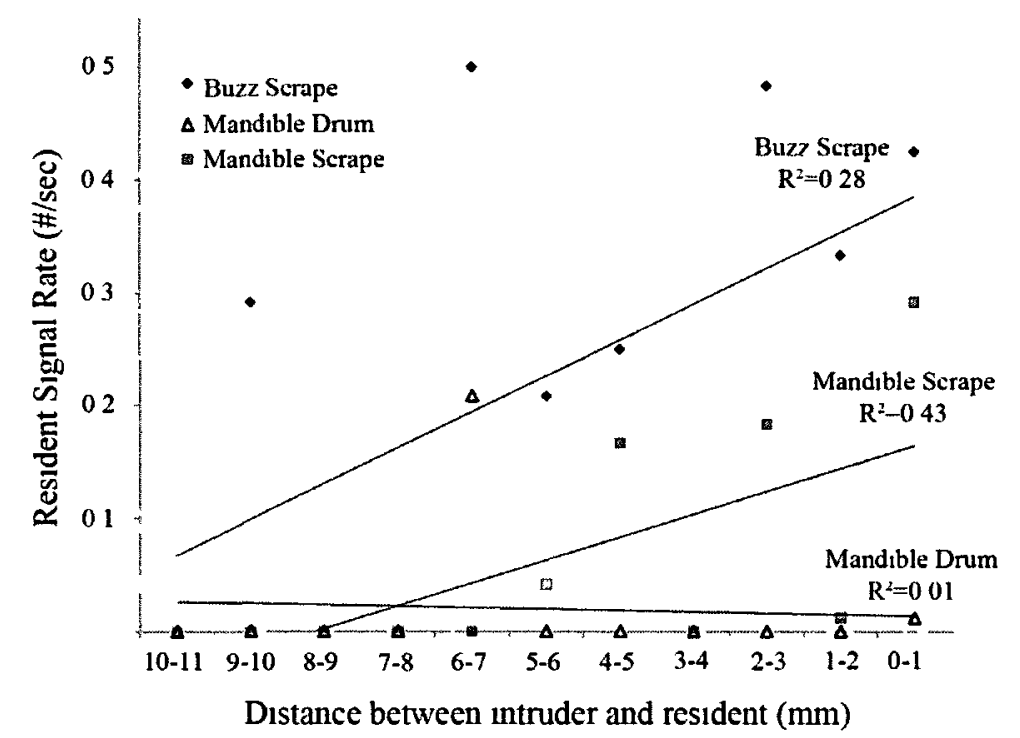

\section{b Intruder Signal Escalation}

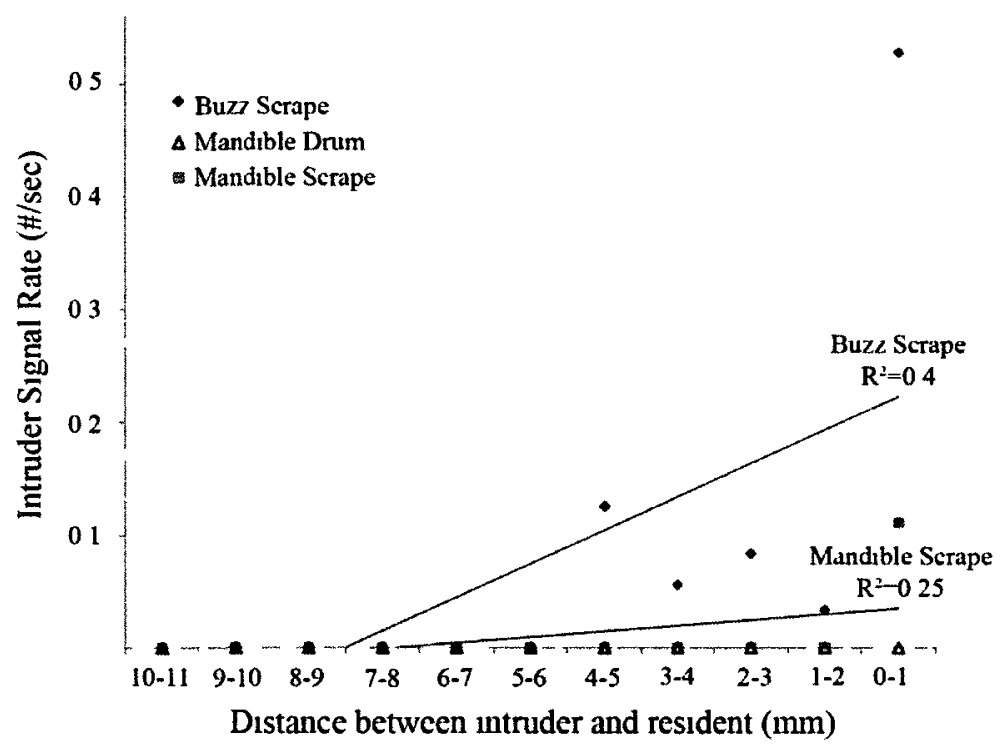

Figure 3.9 Signal escalation as an intruder approaches the nest with a solitary resident. (a) The resident's signal rates of buzz scraping and mandible scraping increased as the distance between the intruder and resident decreased. (b) The intruder's signal rates of buzz scraping and mandible scraping increased as the distance between the intruder and resident decreased. 
respectively. There was a non-significant trend of the resident caterpillar signalling more than the intruder during that time period (Mann-Whitney $\mathrm{U} \chi^{2}=3.3358, \mathrm{P}=0.0678$ ).

\section{Resident's detection}

To quantify the reaction of residents to the introduction of a conspecific to the leaf, data was collected of the initial signal distance and type, as well as the state of the signalling resident in the nest. This analysis does not test formal predictions but can be used to determine if vibratory signals are used for long distance communication for recruitment purposes or short distance signals for spacing. Residents signalled to the introduction of a conspecific at an average distance of $6.56 \pm 4.27 \mathrm{~mm}$. The first signal produced by the resident was a buzz scrape in $86 \%$ of trials and a drum/buzz scrape sequence in $14 \%$ of trials. In all trials the resident was resting when it signalled first to the intruder. During the encounter the intruder also buzz scraped intermittently as it approached the resident (signal rate described above), but always after the resident had already signalled.

\section{Summary of results}

In summary, vibratory signals of early instar $D$. arcuata caterpillars were used within a variety of spacing contexts. Buzz scraping and mandible scraping were associated with walking, possibly to communicate changing spatial information to conspecifics. Caterpillars walk to and from resting locations to feed at the feeding scar and therefore, signals could be used to avoid encountering other individuals during the transition. Anal scraping was associated with feeding in early instars, but not as late 
instars. In early instars, anal scraping may be used to avoid competition once the caterpillar gets to the feeding scar. Also, signal rates of buzz scraping and mandible scraping increased as an intruder approached a resident, with the resident signalling more than the intruder to mediate personal space between the individuals. Lastly, my results support the hypothesis that signalling is used for conspecific communication, either to space or recruit, with higher signal rates in gregarious early instar caterpillars than nongregarious late instar caterpillars. A summary of the predictions and results are provided in Table 3.6 below. 
Table 3.6 Evidence for two hypotheses and predictions for the function of vibratory signalling in $D$. arcuata caterpillars. Results from previous studies are in italics. $\mathrm{BS}=$ buzz scrape, $\mathrm{MS}=$ mandible scrape, $\mathrm{MD}=$ mandible drum, $\mathrm{AS}=$ anal scrape.

\begin{tabular}{|c|c|c|}
\hline \multicolumn{3}{|c|}{ Signals function to space individuals within the group } \\
\hline Prediction & Result & Supported? \\
\hline $\begin{array}{l}\text { S1 Larvae maintain regular } \\
\text { inter-individual distance in } \\
\text { the nest }\end{array}$ & $\begin{array}{l}\text { Caterpillars prefer a inter- } \\
\text { individual distance of } 05- \\
25 \mathrm{~mm} \text { (Lynes, 2006) }\end{array}$ & $\mathrm{Y}$ \\
\hline $\begin{array}{l}\text { S2 Signal rates increase as } \\
\text { a conspecific approaches an } \\
\text { indlvidual's personal space }\end{array}$ & $\begin{array}{l}\text { Signal rates of } B S, M S \text { and } M D \\
\text { increase as an intruder } \\
\text { approaches and enters the nest } \\
\text { (Matheson, Timbers, 2005) }\end{array}$ & $\bar{Y}$ \\
\hline $\begin{array}{l}\text { S3 An individual that is } \\
\text { moving (changing position } \\
\text { in the nest) should signal } \\
\text { while moving to indicate its } \\
\text { position }\end{array}$ & $\begin{array}{l}\text { BS and MS signals are } \\
\text { signıficantly associated with } \\
\text { walkıng }\end{array}$ & $\bar{Y}$ \\
\hline $\begin{array}{l}\text { S4 Signal rates are lower in } \\
\text { solitary individuals than } \\
\text { individuals in groups }\end{array}$ & $\begin{array}{l}\text { No significant difference } \\
\text { between BS, MS and MS } \\
\text { signal rates between solitary } \\
\text { individuals and groups. } \\
\text { Significantly more AS in } \\
\text { solitary individuals. }\end{array}$ & $\begin{array}{l}\text { Y/N (not } \\
\text { for all } \\
\text { signals) }\end{array}$ \\
\hline $\begin{array}{l}\text { S5. Signal rates of } \\
\text { undisturbed gregarıous early } \\
\text { instar caterpillars are higher } \\
\text { than undisturbed non- } \\
\text { gregarious late instar } \\
\text { caterpillars }\end{array}$ & $\begin{array}{l}\text { Overall signal rates of solitary } \\
\text { early instars are significantly } \\
\text { higher than solitary late instars }\end{array}$ & $\mathrm{Y}$ \\
\hline $\begin{array}{l}\text { S6. Signal rates of } \\
\text { undisturbed gregarious early } \\
\text { instar } D \text { arcuata caterpillars } \\
\text { are higher than undisturbed } \\
\text { non-gregarious early instar } \\
D \text { bilineata }\end{array}$ & See Chapter 4 & $\mathrm{Y}$ \\
\hline
\end{tabular}

\begin{tabular}{|c|c|c|}
\hline \multicolumn{3}{|c|}{ Signals function to recruit individuals to the group } \\
\hline Prediction & Result & Supported? \\
\hline $\begin{array}{l}\text { Rl Group formation is an } \\
\text { active and not incidental } \\
\text { process }\end{array}$ & $\begin{array}{l}\text { Caterpillars placed singly on } \\
\text { leaves form groups of } 2-4 \\
\text { Individuals after } 24-48 \text { hours } \\
\text { (Timbers, 2005) }\end{array}$ & $\mathrm{Y}$ \\
\hline $\begin{array}{l}\text { R2 Indlviduals will join a } \\
\text { signalling (occupted) nest } \\
\text { more than a non-signalling } \\
\text { (empty) nest }\end{array}$ & $\begin{array}{l}\text { Caterpillars do not join a } \\
\text { signalling nest more than a non- } \\
\text { signalling nest (Lynes, 2006) }\end{array}$ & $\mathrm{N}$ \\
\hline $\begin{array}{l}\text { R3 Signal rates are higher } \\
\text { in solitary individuals than } \\
\text { individuals in groups }\end{array}$ & $\begin{array}{l}\text { No significant difference } \\
\text { between BS, MS and MS signal } \\
\text { rates between solitary } \\
\text { individuals and groups. } \\
\text { Significantly more AS in } \\
\text { solitary individuals. }\end{array}$ & $\begin{array}{l}\mathrm{Y} / \mathrm{N} \text { (not } \\
\text { for all } \\
\text { signals) }\end{array}$ \\
\hline $\begin{array}{l}\text { R4 Signal rates of } \\
\text { undisturbed gregarıous } \\
\text { early instar caterpillars are } \\
\text { higher than undisturbed } \\
\text { non-gregarious late instar } \\
\text { caterpillars }\end{array}$ & $\begin{array}{l}\text { Overall signal rates of solıtary } \\
\text { early instars are significantly } \\
\text { higher than solıtary late instars }\end{array}$ & $\bar{Y}$ \\
\hline $\begin{array}{l}\text { R5 Signal rates of } \\
\text { undisturbed gregarious } \\
\text { early instar } D \text { arcuata } \\
\text { caterpillars are higher than } \\
\text { undisturbed non-gregarious } \\
\text { early instar } D \text { bilineata }\end{array}$ & See Chapter 4 & $\mathrm{Y}$ \\
\hline
\end{tabular}




\subsection{Discussion}

This chapter tested predictions associated with two hypotheses to explain the function of vibratory signalling in gregarious early instar D. arcuata caterpillars; spacing and recruitment. The primary hypothesis was that signals function to space individuals within the nest, while the alternative hypothesis was that signals function to recruit individuals to the nest. The complex vibratory repertoire produced by group-living early instar D. arcuata caterpillars is unprecedented and, to my knowledge, the collaboration of my research with previous studies (described above) provides the first documented evidence for vibratory mediated spacing in groups of holometabolous larvae. I will first make comparisons between the vibratory signals and discuss how temporal and spectral characteristics may be used by the receiver to differentiate between signals. Next I will discuss the evidence relating to each of the hypotheses mentıoned above. Finally I will draw some conclusions about the adaptive significance of vibratory mediated spacing within groups of caterpillars.

Vibratory repertoire of early instar D. arcuata caterpillars

The vibratory repertoire of $D$. arcuata early instar caterpillars consists of four temporally and spectrally unique signals. Buzz scraping and anal scraping are long, low amplitude and low frequency signals whereas mandible scraping and drumming are short, higher amplitude signals. Additionally, buzz scrapes and anal scrapes, as well as mandible scrapes and drums, can be further distinguished with spectral differences between the pairs of signals. Using a unique combination of temporal, spectral and amplitude properties, receivers can potentially distinguish each signal from another. 
Based on the high signal to noise ratio, a defining characteristic of optimal information transfer (Greenfield, 2002), coupled with intentional movements to produce the vibrations, I am confident that the four vibrations produced by early instar $D$. arcuata caterpillars are signals used for communication. Similar signals are produced in other caterpillar species during territorial conflicts. Mandible drumming is the most common signal and is found in four other moth species (Sparganothis pilleriana in Russ, 1969; Caloptilia serotinella in Fletcher et al., 2006; Drepana bilineata in Bowen et al., 2008; and Oreta rosea in Scott et al., 2010a). Two of those four species also produce mandible scrapes ( $C$. serotinella and $O$. rosea), while anal scraping has only been documented in one of those species (D. bilineata). Lastly, although a form of tremulation has been described in $O$. rosea and $C$. serotinella, the buzz scrape of early instar D. arcuata caterpillars differs in that it combines tremulation with anal scraping. The vibratory repertoire of early instar D. arcuata caterpillars has similar signal types to other moth species, but is the most diverse documented to date and may reflect the added complexity of living in groups.

The question arises, why do early instar $D$. arcuata caterpillars possess such a variety of signals types? Vibratory signals produced by late instar caterpillars are used in territorial behaviour and the three signal types are believed to represent different stages in escalation when caterpillars are approached by a conspecific (Yack et al., 2001; Scott et al., 2010b). Early instar caterpillars, on the other hand, have four vibratory signals that they use during routine behaviour within the group. Increased social complexity in groups of some bird species has driven an increase in their signal diversity (Freeberg, 2006), and therefore social interactions in groups of caterpillars may explain the complex 
vibratory repertoire found in early instars of $D$. arcuata. Rather than using different signal types in escalation of territorial behaviour as with late instars, several signal types in early instars may be used to convey multiple messages within different contexts in a group. To the best of my knowledge, there are no similar examples of vibratory signals produced for communication within a group context in larval Lepidoptera or other holometabolous larvae. Therefore, thorough testing of the hypotheses is essential to understanding the function of vibratory signals in early instar $D$. arcuata caterpillars.

\section{Function of vibratory signals}

Spacing

Results from my and previous studies support the hypothesis that vibratory signals function for spacing within the nest (Table 3.6). Three "themes" were addressed in testing the predictions associated with the spacing hypothesis. The first theme addresses the concept of a caterpillar's "personal space", also known as inter-individual distance, and includes results from predictions S1and S2. The second theme involves differences in signalling rates between gregarious and non-gregarious caterpillars to test predictions S4 and S5 relating to different spacing needs. The final theme, that signals convey information of the signaller, arose from testing the prediction that signals are associated with movement (S3).

Animals in groups often choose inter-individual distances of a few body lengths to prevent crowding but maintain a good distance for information exchange (Krause \& Ruxton, 2002). Maintenance of personal space has not been previously reported in caterpillars yet results from my and previous Yack lab studies demonstrate that early 
instar D. arcuata caterpillars have, and maintain, personal space. First, caterpillars in groups exhibit a preferred inter-individual distance of $0.5-2.5 \mathrm{~mm}$, which corresponds to one or two body lengths (Lynes, 2006). This window of personal space may be a strategy that caterpillars have developed to allow them to receive low amplitude vibratory signals that could decay quickly across the leaf (Cokl et al., 2004), but also prevent overcrowding. Second, in two different manipulation studies carried out by T1mbers (2005) and myself, resident caterpıllars increased buzz scrape and mandible scrape signals as an intruding conspecific approached the nest and the individual's personal space. These results provide support for the predictions that caterpillars have "personal space" and mediate spacing with signals directed at approaching conspecifics.

The second theme focuses on predictions relating to different spacing needs of solitary and grouped caterpillars, and the assumption that non-gregarıous caterpillars signal less than gregarious caterpillars. Predictions associated with this theme were tested by comparing signal rates of solitary early instar $D$. arcuata caterpillars with early instar caterpillars in groups, and by comparing signal rates of gregarious early instar and non-gregarious late instar $D$. arcuata caterpillars. Contrary to the spacing prediction that solitaries would signal less (S4), I found no difference of buzz scrape, mandible scrape and mandible drum signal rates between solitary individuals and individuals in groups. If spacing is a requirement of group living, signals used to mediate spacing should be more abundant in groups than solitary individuals because there is a greater chance of encountering another individual when in a group. These results bring up an interesting idea that signals used to mediate spacing may be hardwired in a gregarious species like the early instars of $D$. arcuata, and signals of solitary caterpillars are innate behaviours 
produced regardless if they are in the presence of another individual. Maynard Smith \& Harper (2003) describe innate traits as a behaviour that is unaffected by the environment and that occurs naturally in the population. Likewise, calls are thought to be partially genetically influenced and are often produced from birth in avian and mammal species (Kondo \& Watanabe, 2009). Therefore, vibratory spacing signals may be a behaviour that is expressed in all environments because it is highly adaptive in groups, and therefore solitary caterpillars also produce signals. On the other hand, signalling in non-gregarious late instar caterpillars has been removed from their routine behaviour all together. My results found that early instar $D$. arcuata caterpillars signal significantly more than late instar caterpillars. If signals are a form of conspecific communication to mediate spacing, then late instar D. arcuata caterpillars that live alone, and have no need for spacing signals, should not produce signals during routine activity (Yack et al., 2001; personal observation). During development, as groups begin to disperse in the third instar and caterpillars move to solitary leaves, signals used to mediate spacing in early instars may change and become signals used within a different context to sult the solitary lifestyle of late instars. I suggest that the space that early instar caterpillars defend within a group on the leaf, changes across instars to become space defended over an entire leaf. Overall, these results lead us to believe that signals produced in undisturbed gregarious early instars are for conspecific communication between members of a group, used within a spacing context.

The final theme addressed within the spacing hypothesis involves the concept of signalling to communicate the signaller's activity and position to group members. In my analysis of signals and associated behaviours, I found strong evidence for certain signals 
occurring with particular behaviours and I propose that these associations are used to convey information to group members. Signals produced to indicate a signaller's state are traditionally termed integrative signals but integrative signals are usually graded to allow the receiver to judge some aspect of the signaller's fitness (Bradbury \& Vehrencamp, 1998). In D. arcuata caterpillars, signal and behaviour associations are strong and stereotyped and are therefore more similar to referential signals produce by animals to inform receivers about distinct information (i.e. type of predator). At this point we don't know enough about the signals to formally classify them into either category but for this discussion I will refer to the signals as referential signals because the definition better parallels the observed behaviour. Associations between signals and particular pieces of information have been found in many species. For example, the structure of predator alarm calls can be very tightly tied to the type of predator in some mammals (e.g. Wong et al., 1999), whereas food calls in birds (e.g. Seddon et al., 2002; Freeberg, 2006) can be clear indicators of the location of food resources. Early instar D. arcuata caterpillars show a significant associatıon of buzz scrapes and mandibles scrapes while walking, as well as a significant association of anal scrapes while feeding. Both trends can be interpreted with respect to spacing. Signalling while moving around the nest can convey spatial information to other individuals and prevent physical confrontation. For example, when a moving caterpillar comes too close to a resting individual, the resting caterpillar will often move out of the way (personal observation). A similar movement and signal relationship has been reported in one vampire bat species, Diaemus youngi, that produces specific social calls while flying to monitor the spatial positions of conspecifics and prevent collisions with individuals in fast flying groups (Carter et al., 2009). Meanwhile, 
in D. arcuata caterpillars, signalling while at the feeding scar may prevent other individuals from entering their personal space "at the table" and avoid competition over resources. Similar "kek" and "chuck" calls in green woodhoopoes and pied babblers are both used to regulate the space between foraging individuals in the group (Radford, 2004; Radford \& Ridley, 2008). I suggest that in caterpillars, which are visually restricted, a form of referential signalling is a way of monitoring which caterpillar is doing what and where they are doing it within the group. As mentioned above, the complexity of the vibratory repertoire of $D$. arcuata may reflect group pressures, like the need to space, and referential signals could be used to space individuals in different contexts.

\section{Recruitment}

Results from my research and previous studies have yet to provide strong evidence to support the recruitment hypothesis. Four predictions have been tested for this hypothesis, and they will be discussed in the order they are presented in Table 3.3.

The underlying reasons for why animals form groups can involve aspects of either social or environmental attraction, or because the benefits of living together outweigh the costs (Krause \& Ruxton, 2002). The first prediction tested during previous studies was that caterpillar groups result from active group formation rather than incidental environmental gatherings (R1). When early instar $D$. arcuata caterpillars were placed singly on a leaf of a birch sprig containing 6 leaves, caterpillars formed groups of 2-4 individuals after 24 hours (Timbers, 2005). Taken alone, this could indicate that there is some form of social attraction involved in group formation, but additional evidence shows that caterpillars prefer to create nests on the leaf tip and sides (Timbers, 2005), 
which may play a role in grouping behaviour. The benefit of occupying a desired location of the leaf may initiate group formation, and then benefits of being in numbers may influence caterpillars to stay in groups, especially if mechanisms are in place to mediate spacing and decrease costs. Therefore, grouping could be environmentally triggered, instead of socially influenced with recruitment signals.

An underlying principle of the recruitment hypothesis is that receivers will detect and respond to recruitment signals by joining the group (Bradbury \& Vehrencamp, 1998). In a previous study, caterpillars did not show a preference between joining an occupied nest with signalling caterpillars, and an empty nest with no signalling (R2) (Timbers, 2005). In additional analysis of this experiment, caterpillars also showed no relationship between the amount of signalling in the nest and the rate of intruder joining (Timbers, 2005). These results strongly suggest that signals do not influence joining behaviour, and decrease the strength of the recruitment hypothesis. If caterpillars are not using signals in their decision to join a nest, then the function of signals should not be to recruit roaming conspecifics.

The final two predictions were tested with my observational trials and relate to differences in signalling rates between solitary individuals and individuals in groups, and also between caterpillars in gregarious early instars and non-gregarious late instars. Early instar D. arcuata caterpillars showed no difference in signal rates in three of the four signal types when alone or in a group (discussed above) but did have significantly higher anal scraping in solitary caterpillars. These results were perplexing, given that caterpillars show no preference to join signalling nests (above) and signal rates did not increase linearly as group size decreased from 5 to 1 . My results also showed that eating lengths 
did not differ across group sizes, and therefore higher signalling in solitary individuals could not be attributed simply to longer feeding bouts. One possible explanation for higher signal rates in solitaries stems from observations of feeding behaviour of caterpillars in groups. Although two caterpillars can be feeding at the same time, on the same feeding scar, caterpillars alternate signalling by anal scraping one after another and never signal at the same time (personal observation). Higher signal rates of solitary individuals may occur because they do not have conspecifics to interrupt or limit their signal rate. Aside from this speculation, the answer to why anal scrapes occur more in solitary individuals than groups is still unknown. Overall, support for the recruitment hypothesis is weak and, given the strong evidence for the spacing hypothesis, I conclude at this time that signals do not function primarily for recruitment purposes. With increasing confidence in the spacing hypothesis from supported predictions, I will now discuss why caterpillars in groups may need to signal to mediate spacing in different contexts.

Why do early instar D. arcuata caterpillars need signals to mediate spacing?

Conspecific competition is a common motivating factor in a variety of behaviours seen in group living anımals. Spacing can be broadly defined as a set of behavioural rules used to avoid interactions with individuals to increase personal fitness (Wilson, 2000), but it can also refer more specifically to avoiding competition among group members for resources such as food, habitat, mating opportunities or breeding grounds. Early instar D. arcuata caterpillars live gregariously within silk shelters and, as immature insects, reproductive competition cannot be suggested as the root of spacing 
behaviour. However, signals can be used to avoid interaction while walking and while feeding communally at common feeding scars where competition could arise over access to food. Plant physical defences, like trichomes, are much more challenging for early instars than for late instars due to their small size, so areas of the leaf that are already torn or weakened may be extremely desirable food sources (Zalucki et al., 2002). Therefore, caterpillars may be exploiting the weakened defences of the plant at the edge of the feeding scar and anal scrapıng may be a mechanism used to mediate spacing between caterpillars throughout this area.

Many animals are able to differentiate between unique individuals in an inclusive group. While group inclusivity often refers to species that are able to identify each unique individual in the group, in the context of some groups it can also relate to awareness of the quantity and proximity of individuals in the group. For example, some species of schooling fish are able to differentiate between the size and composition of different shoals using visual cues (reviewed in Krause \& Ruxton, 2002). Caterpillars may also have a crude awareness of individuals within their group and use this to differentiate between group members and intruding conspecifics or predators. Since $D$. arcuata caterpillars signal while moving and while feeding, other caterpillars could use the signals produced by nestmates as a reference for group organization. When a conspecific early instar intruder approaches a caterpillar in a nest, the resident always signals, whereas a resting individual in the nest does not signal when an established nest mate walks toward their personal space (Matheson, unpublished data). Group members may be able to differentiate between moving individuals in their group and approaching intruders because nest mates are producing regular buzz scrape signals whereas intruders 
are not producing regular signals. The question that now arises is, why would caterpillars signal to an outsider? Further studies are needed to answer this question and gain insight into possible collective territorial behaviour or dominance hierarchies in groups of caterpillars.

\section{Conclusion}

In conclusion, this chapter represents the first known study of vibratory mediated spacing in holometabolous insect larvae. Early instar D. arcuata caterpillars produce vibratory signals to maintain a personal space with conspecifics and convey spatial information to members through a type of referential signalling. Gregarious early instar D. arcuata caterpillars signal more than non-gregarious late instar $D$. arcuata caterpillars, suggesting that signals function for conspecific communication (i.e. spacing) during routine activity. Such behaviour is unprecedented in any other holometabolous larvae and a broader survey of vibratory signalling in caterpillars is greatly needed to understand signalling in early instars $D$. arcuata caterpillars. Future studies of early instar D. arcuata should be done using artificial playbacks to test additional predictions associated with spacing and recruitment. Playback of anal scrape signals to a feeding scar occupied by a group of caterpillars should be performed to see if caterpillars avoid the point of playback. Also, observations of the reaction of roaming caterpillar to a nest with an artificial anal scrape signal could provide answers to why solitary caterpillars anal scrape much more than do individuals in groups, and to determine if anal scrapes function for recruitment. As mentioned above, final predictions for both hypotheses need to be tested 
with comparisons of gregarious early instar $D$. arcuata signal rates and those of early instars of a non-gregarious caterpillar species. 


\section{CHAPTER FOUR}

Vibratory-mediated spacing between leaf territories in a non-gregarious early instar caterpillar, Drepana bilineata (Drepanidae) 


\subsection{Introduction}

The previous chapter on the function of signalling in early instar Drepana arcuata caterpillars, suggests that group-living caterpillars are using vibratory signals to mediate spacing. The final chapter of my thesis tests the prediction that signal rates differ between gregarious early instar $D$. arcuata caterpillars and non-gregarious early instar $D$. bilineata caterpillars due to differences in "social structure". Drepana bilineata is a congener of $D$. arcuata, and shares many life history traits, but differs in one important aspect- it is solitary at all development stages. Thus, this difference in grouping behaviour, is a natural experiment to test predictions about the function of signals. Specifically, this chapter will be testing the prediction that if signalling in early instars of $D$. arcuata functions to space within the nest, or to recruit conspecifics to the nest, signal rates should be higher in gregarious early instar $D$ arcuata caterpillars than non-gregarious early instar D. bilineata caterpillars. I will test this prediction by observing natural undisturbed behaviour of early instar D. bilineata caterpillars and comparing signalling behaviour between the two species.

Adult $D$. bilineata females deposit eggs in rows on the bark and leaves of birch (Betula sp.) trees (Fig. 4.1ab). Unlike gregarious early instars of D. arcuata that live and share resources within a silk shelter, $D$. bilineata caterpillars live alone on individual birch leaves and produce a simple silk mat at the tip of the leaf as seen in Figure 4.1c (Dyar, 1894; personal observation). All instars of $D$. bilineata produce vibratory signals, and signalling in late instars has been suggested to function in territorial contests when established residents are approached by an conspecific intruder (Fig. 4.1d) (Bowen et al., 2008). 


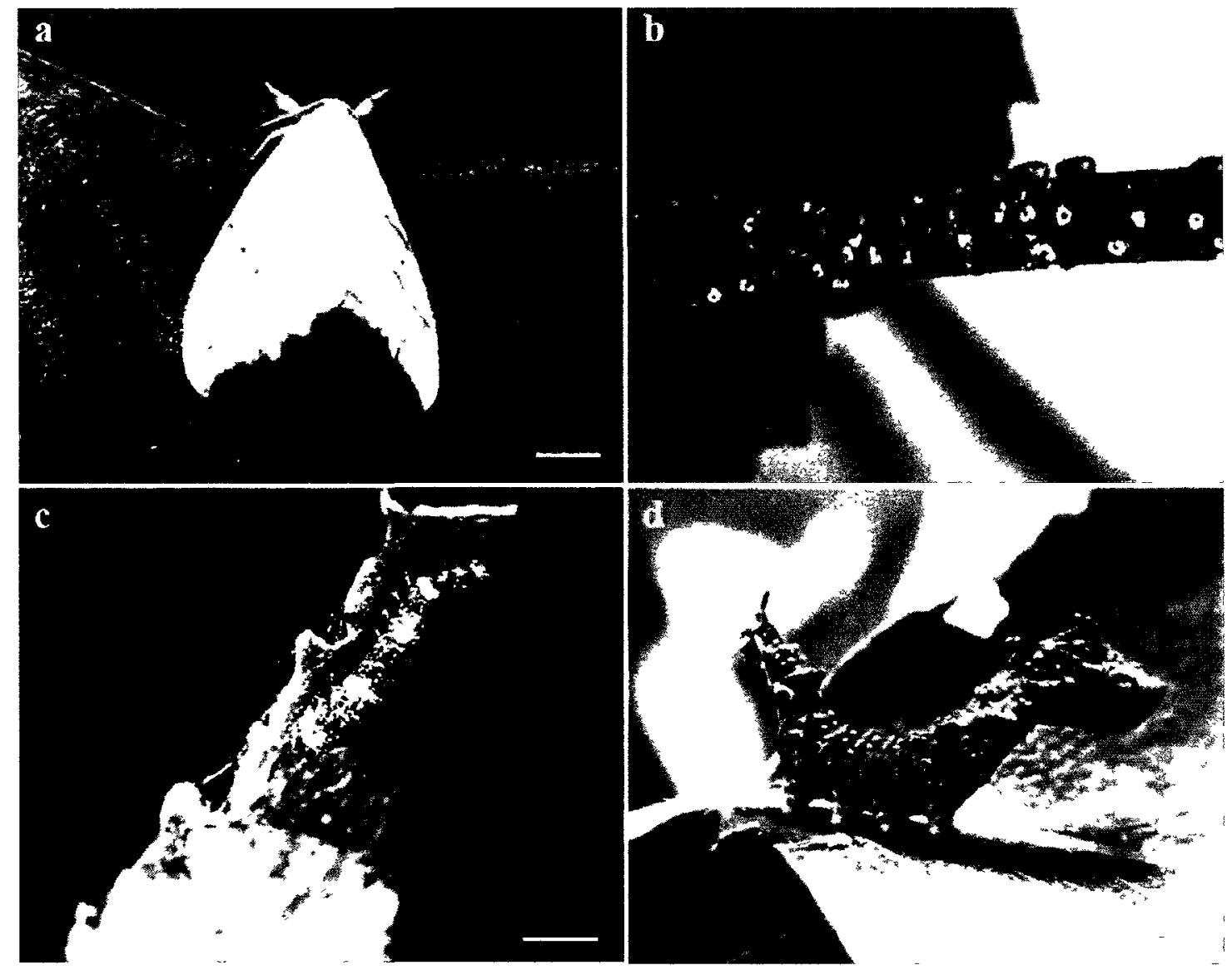

Figure 4.1 Life history stages of Drepana bilineata. (a) Adult resting on leaf. Scale bar $4 \mathrm{~mm}$. (b) Rows of eggs on birch twig. Scale bar $1 \mathrm{~mm}$. (c) A first instar larva resting on a leaf tip with visible feeding scar. Scale bar $1 \mathrm{~mm}$. (d) A late instar larvae resting in characteristic "dragon" posture. Scale bar $3 \mathrm{~mm}$. Photos (a), (b) and (d) were taken by Jayne Yack. Photo (c) was taken by Sarah Matheson. 
Examining signalling behaviour of $D$. bilineata created an opportunity to study the undocumented use of vibratory signals in early instars of this species and, therefore, more analysis was carried out than initially planned. Based on life history observations and preliminary data, I propose that signals in early instar $D$. bilineata are used to advertise or defend leaf tips. The leaf tip can be considered a territory in its simplest form, as a predetermined area from which intruders are excluded through advertisement, threat or attack (Wilson, 2000), and so I suggest that D. bilineata caterpillars may be using vibratory signals in territorial behaviour to maintain exclusive ownership over a leaf tip. Using observational data, along with staged encounters, I am testing some preliminary predictions for the hypothesis that vibratory signals produced by early instar D. bllineata caterpillars have a territorial function.

The predictions for this hypothesis are:

1. Caterpillars occupy an exclusive area of the leaf

2. Intruders rarely approach a leaf tip occupied by a signalling resident

3. Signal rates of the resident are higher when a conspecific is on the leaf than when the resident is undisturbed

\subsection{Chapter Objectives}

The first objective of this chapter is to test predictions associated with the hypothesis that vibratory signals in $D$. arcuata caterpillars function for conspecific communication. The second objective is to collect life history information about $D$. bilineata and test three preliminary predictions associated with the hypothesis that $D$. 
bilineata caterpillars use vibratory signals for territorial spacing at the leaf tip.

Information for the above will be collected by recording video and vibratory signals of caterpillars on undisturbed leaves over 30 minute trials, followed by the introduction of conspecific intruder to the leaf for a 20 minute interaction period.

\subsection{Methods}

Animals and experimental setup

Caterpillars of Drepana bilineata (Drepanidae) were reared from eggs obtained from moths collected at sheets illuminated with $15 \mathrm{~W}$ ultraviolet collecting lights (Bioquip, Rancho Dominguez, California) in August 2009 in Howe Bay (Prince Edward

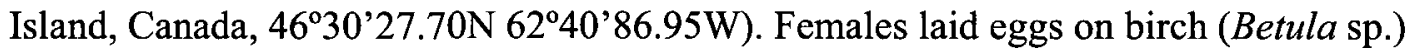
leaves within an enclosure while being transported from PEI to Carleton University in Ottawa, Ontario. Larvae were reared indoors on cuttings of birch (Betula sp.) at Carleton University under a 16:8 LD photoperiod at $21-26^{\circ} \mathrm{C}$. First instar larvae (1-3 days old) were used for all trials. To allow caterpillars to establish themselves on leaves for both the observation and manipulation trials, a newly hatched larva was placed singly on a leaf of a birch sprig and left undisturbed for a minimum of 12 hours.

\section{Vibration recordings and signal characterization}

Vibratory signals were recorded from caterpillars using a laser-doppler vibrometer (PVD-100, Polytec Inc., Irvine, CA, USA) with the beam of the laser focused on a circle of reflective tape ( $2 \mathrm{~mm}$ diameter) attached the upper surface of the leaf approximately $1-2 \mathrm{~cm}$ from the caterpillar. Signals detected by the laser (velocity $20 \mathrm{~mm} / \mathrm{s}$; 
high pass filter off; low pass filter $20 \mathrm{kHz}$ ) were recorded to a Marantz data recorder (PMD 671, D\&M Professional, Itasca, IL) at a sampling rate of $48 \mathrm{kHz}$. In conjunction with vibration recordings, all trials were videotaped using a Sony HDR-XR520V Handycam (Tokyo, Japan) with the digital output from the laser vibrometer plugged into the microphone port. All trials were performed within an acoustic chamber (C-14A MR, Eckel Industries Ltd., Cambridge, MA, USA) to prevent extraneous noise.

Preliminary observations indicated that caterpillars produce two unique vibratory signals which were later analyzed for temporal and spectral characteristics using RavenPro Bioacoustics Research Program 1.4 (Cornell Laboratory of Ornithology, Ithaca, NY, USA). An overall mean \pm SD of signal duration for each signal type was calculated using means of signal durations of 65 different signals ( 40 buzz scrape and 25 mandible drum) from 9 different individuals. Spectral values of frequency range and peak frequency were calculated from 10 signals from 5 individuals for each signal type using a 1024 hanning window in RavenPro.

Initial analysis indicated that signals are produced in bouts. Bouts were defined as a combination of signals bounded by at least one second of inactivity. To test if bouts are produced in regular patterns, four characteristics were calculated including (i) bout duration, (ii) total signals in a bout, (iii) amount of each signal type in a bout, and (iv) inter-signal duration. Data were collected from 15 different bouts across 5 individuals.

Set-up for video recordings and behaviour analysis

To characterize signalling behaviour of early instar $D$. bilineata caterpillars, observation trials were performed by recording vibrations and video of an established 
individual. A randomly selected individual was positioned in the recording apparatus described above and left isolated for approximately 5 minutes before recordings began. In total, 18 half-hour nest observation trials were examined. Observation trials were used to characterize vibratory signals and analyze undisturbed signal rates and signal/behaviour relationships.

Analysis of signal rates and behaviour patterns used time sequenced files of individual caterpıllar's vibratory signals and behaviours using JWatcher Video 1.0 (Blumstein et al., 2010). Initial observations were made to categorize routine caterpillar activity in to four behavioural states (eating, resting, walking, laying silk) and signals into two signal types (buzz scrape and mandible drum). Video recordings of each trial were then viewed at reduced speed and individual behaviours and vibratory signals were time marked using designated keys of a keyboard. This method provided a time sequenced list of traits that could be analysed separately for each individual. Data files from JWatcher were outputted into Microsoft Excel for analysis.

\section{Comparison of signal rates between $\mathrm{D}$. bilineata and $\mathrm{D}$. arcuata}

To understand the function of vibratory signallıng in groups of $D$. arcuata caterpillars, signal rates of gregarious early instar caterpillars were compared against signal rates of non-gregarious $D$. bilineata early instar caterpillars. Drepana arcuata caterpillars signal when alone and even show similar associations of signals and behaviours to caterpillars in groups (see Results from Chapter 3). Comparisons were made using overall mean \pm SD signal rates of all signal types to compare signalling abundance, plus individual mean $\pm \mathrm{SD}$ comparisons of the signal rates of buzz scrapes and 
mandible drums. Signal rates $(\# / \mathrm{min})$ were statistically compared with a Mann-Whitney U test using JMP8 statistical software.

Signal/behaviour relationships of $\mathrm{D}$. bilineata caterpillars

Signal and behaviour relationships were calculated to provide further comparison between signalling behaviour of the two species. For all trials, signal rates were calculated by measuring the number of signals during each behavioural state. This provided signal rates (\#/min) of buzz scraping and mandible drumming for walking, resting, eating and laying silk (a total of 8 signal rates).

\section{Caterpillar manipulation and analysis}

Staged encounters were used to test two predictions associated with the territorial spacing hypothesis. Interaction trials were conducted immediately following the nest observation trials (see above) while the leaf was still positioned in the recording apparatus. The encounter was simulated by placing a single larva on the leaf at a distance of $3-5 \mathrm{~cm}$ from the nest as was done for early instar $D$. arcuata trials. Recordings were made for 20 minutes after the introduction of the conspecific whether the intruder did or did not approach the nest. Time sequenced files of individual vibratory signals and behaviours of the resident were created using the same method as described for observation trials. Joining trials were analyzed for how often the intruder approached the signalling resident (intruder approach frequency), and resident signal rates during different conditions. 
Intruder approach frequency

Intruder approach frequency was calculated by measuring the percentage of trials where the planted intruder initially walked toward the signalling resident or walked away toward the petiole. This value was calculated from 15 trials with $D$. bilineata caterpillars and 33 trials with $D$. arcuata caterpillars.

Resident signal rates

Signal rates of buzz scraping and mandible drumming of the resident were calculated when (a) the resident was undisturbed on a leaf, (b) a conspecific intruder was on the leaf, and, (c) a conspecific intruder was in the resident's territory. The intruder was considered to enter the resident's territory when it crossed the boundary of the feeding scar (a caterpillars home range is generally bound by the leaf tip and a feeding scar, personal observation) (Fig. 4.2a). Signal rates between each condition were compared with a Tukey-Kramer HSD using JMP8 statistical software.

\subsection{Results}

Life history observations

During observation and manipulation trials, early instar caterpillars were placed individually on the center of a leaf of a birch sprig. In 25 trials, after 12 hours, $84 \%$ of caterpillars took up residence at the leaf tip, with the remaining $16 \%$ on the edge of the leaf (Fig. 4.2b). 


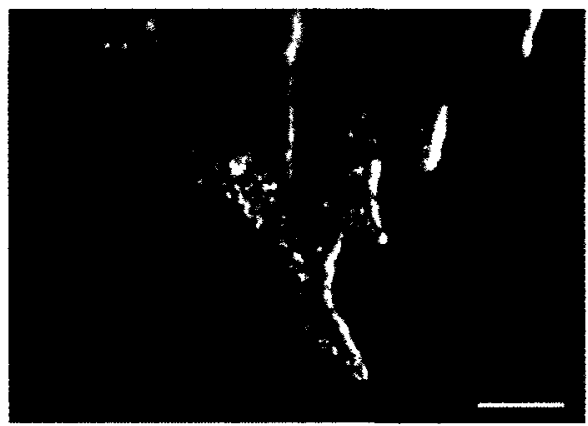

b
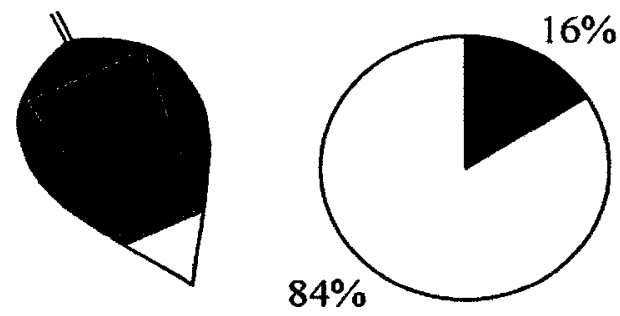

Figure 4.2 Leaf area preferred by early instar $D$. bilıneata caterpillars. (a) Caterpillar resting on leaf tip. Scale bar $1 \mathrm{~mm}$. (b) Distribution of caterpillars occupied on leaf tip (yellow) and leaf edges (blue). No caterpillars settled on the leaf center or area near the petiole. 
Signal analysis

Early instar $D$. bilineata caterpillars produce two distinct vibratory signals; buzz scraping and mandible drumming.

Buzz scrape. A buzz scrape signal involves a sequence of body movements. The caterpillar begins by lowering its head to the leaf surface (Fig. 4.3b). Next the anal segments are lowered toward the leaf so that body is flattened (Fig. 4.3c). Then the anal segments are contracted anteriorly against the leaf surface dragging a chitinous modified anal seta across the leaf surface while the head rises up and the anterior part of the body oscillates vertically (Fig. 4.3d). During this motion the head makes brief contact with the leaf, producing multiple pseudo mandible drums. Lastly, the head and anal segments are raised to return to the resting posture (F1g. 4.3ae). Mean \pm SD signal duration of buzz scraping from 40 signals across 8 individuals is $256 \pm 54 \mathrm{~ms}$. Buzz scrapes are broadband with a peak frequency at $140.6 \mathrm{~Hz}$ (Fig. $4.4 \mathrm{~b}$ ).

Mandible drum. A mandible drum is a simple signal produced by one body movement consisting of lowering the head vertically toward the leaf surface and striking the surface with the mandibles. Mean \pm SD signal duration of mandible drumming from 25 signals across 8 individuals is $30 \pm 11 \mathrm{~ms}$. Mandible drums are broadband with peak frequencies at $140.6 \mathrm{~Hz}$, and $562.5 \mathrm{~Hz}$ (Fig. 4.4c).

Vibratory signals are most often produced in combinations called bouts, which are comprised of a sequence of buzz scrapes with mandible drums at the end. Mean $\pm \mathrm{SD}$ duration of signallıng bouts was $2.32 \pm 0.67$ seconds. Bouts contain an average of $6.56 \pm 1.82$ signals, comprising of $4.44 \pm 0.81$ buzz scrapes and $2.13 \pm 1.45$ mandible drums (Fig. 4.4a). Mean \pm SD time between signals within a bout was $186 \pm 49 \mathrm{~ms}$. 

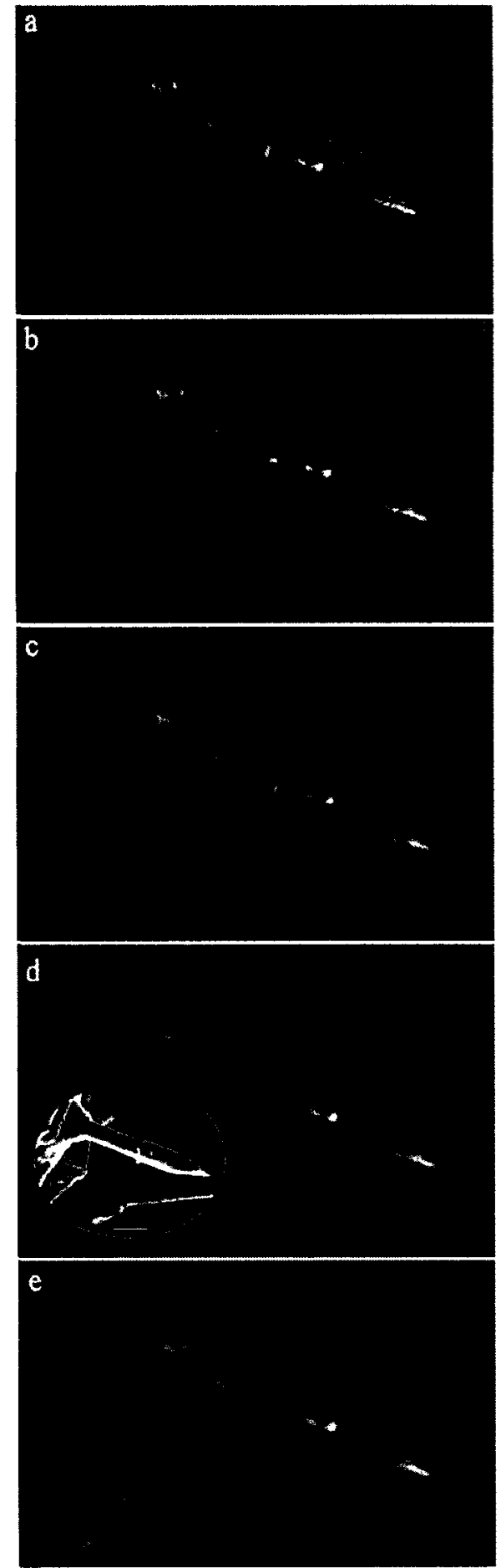

Figure 4.3 Body movements associated with buzz scrape in early instar $D$ bilineata. (a) Resting posture (b) Head is lowered toward leaf surface (c) Anal segments are lowered, body is flattened against the leaf (d) Anal segments are contracted and anal oar (1nset, scale bar $=10 \mu \mathrm{m}$ ) is dragged across the leaf surface while the head is raised and anterior part of the body oscillates with the head briefly contacting the leaf (d) Head and anal segments are raised to onginal position. 
a

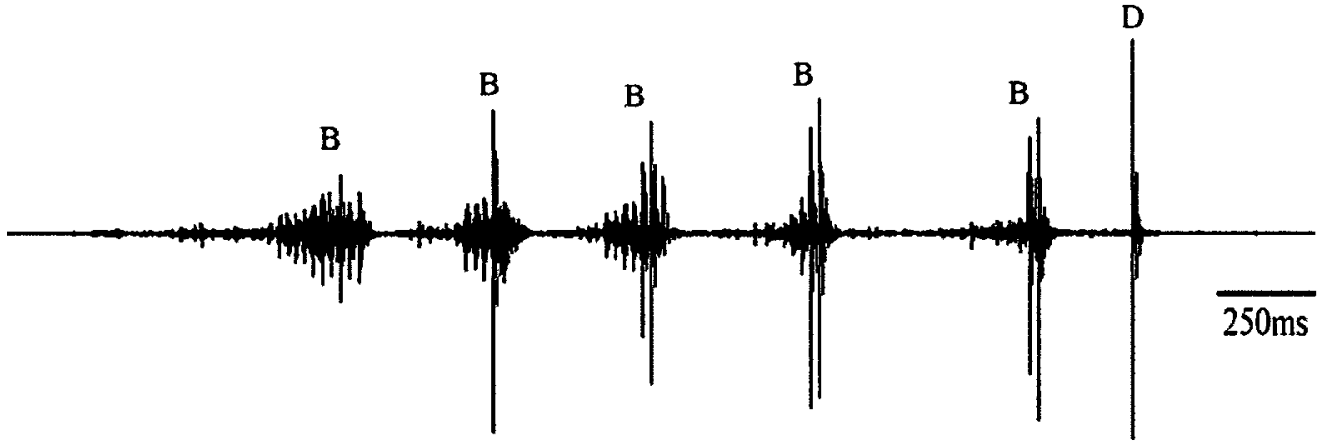

b Buzz. Scrape
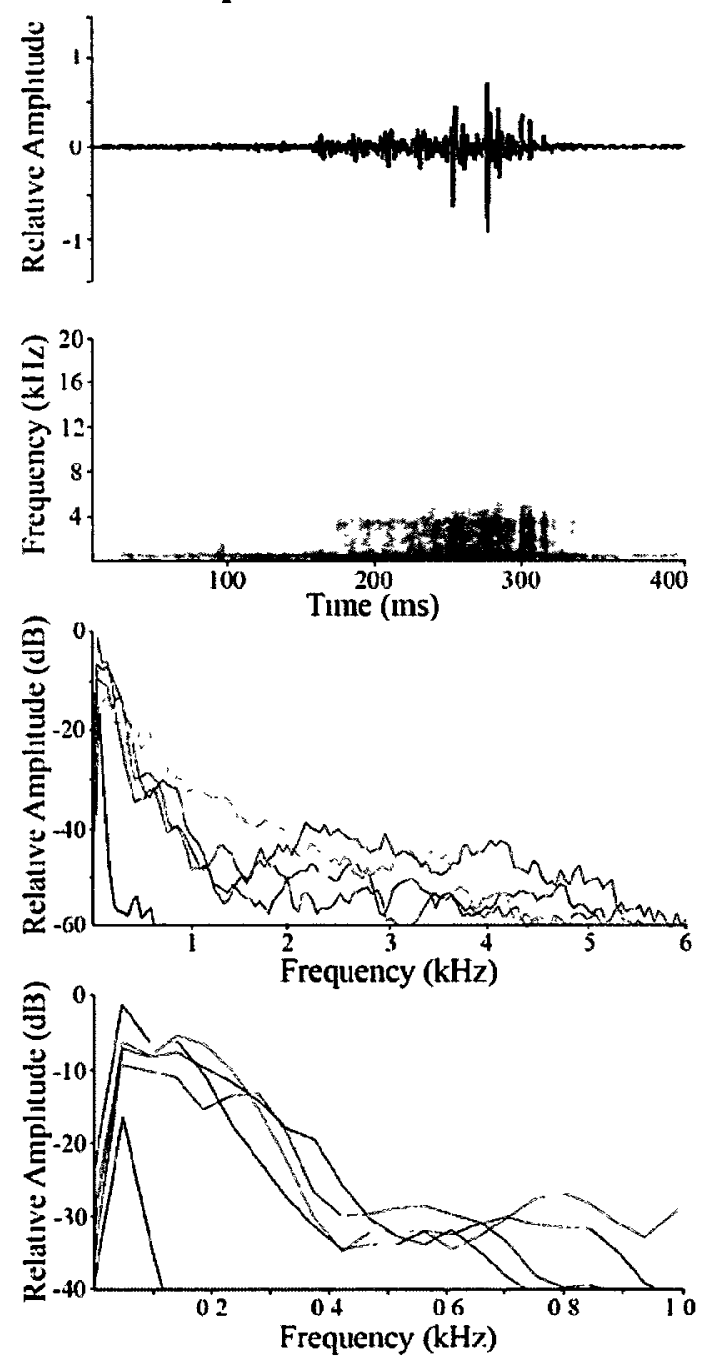

c Mandible Drum
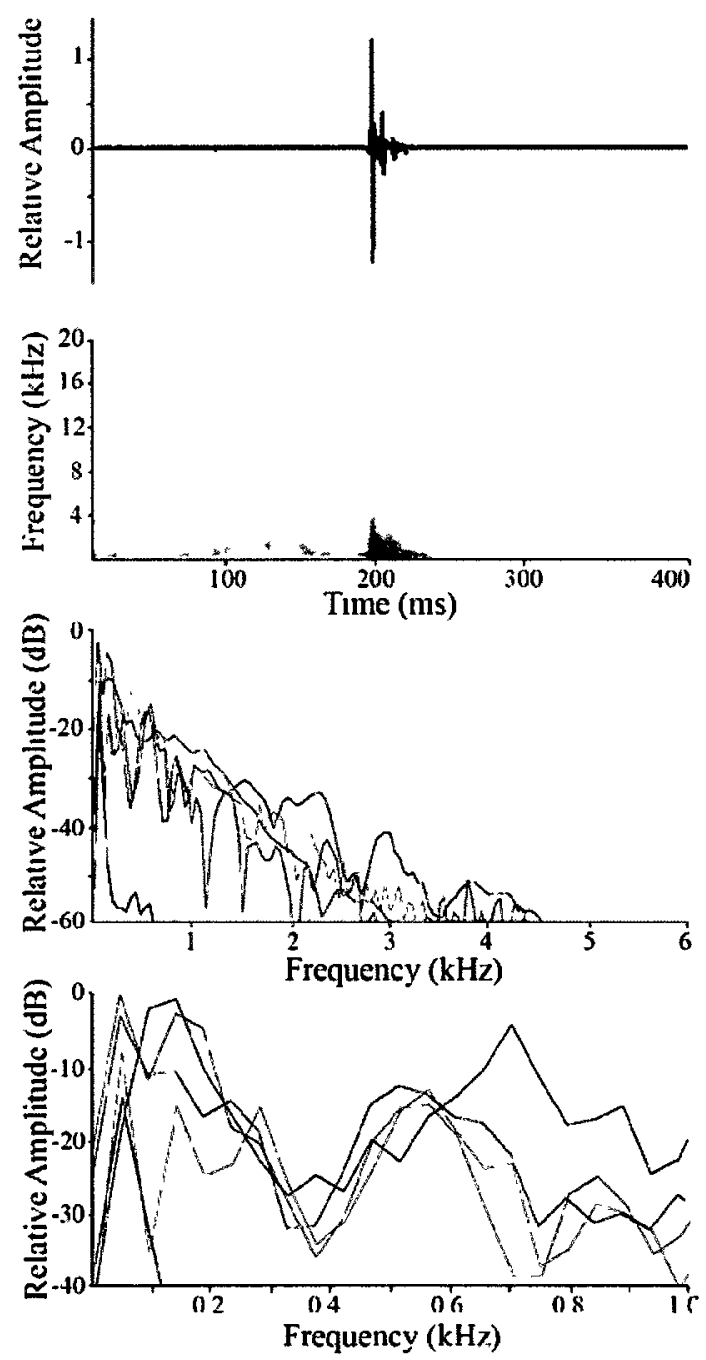

Figure 4.4 Vibratory signals produced by early instar $D$. bilineata caterpillars. (a) Bout of signalling. (b) Buzz Scrape (B) and, (c) Mandible drum (D). Two power spectra are provided for each signal to show the frequency range (top) and peaks (bottom). 
Comparison of signal rates between $\mathrm{D}$. bilineata and $\mathrm{D}$. arcuata

Signal rates of undisturbed caterpillars were calculated to test the prediction that signal rates of gregarious early instar caterpillars are higher than non-gregarious early instar caterpillars. Solitary individuals were used for both species to provide an equal comparison. Signal rate values are provided in Table 4.1 with other life history comparisons between the two species. D. arcuata caterpillars produced significantly more overall signallıng and significantly more buzz scrapes than $D$. bilineata caterpillars (Mann Whitney $\chi^{2}=11.3272, \mathrm{P}=0.0008$; Mann Whitney $\chi^{2}=3.9406, \mathrm{P}=0.0471$, respectively). Mandible drumming signal rates did not differ between species (Mann Whitney $\left.\chi^{2}=0.4396, \mathrm{P}=0.5078\right)$.

Signal/Behaviour relationships of $\mathrm{D}$. bilineata caterpillars

Buzz scrape. The mean \pm SD signal rate of buzz scraping is $7.21 \pm 14.85 \# / m i n$ while resting, $5.13 \pm 17.86$ while walking, $0.44 \pm 2.20$ while eating and 0 while laying silk. There is a significant difference between buzz scrape rates during different states (Kruskal-Wallis, $\chi^{2}=26.2, \mathrm{df}=3, \mathrm{P}<0.0001$ ). Post-hoc testing showed that the rate of buzz scraping during resting is significantly higher than during walking, eating and laying silk (Mann-Whitney $\chi^{2}=6.34, \mathrm{df}=1, \mathrm{P}=0.0118 ; \chi^{2}=22.02, \mathrm{df}=1, \mathrm{P}<0.0001 ;$ and $\chi^{2}=6.32, \mathrm{df}=1$, $\mathrm{P}=0.012$, respectively) (Fig. 4.5a). Buzz scrapes are clearly associated with resting. Mandible drum. The mean $\pm \mathrm{SD}$ signal rate of mandible drumming is $1.46 \pm 5.16 \# / \mathrm{min}$ while resting, $0.61 \pm 1.49$ while walking, and $0.1 \pm 0.1$ while eating and 0 while laying silk. There is a significant difference between mandible drum rates during different states (Kruskal-Wallis, $\chi^{2}=12.25, \mathrm{df}=3, \mathrm{P}=0.0066$ ). Post-hoc testing showed that mandible 
Table 4.1 Life history and signal characteristics of non-gregarious early instar Drepana bilineata caterpillars and gregarious early instar Drepana arcuata caterpillars.

\section{Drepana bilineata}

Group size

Habitat

Signal types

\section{Overall Signal}

Rate \pm SD

$(\mathrm{P}=0.0008)$

Buzz Scrape

Signal Rate \pm SD

$(P=0.0471)$

Mandible Drum

Signal Rate \pm SD

$(P=0.5078)$

Silk mat

buzz scrape and

mandible drum

$0.65 \pm 0.72 \# / \mathrm{min}$

$(\mathrm{N}=17)$

$0.54 \pm 0.58 \# / \mathrm{min}$

$(\mathrm{N}=17)$

$0.17 \pm 0.2 \# / \mathrm{min}$

$(\mathrm{N}=17)$

\section{Drepana arcuata}

$2-7$

Silk mat and shelter

buzz scrape, mandible scrape, anal scrape and mandible drum

$5.57 \pm 3.69 \# / \mathrm{min}$

$(\mathrm{N}=10)$

$1.42 \pm 1.42 \# / \mathrm{min}$

$(\mathrm{N}=10)$
$0.56 \pm 0.93 \# / \mathrm{min}$ $(\mathrm{N}=10)$ 
a Drepana bilineata solitary individual

25

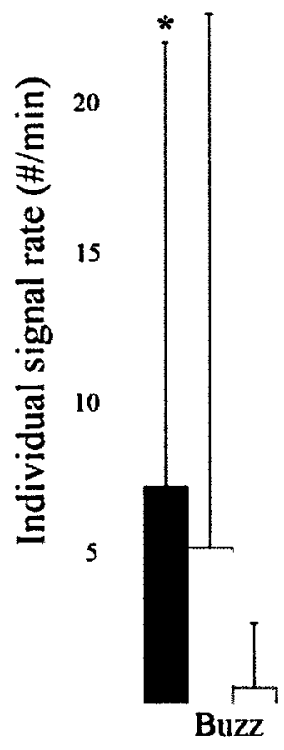

Scrape
Resting

Walkung

Eatung

Iㅔㄴ Laying Silk

\section{b Drepana arcuata solitary individual}

20
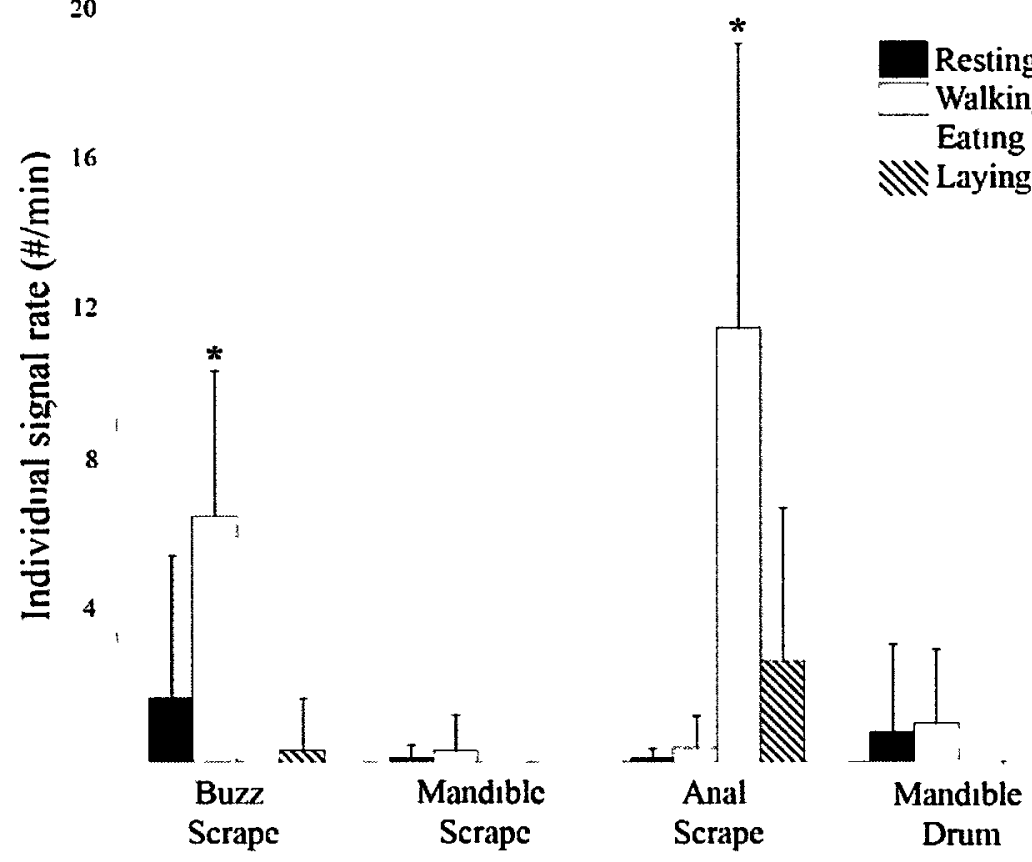

Figure 4.5 Signal/behaviour relationships for solitary D. bilineata (a) and D. arcuata (b) caterpillars. Buzz scraping is significantly associated with resting in $D$. bilineata while buzz scraping is associated with walking in $D$. arcuata. There is no signal associated with feeding in $D$. bilineata but there is a significant association with anal scrapes and feeding in D. arcuata. 
drumming is significantly hıgher during resting than while eating (Mann-Whitney $\chi^{2}=9.56, \mathrm{df}=1, \mathrm{P}=0.002$ ) but not higher than during walking or laying silk (MannWhitney $\chi^{2}=2.92, \mathrm{df}=1, \mathrm{P}=0.0878$ and $\chi^{2}=2.83, \mathrm{df}=1, \mathrm{P}=0.0921$, respectively) (Fig. 4.5a). There is a non-significant trend that mandible drums are associated with resting.

Both buzz scrape and mandible drum rates of early instar $D$. bilineata caterpillars are associated with resting (Fig. 4.5a). In early instars of D. arcuata buzz scraping and anal scraping are associated with walking and eating, respectively (Fig. $4.5 \mathrm{~b}$ ). Comparison of signal/state relationships between $D$. bilineata and $D$. arcuata demonstrates a difference in the function of vibratory signals in different spacing contexts.

Staged encounters

Intruder approach frequency

When a $D$. bllineata intruder was planted on the leaf it initially approached the signalling resident in $33 \%$ percent of trials. This differs from the $67 \%$ of $D$. arcuata intruders that approached a group of caterpillars. Also, the resident D. bilineata caterpillar consistently signalled when the intruder was placed on the leaf, which did not occur with $D$. arcuata resident caterpillars.

\section{Resident signal rates}

Signal rates of an early instar $D$. bilineata resident were calculated when the resident was undisturbed on a leaf $(U)$, when a conspecific intruder was on the leaf $(L)$, and, when a conspecific intruder was in the resident's territory (T). See Figure 4.6a for a 
pictorial depiction of the three conditions. The signal rate of buzz scraping was significantly higher when the intruder was in the resident's territory than when the intruder was on the leaf and when the resident was undisturbed ( $T>L$ and $T>U$ ) (TukeyKramer HSD, $\mathrm{P}<0.0001$ for both pairs) (Fig. 4.6b). The signal rate of mandible drumming was also significantly higher when the intruder was in the resident's territory and on the leaf than when the resident was undisturbed ( $\mathrm{T}>\mathrm{U}$ and $\mathrm{L}>\mathrm{U}$ ) Tukey-Kramer HSD, $\mathrm{P}=0.015$ and $\mathrm{P}=0.0457$, respectively) (Fig. 4.6b). The signal rate of buzz scraping was significantly higher when the intruder was on the leaf than when the resident was undisturbed $(\mathrm{L}>\mathrm{U}$ ) (Tukey-Kramer HSD, $\mathrm{P}=0.0045$ ) (Fig. 4.6b). The signal rate of mandible drumming did not increase significantly when the resident moved from just being on the leaf to being in the territory $(\mathrm{T}=\mathrm{L})$ (Tukey-Kramer HSD, $\mathrm{P}=0.5502$ ) (Fig. 4.6b). Durnng staged encounters $D$. bilineata intruders did not signal when they were walking toward the resident, which differs from $D$. arcuata intruders who buzz scraped intermittently as they approached the resident.

Jumping

During staged encounters I observed that resident $D$. bilineata caterpillar will "jump" off the leaf and hang on a silk thread when approached by a conspecific. Previous literature on other species has termed this behaviour as "lifeline" climbing or jumping (Brackenbury, 1996). Jumping occurred in $85.7 \%$ of trials where the intruder approached the resident and made body contact, indicating that body contact may trigger residents to jump off the leaf. Residents never jumped off the leaf when they were alone. During joining trials with early instar $D$. arcuata caterpillars (chapter 3), no resident ever jumped 


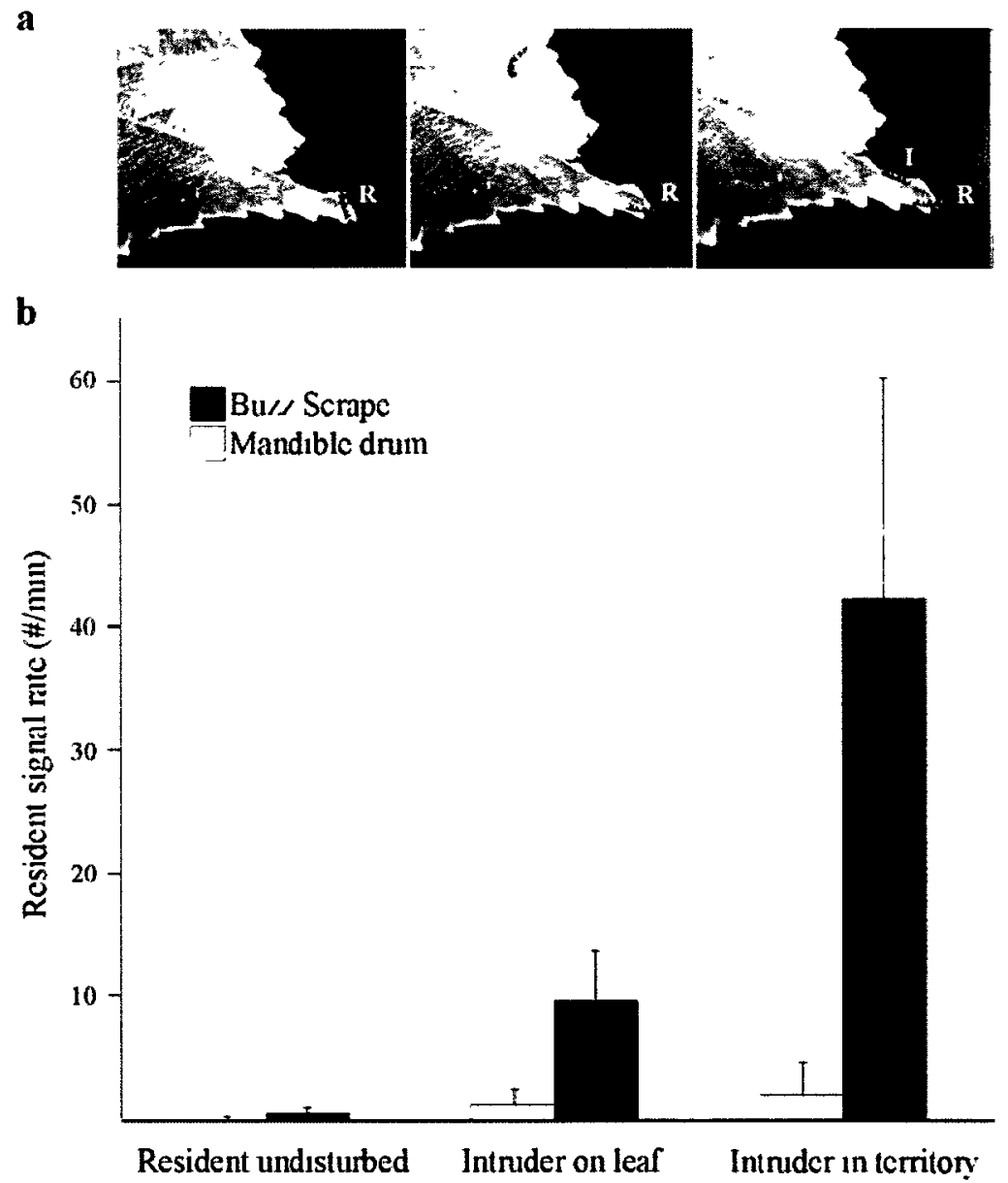

Figure 4.6 Signal rates of an early instar $D$. bilineata resident during a staged encounter. (a) Three experimental conditions; resident ( $R$ ) is undisturbed on the leaf tip, a conspecific intruder (I) is also on the leaf and, a conspecific intruder is inside the resident's territory. (b) Signal rates of resident caterpillar during the three different conditions. Signal rates increase significantly when the intruder is in the resident's territory. 
off the leaf, so this is an interesting difference between the two species.

\subsection{Discussion}

During all instars $D$. bilineata caterpillars live alone on individual birch leaves where they produce a simple silk mat on the area of the leaf they are occupying. Research on vibratory sıgnalling in late instars of this species shows that caterpillars defend leaves from conspecifics using two vibratory signals, mandible drumming and anal scraping, that increase in rate as the intruder approaches the resident (Bowen et al., 2008). To date, little is known about vibratory signalling in early instar caterpillars, who exclusively occupy leaf tips. The purpose of this chapter was to test predictions for the function of signalling in early instars of $D$. arcuata, using $D$. bilineata as a congener with similar life history but differing in "social" structure. Comparative results between species will be addressed in the first part of my discussion. In observing signalling behaviour of early instar D. bilineata caterpillars, I hypothesized that signalling in this species functions to defend the leaf tip. Results from predictions of this "territorial" hypothesis will be presented in the second part of my discussion.

Comparing signal rates between $\mathrm{D}$. arcuata and $\mathrm{D}$. bilineata

In chapter three I concluded that vibratory signalling in $D$. arcuata caterpillars is used for spacing within a group, yet, the prediction that signal rates of undisturbed gregarious $D$. arcuata caterpillars are higher than undisturbed non-gregarious $D$. bilineata caterpillars (S6 or R5 in Table 3.3) remained untested. Late instar D. arcuata 
caterpillars, which are solitary, signal significantly less than caterpillars in earlier gregarious instars (see Results in Chapter 3), demonstrating the use of vibratory signals for conspecific communication during routine activity in early instars. In this chapter I found that the signalling rate of undisturbed early instar $D$. arcuata caterpillars was significantly higher than undisturbed early instar D. bilineata caterpillars. Higher signalling in $D$. arcuata supports the hypothesis that signalling is used to recruit individuals to the group, but also supports the spacing hypothesis if solitary individuals of early instar D. arcuata are considered to represent the "gregarious" condition with innate signalling tendencies (see chapter 3 discussion).

Territorial spacing in $\mathrm{D}$. bilineata

The primary reason for observing signalling in $D$. bilineata caterpillars was to test final predictions from chapter three. However, while collecting signal information of $D$. bilineata caterpillars, the question arose, why do non-gregarious caterpillars signal at all? Based on life history information and preliminary observatıons, I developed the hypothesis that signals are used to defend leaf tips and mediate spacing between individuals in territories. This part of the discussion will address three predictions for the "territorial spacing" hypothesis and will conclude by suggesting why advertisement signals produced by undisturbed caterpillars may be advantageous.

One of the fundamental concepts of territoriality involves an individual protecting a designated area. Therefore, I predicted that if signalling was for a territorial function, then caterpillars should occupy an exclusive area. My results indicate that in early instar D. bilineata caterpillars, the protected area is the leaf tip. Caterpillars placed individually 
in the center of the leaf showed a significant preference to settle on the leaf tip. In addition, D. bilineata caterpillars always live alone on the leaf tip (Dyar, 1894; personal observation), and, therefore, occupancy of the territory appears to be exclusive to a single caterpillar.

The next two predictions addressed behaviours during staged encounters by measuring how often an intruder approached a signalling resident and signal rates of a resident during different conditions of staged encounters. When the intruder was planted on the leaf $3-5 \mathrm{~cm}$ away from the territory, the resident began signalling immediately in all trials. I also found that early instar D. bilineata caterpillars approached solitary signalling residents much less than during similar trials between early instar $D$. arcuata caterpillars, whose residents do not signal until the intruder is almost in the nest. These results suggest that signals produced by early instar $D$. bulineata caterpillars function to mediate spacing over long distances to defend a territory, whereas $D$. arcuata caterpillars signal to maintain their personal space in the group. Secondly, I found a significant trend of escalating signal rates as an early instar $D$. bllineata resident went from being alone, to having an intruder on the leaf, to having an intruder inside its territory. Territorial signals produced in late instar caterpillars of two other drepanid moths (D. arcuata in Yack et al., 2001; O. rosea in Scott et al., 2010a ) and in D. bilineata late instars (Bowen et al., 2008) also increase in rate as an intruder approaches a resident. This demonstrates an increasing mechanism to mediate space as an intruder approaches the territory.

Why is mediating distance from a conspecific intruder so important? Early instar D. bilineata caterpillars often jump and hang from silk threads when an approaching conspecific makes physical contact. This behaviour, described as life-line hanging, 
occurs when some caterpillar species become alarmed (Brakenbury, 1996). Most species that employ life-line hanging are free-living (Sugiura \& Yamazaki, 2006) and may be using this escape mechanism as an alternative to building a protective silk shelter. If physical conflicts in early instar $D$. bilineata caterpillars result in costly jumping behaviour, mechanisms to avoid conflict and mediate spacing at long distances could be extremely adaptive.

Advertisement signals in undisturbed early instar D. bilineata caterpillars

Unlike other territorial late instar caterpillars like D. arcuata, $O$. rosea and $D$. bilineata, early instars of $D$. bilineata also produce signals during undisturbed routine behaviour, although at a much lower rate than when in the presence of a conspecific (Yack et al., 2001; Bowen et al., 2008; Scott et al., 2010a). Drepana bllineata caterpillars hatch from eggs laid in rows but immediately become solitary and disperse to find a food source. The search pattern for resources often overlaps when individuals start from the same place (Krause \& Ruxton, 2002) and this could be especially true if the resource is a specific location like the leaf tip that $D$. bilineata caterpillars prefer to occupy. Once established on a territory, the signals produced intermittently by undisturbed caterpillars could be used to mediate space by functioning as an advertisement signal of leaf occupancy. One of the most direct forms of territorial maintenance is through repetitious signalling, directed not at a specific individual but, broadcast into the environment (Wilson, 2000). Many birds like the chipping sparrow, Spizella passerina, use a repeated single syllable during their territorial advertisement songs to increase the clarity of the message (Liu \& Kroodsma, 2007). The bouts of 
signals produced intermittently by undisturbed $D$. bilineata caterpillars, containing repeated and regular buzz scraping and mandible drumming, may be used to broadcast a clear and reliable message of occupancy to roaming conspecifics.

There are two possible reasons why advertisement signals could be advantageous to early instars and not to late instars. First, some hemipteran predators can detect vibrations produced by caterpillars and use vibrations to locate their prey (Pfannenstiel et al., 1995). Vibrations produced by late instars could be above the receptive threshold for predator detection and are only used in territorial contests, when the immediate cost of losing a territory outweighs the potential cost of predation. The vibrations produced by early instar caterpillars, that are only a few millimetres in length, may not be detectable to predators and, therefore, do not incur any predatory costs. The second has to do with the observed result of physical contact between early instar $D$. bilineata caterpillars. If territorial signals do not mediate space between caterpillars, the resident must expend valuable energy in jumping off the leaf. The relationship between increased pressure to maintain space and avoid physical conflict, with decreased pressure from predators, could result in the development of vibratory advertisement signals in early instar $D$. bilineata caterpillars.

Summary

In summary, gregarious early instar D. arcuata caterpillars have significantly higher signalling rates than non-gregarious early instar $D$. bilineata caterpillars, when caterpillars are undisturbed on an established leaf. These results suggest that signalling in early instar D. arcuata caterpillars is used for group communication, to function for 
spacing or recruitment. Early instar D. bilineata caterpillars demonstrate exclusive use of a leaf tip, which they defend using vibratory signals that escalate as an intruder approaches their territory. There are some interestıng differences in signalling behaviour during conspecific encounters in $D$. bilineata and $D$. arcuata early instar caterpillars. When a conspecific intruder is placed on a leaf containing an established $D$. bilineata resident, the resident signals immediately which results in the intruder walking away from the resident. In contrast, $D$. arcuata residents do not signal immediately and intruders approach the nest much more than $D$. bilineata intruders. Also, D. bilineata intruders do not signal while approaching the nest but $D$. arcuata intruders do signal intermittently. Therefore, signalling in D. bilineata caterpillars most likely functions for long distance territorial spacing whereas $D$. arcuata signals function for close range with1n group spacing. Additionally, signalling in undisturbed early instar D. bilineata caterpillars may function to advertise occupancy of the leaf to roaming conspecifics. 


\section{GENERAL CONCLUSIONS}

The goal of this thesis was to examine possible mechanisms to mediate spacing in groups of holometabolous insect larvae using coleopteran and lepidopteran model species. To my knowledge, this is the first study to test predictions for the hypothesis that vibratory signals/cues are used to mediate space in any holometabolous larva. Three models were examined; bark beetle larvae (Scolytus multistriatus) living in aggregations underneath bark and caterpillar larvae (Drepana arcuata) living together in silk shelters, or alone on leaf tips (Drepana bilineata). Bark beetle larvae live in a sensory limited environment, and my prelimınary results demonstrate that vibrations produced by conspecifics are available to larvae, and may be used to avoid contact with neighbours. The next step in this research is to further record vibrations from the phloem side of a phloem sandwich, in close proximity to larvae, to add to my preliminary data set. Future studies should also examine the effect of artificial vibrations on developing larvae, to understand if larvae are able to perceive and respond to vibratory stimuli. Results from the second model species, $D$. arcuata, provide strong support for the hypothesis that larvae in groups use vibratory signals to mediate spacing. Early instar caterpillars show a regular preferred inter-individual distance which is maintained in different contexts using referential signals and escalation of signal rates as a conspecific caterpillar approaches their "personal space". Undisturbed early instar $D$. arcuata caterpillars signal significantly more than solitary late instar caterpillars, which reflects their communication needs associated with group-living behaviour. In comparing congener species, gregarious early instar $D$. arcuata caterpillars were shown to signal significantly more during undisturbed routine behaviour than did solitary $D$. bilineata caterpillars, 
suggesting once again that vibratory signals of $D$. arcuata caterpillars function for conspecific communication within the group. Vibratory-mediated spacing is also seen in early instar D. bilineata caterpillars that occupy exclusive leaf tip "territories". The results show that the signals of resident caterpillars escalate in rate to mediate spacing as a conspecific intruder approaches. In addition, $D$. bilineata residents signal much earlier to an intruder than D. arcuata residents, which results in fewer approaches. Therefore, vibratory signalling in early instar $D$. bilineata caterpillars serves a territorial function. This study has shown that vibratory signalling in caterpillars is used to mediate space in two different contexts; between individuals within the nest in D. arcuata caterpillars and, between individuals on leaf tips in $D$. bilineata caterpillars. With accumulating evidence that holometabolous insect larva are living in a "vibratory world", future studies should direct their focus toward locating potential vibratory receptors to provide strong evidence that vibratory signals are indeed received by larvae. 


\section{APPENDIX 1}

Preliminary work rearing S. multistriatus larvae

The adult flight periods of S. multistriatus in Ottawa, Ontario occur in May and July which made it difficult to collect adults for experimentation at the beginning of my thesis research in September 2008. To proceed with preliminary investigations on the life history of S. multistriatus, two infested elm trees were cut down from a private property in Kars, Ontario in September 2008 (with permission from owners). The bark was removed from these trees to examine, preserve and make notes on larvae and gallery patterns in preparation for experiments the following spring. Preserved larvae were also used for a graduate course on histological techniques. In addition to obtaining colonized elm bolts from the field, an investigation began into the possibılity of rearıng larvae on artificial media, which would allow for a reliable supply of beetles once the technique had been developed.

The first project was to establish a rearing method of beetles using artificial media to supplement elm during various life stages. Numerous forms of artificial media have been suggested to substitute for larval and adult food, as well as substrate for adult oviposition (Galford, 1967, 1969, 1971, 1972; Peacock et al., 1967). Each of these formulations have had varying levels of success but a consensus arose that one media would not suffice for all life stages. Therefore, the use of separate adult, oviposition and larval medias for each developmental stage was explored. Fortunately, Insect Production Services (a division of the Government of Canada's Canadian Forestry Service, www.insect.glfc.cfs.nrcan.gc.ca) recently developed a cerambycid media with similar ingredients to previously published developmental diets for scolytid larvae. During 
preliminary tests in September and October 2008, late instar S. multistriatus larvae were removed from the bark of an elm bolt and transplanted them individually into containers of cerambycid media. Over 50\% the larvae placed in the media emerged as adult $S$. multistriatus after four months diapause. The rest of the larvae failed to pupate due to unknown factors. The next task in rearing $S$. multistriatus was to encourage mated females to oviposit on media in a laboratory setting. Twenty adults were field collected in September 2008 and used for preliminary tests with artificial media. Adults (10 female, 10 male) were placed in an enclosed arena with prepared adult elm diet and larval diet (recipes below). Adult diet and oviposition media were created with recipes adapted from Peacock et al. (1967) and Galford (1969). Adults were observed eating the elm diet but no tunneling occurred over the 5 day observation period. Based on the complications of using artificial media, I recommend using a simpler technıque of placing adults in containers with elm bolts and allowing natural mating and oviposition (Cannon, 1985). 
Adult EIm Diet (modified from Peacock et al., 1967)

$18 \mathrm{~g}$

$250 \mathrm{~mL} \quad$ water

1. Mix dry ingredients in a beaker.

2. Add water and mix together.

3. Heat mixture to $80^{\circ} \mathrm{C}$ mixing constantly.

4. Pour mixture into petri dish to cool.

5. Store in refrigerator.

\section{Ovipositional Media (modified from Galford, 1969)}

$\begin{array}{ll}30 \mathrm{~g} & \text { toasted wheat germ } \\ 70 \mathrm{~g} & \text { alphacel (hydrolyzed) } \\ 8 \mathrm{~g} & \text { agar } \\ 0.1 \mathrm{~g} & \text { vanillin } \\ 0.5 \mathrm{~g} & \text { sodium benzoate } \\ 200 \mathrm{~mL} & \text { distilled water }\end{array}$

1. Combine agar and water and bring to a boil.

2. At high mixing speed, add sodium benzoate and blend for 1 minute.

3. Add wheat germ and vanillin and blend on low for 5 minutes.

4. Add alphacel until viscous.

5. Pour mixture into petri dish to cool.

6. Store in refrigerator.

Laval Media (modified from Galford, 1969)

$\begin{array}{ll}30 \mathrm{~g} & \text { toasted wheat germ } \\ 70 \mathrm{~g} & \text { alphacel } \\ 8 \mathrm{~g} & \text { agar } \\ 0.4 \mathrm{~g} & \text { sorbic acid } \\ 0.3 \mathrm{~g} & \text { methyl paraben } \\ 200 \mathrm{~mL} & \text { distilled water }\end{array}$

1. Combine agar and water and bring to a boil.

2. At high mixing speed, add methyl paraben and sorbic acid and blend for 1 minute.

3. Add wheat germ and blend on low for 5 minutes.

4. Add alphacel until viscous.

5. Pour mixture into petri dish to cool.

6. Store in refrigerator. 


\section{REFERENCES}

Bajec IL \& Heppner FH. 2009. Organized flight in birds. Animal Behaviour, 78, 777789.

Beauchamp G. 2007. Exploring the role of vision in social foraging: what happens to group size, vigilance, spacing, aggression and habitat use in birds and mammals that forage at night? Biology Reviews, 82, 511-525.

Blumstein DT, Daniel JC \& Evans CS. 2010. JWatcher V1.0. University of California Los Angeles and Macquarie University, Sydney.

Bowen JL, Mahony SJ, Mason AC \& Yack JE. 2008. Vibration-mediated territoriality in the warty birch caterpillar Drepana bilineata. Physiological Entomology, 33, 238250.

Brackenbury J. 1996. Novel locomotory mechanisms in caterpillars: lifeline-climbing in Epinotia abbreviana (Tortricidae) and Yponomeuta padella (Yponomeutidae). Physiological Entomology, 21, 7-14.

Bradbury JW \& Vehrencamp SL. 1998. Principles of Animal Communication. Sinauer Associates, Sunderland.

Bryant SR, Thomas CD \& Bale JS. 2000. Thermal ecology of gregarious and solitary nettle-feeding nymphalid butterfly larvae. Oecologia, 122, 1-10.

Byers J. 1989. Behavioural mechanisms in reducing competition in bark beetles. Holarctic Ecology, 12, 466-476.

Cannon WN. 1985. Gallery construction and oviposition of Scolytus multistriatus (Coleoptera: Scolytidae) in relation to temperature and adult density. Environmental Entomology, 14, 641-643.

Carter GG, Fenton MB \& Faure PA. 2009. White-winged vampire bats (Diaemus youngi) exchange contact calls. Canadian Journal of Zoology, 87, 604-608.

Chapman JW. 1910. The introduction of a European scolytid (the smaller European elm bark beetle, Scolytus multistriatus Marsh.) into Massachusetts. Psyche, 17, 63-69.

Clark PJ \& Evans FC. 1954. Distance to nearest neighbor as a measure of spatial relationships in populations. Ecology, 35, 445-453.

Cocroft RB. 1999. Parent-offspring communication in response to predators in a subsocial treehopper (Hemiptera: Membracidae: Umbonia crassicornis). Ethology, $105,553-568$. 
Cocroft RB \& Rodriguez RL. 2005. The behavioral ecology of insect vibrational communication. BioScience, 55, 323-334.

Cokl A \& Virant-Doberlet M. 2003. Communication with substrate-borne signals in small plant-dwelling insects. Annual Review of Entomology, 48, 29-50.

Cokl A, Presern J, Virant-Doberlet M, Bagwell, GJ \& Millar JG. 2004. Vibratory signals of the harlequin bug and their transmission through plants. Physiological Entomology, 29, 372-380.

Condor PJ. 1949. Individual distance. Ibis, 91, 649-655.

de Jong M \& Saarenmaa H. 1985. A mechanistic simulation model for the movement and competition of bark beetle larvae (Coleoptera, Scolytidae). Ecological Modelling, 27, 109-138.

de Jong M \& Grijpma P. 1986. Competition between larvae of Ips typographus. Entomologica Experimenta Applica, 41, 121-133.

Denno RF \& Benrey B. 1997. Aggregation facilitates larval growth in the neotropical nymphalid butterfly Chlosyne janais. Ecological Entomology, 22, 133-141.

DeVries PJ. 1990. Enhancement of symbiosis between butterfly caterpillars and ants by vibrational communication. Sclence, 248, 1104-1106.

Dyar HG. 1894. Life history of Falcarla bllineata Packard. Journal of the New York Entomological Society, 2, 108.

Faccoli M. 2001. Elm bark beetles and Dutch elm disease: tests of combined control. Journal of Pest Science, 74, 22-29.

Fitzgerald TD. 1993. Sociality in caterpillars. In Caterpillars: Ecological and evolutionary constraints on foraging (e.d. NE Stamp \& TM Casey), pp. 372-403. Routledge, Chapman \& Hall Inc., New York.

Fitzgerald TD \& Visscher CR. 1995. Foraging behavior and growth of isolated larvae of a social caterpillar, Malacosoma americanum. Entomologia Experimentalis et Applicata, 81, 293-299.

Fitzgerald TD \& Underwood DLA. 1998. Communal foraging behaviour and recruitment communication in Gloveria sp. Journal of Chemical Ecology, 24, 13811396.

Fitzgerald TD \& Pescador-Rubio A. 2002. The role of tactile and chemical stimuli in the formation and maintenance of the processions of the social caterpillar Hylesia lineate (Lepidoptera: Saturniidae). Journal of Insect Behavior, 15, 659-674. 
Fletcher LE, Yack JE, Fitzgerald TD \& Hoy RR. 2006. Vibrational communication in the cherry leaf roller caterpillar Caloptilia serotinella (Gracillariodea: Gracillariidae). Journal of Insect Behavior, 19, 1-18.

Fletcher LE. 2007. Vibrational signals in a gregarious sawfly larva (Perga affinis): group coordination or competitive signaling? Behavioural Ecology and Sociobiology, $61,1809-1821$.

Fletcher LE. 2008. Cooperative signalling as a potential mechanism for cohesion in a gregarious sawfly larva, Perga affinis. Behavioral Ecology and Sociobiology, 62, 1127-1138.

Freeberg TM. 2006. Complexity in the chick-a-dee call of Carolina chickadees (Poecile carolinensis): Associations of context and signaller behaviour to call structure. The Auk, 125, 896-907.

Galford JR. 1967. A technique for rearıng larvae of the smaller European elm bark beetle on an artificial medium. Journal of Economic Entomology, 60, 1192.

Galford JR. 1969. A larval and ovipositional medium for the smaller European elm bark beetle. Journal of Economic Entomology, 62, 1166-1168.

Galford JR. 1971. Improved techniques for rearing the smaller European elm bark beetle on artificial media. Journal of Economic Entomology, 64, 1327-1328.

Galford JR. 1972. Some basic nutritional requirements of smaller European elm bark beetle larvae. Journal of Economic Entomology, 65, 681-684.

Greenfield MD. 2002. Signalers and receivers: mechanisms and evolution of arthropod Communication. Oxford University Press, New York.

Gubbins C. 2002. Use of home ranges by resident bottlenose dolphins (Tursiops truncatus) in a South Carolina estuary. Journal of Mammalogy, 83, 178-187.

Guedes RNC, Matheson SM, Frei B, Smith ML \& Yack JE. 2011. Vibration sensitivity and discrimination in the masked birch caterpillar (Drepana arcuata). Journal of Comparative Physiology A, (in review).

Hajek AE \& Dahlsten DL. 1985. Factors influencing the mortality of Scolytus multistriatus (Coleoptera: Scolytidae) in elm branches in California. Canadıan Entomologist, 117, 819-828.

Hebert PDN. 1983. Egg dispersal patterns and adult feeding behaviour in the Lepidoptera. Canadian Entomologist, 115, 1477-1481. 
Hill PSM. 2008. Vibrational communication in animals. Harvard University Press, USA.

Hill PSM. 2009. How do animals use substrate-borne vibrations as an information source? Naturwissenschaften, 96, 1355-1371.

Hirsch BT. 2007. Costs and benefits of within-group spatial position: a feeding competition model. Quarterly Review of Bıology, 82, 9-27.

Hupe GJ \& Lewis JE. 2008. Electrocommunication signals in free swimming brown ghost knifefish, Apteronotus leptorhynchus. The Journal of Experimental Biology, $211,1657-1667$

Jefferies D \& Fairhurst C. 1982. Stridulatory organs of the elm bark beetles Scolytus multistriatus Marsham and Scolytus scolytus Fabricus. Journal of Natural History, 16, 759-762.

Kaston BJ \& Riggs DS. 1937. Studies on the Larvae of the Native Elm Bark Beetle. Journal of Economic Entomology, 30, 98-108.

Keeling L. 1995. Spacing behaviour and an ethological approach to assessing optimum space allocations for groups of laying hens. Applied Animal Behaviour Science, 44, 171-186.

Kinn DN \& Miller MC. 1981. A phloem sandwich unit for observing bark beetles, associated predators, and parasites'. Southern Forest Research Station Research Note, SO-269, 1-3.

Kondo N \& Watanabe S. 2009. Contact calls: information and social function. Japanese Psychological Research, 51, 197-208.

Krause J \& Ruxton GD. 2002. Living in Groups. Oxford University Press, New York.

Liu W \& Kroodsma DE. 2007. Dawn and daytime singing behaviour of chipping sparrows (Spizella passerina). The Auk, 124, 44-52.

Lynes B. 2006. Function of signalling in early instar D. arcuata with a focus on spacing behaviour. Honours thesis, Carleton University.

Mankin RW, Mizrach A, Hetzroni A, Levsky S, Nakache Y \& Soroker V. 2008a. Temporal and spectral features of sounds of wood-boring beetle larvae: 1dentifiable patterns of activity enable improved discrimination from background noise. Florida Entomologist, 91, 241-248.

Mankin RW, Smith MT, Tropp JM, Atkinson EB \& Young DY. 2008b. Detection of Anoplophora glabripennis (Coleoptera: Cerambycidae) larvae in different host trees 
and 26 tissues by automated analysis of sound-impulse frequency and temporal patterns. Journal of Economic Entomology, 101, 838-849.

Maynard Smith J \& Harper D. 2003. Animal signals. Oxford University Press, New York.

Ord TJ. 2008. Dawn and dusk "chorus" in visually communicating Jamaican anole lizards. American Naturalist, 172, 585-592

Palombit RA. 1992. A preliminary study of vocal communication in wild long-tailed macaques (Macaca fascicularis). II. Potential of calls to regulate intragroup spacing. International Journal of Primatology, 13, 183-207.

Peacock JW, Kennedy BH \& Fisk FW. 1967. A bioassay technique for elm bark beetle feeding stimulants. Annals of the Entomological Society of America, 60, 480-481.

Petherick JC. 2007. Spatial requirements of animals: allometry and beyond. Journal of Veterinary Behaviour, 2, 197-204.

Pfannenstiel RS, Hunt RE \& Yeargan KV. 1995. Orientation of a hemipteran predator to vibrations produced by feeding caterpillars. Journal of Insect Behaviour, 8, 1-9.

Quiroz A, Pettersson J, Pickett JA, Wadhams LJ \& Niemeyer HM. 1997. Semiochemicals mediating spacing behaviour of bird cherry-oat aphid, Rhopalosiphum padi, feeding on cereals. Journal of Chemical Ecology, 23, 25992607.

Radford AN. 2004. Vocal mediation of foraging competition in the cooperatively breeding green woodhoopoe (Phoeniculus purpureus). Behavioural Ecology and Sociobiology, 56, 279-285.

Radford AN \& Ridley AR. 2008. Close calling regulates spacing between foraging competitors in the group-living pied babbler. Animal Behaviour, 75, 519-527.

Reader T \& Hochuli DF. 2003. Understanding gregariousness in a larval Lepidoptera: the roles of host plant, predation, and microclimate. Ecological Entomology, 28, 729 737.

Readio PA. 1935. The entomological phases of the Dutch elm disease. Journal of Economic Entomology, 28, 341-353.

Rose AH \& Lindquist OH. 1997. Insects of Eastern Hardwood Trees. (Canadian Forestry Service, Forestry Technical Report 29). 
Russ K. 1969. Beiträge zum territorialverhalten der raupen des springwurmwicklers, Sparganothis pilleriana Schiff (Lepidoptera: Tortricidae). Pflanzenschutzberichte, 40, $1-9$.

Ruzicka Z \& Zemek R. 2008. Deterrent effects of larval tracks on conspecific larvae in Cycloneda limbifer. BioControl, 53, 763-771.

Saliba LJ. 1972. Gallery orientation in Cerambycid larvae. The Entomologist, 105, 300204.

Scordato ES \& Drea CM. 2007. Scents and sensibility: information content of olfactory signals in the ringtailed lemur, Lemur catta. Animal Behaviour, 73, 301-314.

Scott JL, Matheson SM \& Yack JE. 2010a. Variation on a theme: vibrational signaling in caterpillars of the rose hook-tip moth, Oreta rosea. Journal of Insect Science, 10, 1 15.

Scott JL, Kawahara AY, Skevington JH, Yen SH, Sami A, Smith ML \& Yack JE. $2010 \mathrm{~b}$. The evolutionary origins of ritualized acoustic signals in caterpillars. Nature Communications, 1: article number 4

Seddon N, Tobias JA \& Alvarez A. 2002. Vocal communication in the pale-winged trumpeter (Psophia leucoptera): Repertorre, context and functional reference. Behaviour, 139, 1331-1359.

Stamp NE. 1980. Egg deposition patterns in butterflies: why do some species cluster their eggs rather than deposit them singly? The American Naturalist, 115, 367-380.

Sugiura S \& Yamazaki K. 2006. The role of silk threads as lifelines for caterpillars: pattern and significance of lifeline-climbing behaviour. Ecological Entomology, 31, 52-57.

Svihra P \& Clark J. 1980. The courtship of the elm bark beetle. California Agriculture, 9.

Tautz J, Roces F \& Holldobler B. 1995. Use of a sound-based vibratome by leaf-cutting ants. Science, 267, 84-87.

Thomas JB. 1957. Use of larval anatomy in the study of bark beetles (Coleoptera: Scolytidae). Canadian Entomologist, 5, S1.

Timbers T. 2005. Vibration-mediated spacing in gregarıous caterpillars. Honours thesis, Carleton University.

Tragardh I. 1930. Studies on the galleries of the bark beetles. Bulletin of Entomological Research, 21, 469-480. 
Travassos MA \& Pierce NE. 2000. Acoustics, context and function of vibrational signaling in a lycaenid butterfly-ant mutualism. Animal Behaviour, 60,13-26.

von der Emde G, Schwarz S, Gomez L, Budelli R \& Grant K. 1998. Electric fish measure distance in the dark. Nature, 395, 890-894.

Wallace P. 1940. Notes on the smaller European elm bark beetles. Connecticut Experiment Station Bulletin, 434, 293-311.

Wilson EO. 2000. Part II: Social Mechanisms. In Sociobiology' The New Synthesis. pp. 130-378. Harvard University Press, USA.

Wood SL. 1982. The bark and ambrosia beetles of North and Central America (Coleoptera: Scolytidae), a taxonomic monograph. Great Basin Naturalist Memoirs, 6, $1-1356$.

Wong J, Stewart PD \& MacDonald DW. 1999. Vocal repertoire in the European badger (Meles meles): Structure, context, and function. Journal of Mammalogy, 80, 570-588.

Yack JE, Smith ML \& Weatherhead PJ. 2001. Caterpillar talk: acoustically mediated territoriality in larval Lepidoptera. Proceedings of the National Academy of Science, 98: 11371-11375.

Zalucki MP, Clarke AR \& Malcolm SB. 2002. Ecology and behaviour of first instar larval Lepidoptera. Annual Review of Entomology, 47, 361-393. 